University of Rhode Island

DigitalCommons@URI

Open Access Master's Theses

2014

\title{
THE NUTRITION AND PHYSICAL ASSESSMENT OF PATIENTS WITH NEUROLOGICAL DISORDERS
}

Dara Lyn LoBuono

University of Rhode Island, dara_lobuono@my.uri.edu

Follow this and additional works at: https://digitalcommons.uri.edu/theses

\section{Recommended Citation}

LoBuono, Dara Lyn, "THE NUTRITION AND PHYSICAL ASSESSMENT OF PATIENTS WITH NEUROLOGICAL DISORDERS" (2014). Open Access Master's Theses. Paper 330.

https://digitalcommons.uri.edu/theses/330

This Thesis is brought to you for free and open access by DigitalCommons@URI. It has been accepted for inclusion in Open Access Master's Theses by an authorized administrator of DigitalCommons@URI. For more information, please contact digitalcommons-group@uri.edu. 
THE NUTRITION AND PHYSICAL ASSESSMENT OF

PATIENTS WITH NEUROLOGICAL DISORDERS

BY

DARA LYN LOBUONO

A THESIS SUBMITTED IN PARTIAL FULFILLMENT OF THE

REQUIREMENTS FOR THE DEGREE OF

MASTER OF SCIENCE

IN

NUTRITION AND FOOD SCIENCES

UNIVERSITY OF RHODE ISLAND

2014 


\section{MASTER OF SCIENCE}

$\mathrm{OF}$

DARA LOBUONO

\section{APPROVED:}

Thesis Committee:

Major Professor

Ingrid Lofgren

Leslie Mahler

Geoffrey Greene

Nasser H. Zawia DEAN OF THE GRADUATE SCHOOL

UNIVERSITY OF RHODE ISLAND

2014 


\begin{abstract}
Objective: To describe cognitive, nutritional and physical functioning status of those with diagnosed neurological disorders for at least one year.

Design: This is a cross-sectional study.

Setting: University of Rhode Island's Speech and Hearing Clinic.

Participants: Community-dwelling adults living with Parkinson's disease (PD) or acquired brain injury (ABI) for $\geq 12$ months.

Main Outcome Measure(s): Cognitive-linguistic status was measured via the Repeatable Battery for the Assessment of Neuropsychological Status (RBANS). Nutritional and cardio-metabolic status were measured using the dietary screening tool (DST), anthropometrics (height, weight, body mass index (BMI), body composition), biochemical (lipid and glucose profile), and clinical (blood pressure) measures. Physical activity and functioning were measured via the Physical Activity and Disability Survey (PADS), short physical performance battery (SPPB), and the timed up and go (TUG) test.
\end{abstract}

Results: Twelve participants were assessed (8 PD, 4 ABI). Participants with PD had significantly higher total RBANS scores than participants with ABI (87.1 14 .6 vs. 66.0 $\pm 12.6, \mathrm{p}=0.034, d=2.455)$. Mean BMI $(\mathrm{n}=12)$ was $26.8 \pm 3.0 \mathrm{~kg} / \mathrm{m}^{2}$ and the majority of participants were overweight. DST scores indicated $58 \%(\mathrm{~N}=7)$ at possible nutrition risk and 25\% ( $\mathrm{N}=3)$ were at nutrition risk. Mean PADS scores $(94.9 \pm 89.7)$ indicated participants were physically active. A positive correlation was found between general activity scores and DST scores $(r=0.697, \mathrm{p}=0.012)$. Fifty percent of participants 
reported suboptimal SPPB, balance or TUG scores. Multiple risk factors for development of CVD were present in all participants.

Conclusion: Deficits in cognition, low dietary quality and physical functioning, and cardio-metabolic risk factors are frequently reported in patients with neurological disorders. These findings confirmed the presence of cognitive, dietary and physical decline in our participant group and support the need for an interdisciplinary team to work with patients and caregivers to improve health and prevent further development of comorbidities in this population. 


\section{ACKNOWLEDGMENTS}

I have grown tremendously as a person in my two years at the University of Rhode Island, and there are many individuals I would like to thank for guiding and supporting me along the way. First, I would like to thank my major advisor, Dr. Ingrid Lofgren. You have helped me improve my writing, oral presentation, communication and organizational skills. Thank you to my committee members, Dr. Leslie Mahler and Dr. Geoffrey Greene for all your guidance, support and encouragement. I have learned tremendously from you both. I would also like to thank Dr. Furong Xu, my committee chair, for her help and expertise.

To my fellow graduate students and dietetic interns, thank you for all your help and support. Thank you to the members of the Lipid lab, Jen, Amy and Liz. Thank you to Leah and Emily for all your help and hard work these past months. As well as a very special thank you to the faculty and students in Communicative Disorders and Kinesiology for helping to make this research project possible. Thank you to the clients of LOUD Crowd and Gateway Café to help me deepen my understanding of my research topic. I would also like to thank Dr. Kathleen Woolf of New York University, for helping me discover my passion for research.

Lastly, I would like to thank my family and friends. I do not know where I would be today without you. For this, I dedicate this thesis to my parents, for all their love and support, and in hopes I will continue to take them by surprise. 


\section{PREFACE}

This thesis was written to comply with the University of Rhode Island graduate school Manuscript Thesis Format. This thesis contains one manuscript: The Nutrition and Physical Assessment of Patients with Neurological Disorders. This manuscript has been written in a form suitable for publication in Archives of Physical Medicine and Rehabilitation. 


\section{TABLE OF CONTENTS}

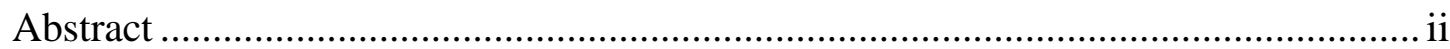

Acknowledgments .......................................................................................... iv

Preface

Table of Contents ............................................................................................. vi

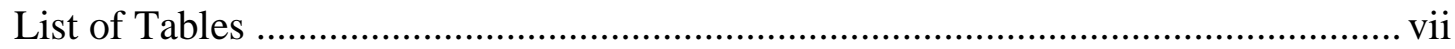

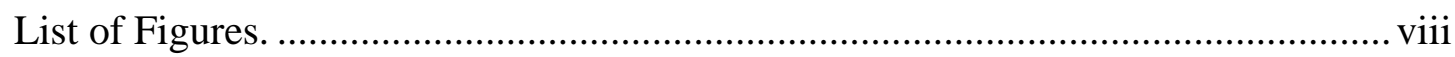

Chapter 1: The Nutrition and Physical Assessment of Patients with Neurological

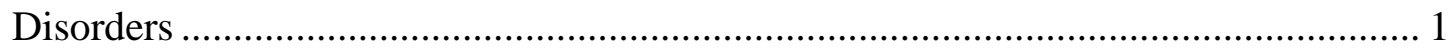

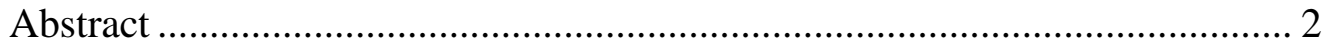

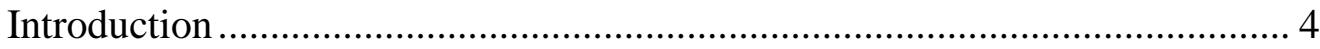

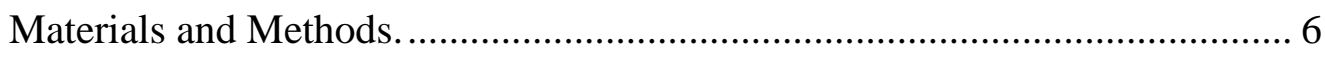

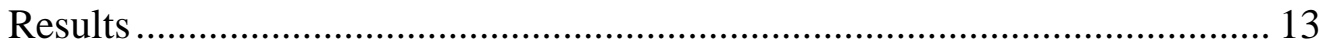

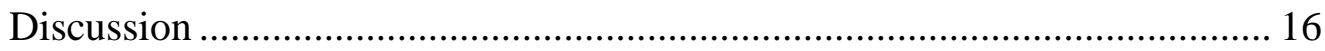

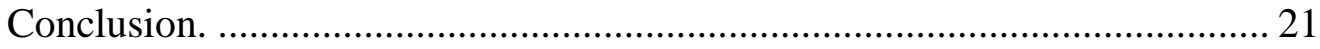

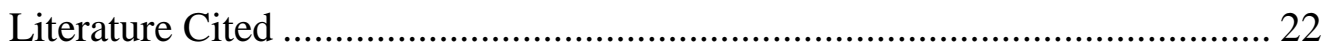

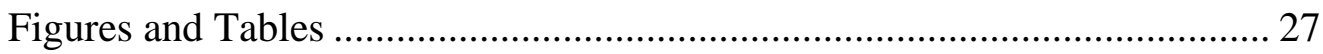

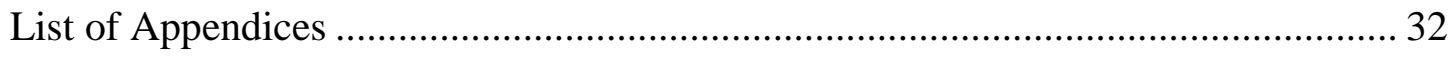

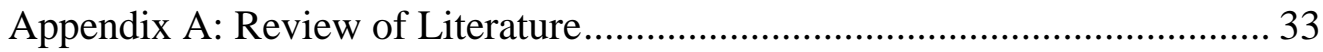

Appendix B: Extended Materials and Methods ………………………........... 98

Appendix C: Consent Form for Research .................................................. 111

Appendix D: Assessment Materials .......................................................... 116 


\section{LIST OF TABLES}

TABLE $\quad$ PAGE

Table 1. Characteristics of All Participants and by Neurological Disorder ................ 27

Table 2. Nutrition and Cardio-Metabolic Risk Factors By Participant ...............28

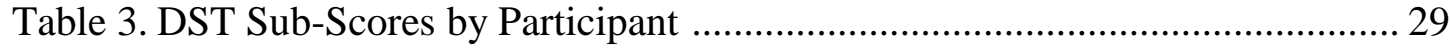

Table 4. Physical Barriers, Physical Activity and Physical Function ........................... 30 


\section{LIST OF FIGURES}

FIGURE PAGE

Figure 1. Top Nutrition, Cardio-Metabolic and Physical Risk Factors ........................ 31 


\title{
CHAPTER 1
}

\section{The Nutrition and Physical Assessment of Patients with Neurological Disorders}

\author{
Dara L. LoBuono ${ }^{\mathrm{b}}$, Amy Taetzsch $^{\mathrm{b}}$, Matthew J. Delmonico ${ }^{\mathrm{c}}$, Ingrid E. Lofgren ${ }^{\mathrm{b}}$, \\ Leslie Mahler $^{\mathrm{a}}$
}

${ }^{\text {a} D e p a r t m e n t ~ o f ~ C o m m u n i c a t i v e ~ D i s o r d e r s, ~ U n i v e r s i t y ~ o f ~ R h o d e ~ I s l a n d, ~ I n d e p e n d e n c e ~}$

Square I, Kingston, Rhode Island, 02881, United States

${ }^{\mathrm{b}}$ Department of Nutrition and Food Sciences, University of Rhode Island, Ranger Hall, Kingston, Rhode Island, 02881, United States

${ }^{c}$ Department of Kinesiology, University of Rhode Island, Independence Square II, Kingston, Rhode Island, 02881, United States

To be submitted to Archives of Physical Medicine and Rehabilitation 


\begin{abstract}
Objective: To describe cognitive, nutritional and physical functioning status of those with diagnosed neurological disorders for at least one year.

Design: This is a cross-sectional study.

Setting: University of Rhode Island's Speech and Hearing Clinic.

Participants: Community-dwelling adults living with Parkinson's disease (PD) or acquired brain injury (ABI) for $\geq 12$ months.

Main Outcome Measure(s): Cognitive-linguistic status was measured via the Repeatable Battery for the Assessment of Neuropsychological Status (RBANS). Nutritional and cardio-metabolic status were measured using the dietary screening tool (DST), anthropometrics (height, weight, body mass index (BMI), body composition), biochemical (lipid and glucose profile), and clinical (blood pressure) measures. Physical activity and functioning were measured via the Physical Activity and Disability Survey (PADS), short physical performance battery (SPPB), and the timed up and go (TUG) test.
\end{abstract}

Results: Twelve participants were assessed (8 PD, 4 ABI). Participants with PD had significantly higher total RBANS scores than participants with ABI (87.1 14 .6 vs. 66.0 $\pm 12.6, \mathrm{p}=0.034, d=2.455)$. Mean BMI $(\mathrm{n}=12)$ was $26.8 \pm 3.0 \mathrm{~kg} / \mathrm{m}^{2}$ and the majority of participants were overweight. DST scores indicated $58 \%(\mathrm{~N}=7)$ at possible nutrition risk and 25\% ( $\mathrm{N}=3)$ were at nutrition risk. Mean PADS scores $(94.9 \pm 89.7)$ indicated participants were physically active. A positive correlation was found between general activity scores and DST scores $(r=0.697, \mathrm{p}=0.012)$. Fifty percent of participants 
reported suboptimal SPPB, balance or TUG scores. Multiple risk factors for development of CVD were present in all participants.

Conclusion: Deficits in cognition, low dietary quality and physical functioning, and cardio-metabolic risk factors exist in patients with neurological disorders. These findings confirmed the presence of cognitive, dietary and physical decline in our participant group and support the need for an interdisciplinary team to work with patients and caregivers to improve health and prevent further development of comorbidities in this population.

Key words: Parkinson's disease, stroke, traumatic brain injury 


\section{INTRODUCTION}

Parkinson's disease (PD), traumatic brain injury (TBI), and stroke are neurological disorders that can result in lifelong challenges that impact cognitive,

physical, and psychosocial functioning ${ }^{1-5}$, which, in turn, can jeopardize dietary intake and increase likelihood of nutritional risk and cardiovascular disease (CVD).

Parkinson's disease is a progressive, neurodegenerative, movement disorder affecting nearly one million people in the United States ${ }^{6}$. Traumatic brain injury and stroke are types of acquired brain injury (ABI), defined as structural damage to the brain ${ }^{7,8}$. Nearly 2,500,000 people experience a TBI or stroke annually in the United States ${ }^{8,9}$. While these neurological diseases are each unique and have different long-term effects, they share similar complications that can negatively impact nutritional status and dietary intake, as well as physical function.

Limited research exists examining the interaction between cognition, nutritional status, and physical function for those with PD and ABI one year or more after diagnosis. Unintentional weight loss is typical at the time of PD diagnosis and nutritional status declines as the disease progresses ${ }^{1}$. Malnutrition and muscle wasting are consistently reported in the acute stages of $\mathrm{ABI}^{10-13}$. Since nutritional status is compromised in the acute phase after an ABI, long-term nutritional status is likely to be poor ${ }^{13}$. However, due to a scarcity of research, little is known about the long-term nutritional status of those with ABI. Cognitive and physical impairment associated with these neurological disorders may contribute to metabolic and nutritional imbalances ${ }^{1,3,5,14,15}$. 
The cardio-metabolic effect of PD seems to be two-fold, research indicates those with PD may have sub-optimal lipid profiles and glucose intolerance ${ }^{16}$, while other research indicates there may be a protective cardio-metabolic effect of PD, even in those with PD that are overweight ${ }^{17,18}$. Cardio-metabolic effects of ABI have been less investigated. Those with TBI are at increased risk for significant weight change, and diseases related to diet and activity, such as coronary heart disease (CHD) and metabolic syndrome ${ }^{3,15}$. An obesity paradox seems to exist following stroke ${ }^{12,19}$. Being overweight or obesity increases risk of a first-time stroke, however, those who are overweight or obese post-stroke, have better functional outcomes ${ }^{12,19}$, and are less likely to have a reoccurring stroke in the years following stroke $\mathrm{e}^{20,21}$.

Research has yet to examine and describe the long-term status (a year or more since diagnosis) of the cognitive, nutritional and physical functioning status across all three neurological diagnoses. The purpose of this cross-sectional study is to describe the cognitive function, dietary quality, and physical activity and functioning in those living with $\mathrm{PD}$ or $\mathrm{ABI}$ for a year or more. A secondary aim is to analyze how compromised cognition, nutrition and physical activity and functioning increase cardiovascular risk in those living with PD or ABI. An exploratory aim is to assess differences between PD and ABI across the areas of cognition, nutrition, and physical activity. 


\section{MATERIALS AND METHODS}

Design

This cross-sectional study is a sub-study of a five-year longitudinal, observational study examining the nutritional status, cognitive and physical activity levels of those living with neurological disorders, specifically, PD, TBI, and stroke. Data used in this study was obtained during baseline assessments through the University of Rhode Island (URI)'s Department of Communicative Disorders' Clinic, and included study staff from the Departments of Nutrition and Food Sciences and Kinesiology. Study approval was obtained from URI's Institutional Review Board, and written informed consent of all participants was obtained. Two baseline assessments were conducted in November and December 2013 at the URI Kingston's Campus Speech and Hearing Clinic.

\section{Participants, Setting and Recruitment}

For the purposes of this sub-study participants had to be diagnosed with PD, TBI or stroke for at least 12 months and be between the ages of 18-85. Participants were recruited via brochures and word-of-mouth to clients currently obtaining services at the Department of Communicative Disorder's Speech and Hearing Clinic. Fifteen

people were eligible to participate, 13 completed the informed consent process, and 12 completed baseline assessments. Participants completed evaluations related to cognitive-linguistic status, nutritional status, physical activity and functioning, and cardio-metabolic risk, as well as a past medical history questionnaire and questionnaires related to life satisfaction and resilience. 


\section{Assessment Visit and Data Collection}

\section{Anthropometrics}

Height $(\mathrm{cm})$ and weight $(\mathrm{kg})$ were measured using a stadiometer (Webb City Missouri). Height was rounded to the nearest $0.5 \mathrm{~cm}$ and weight was rounded to the closest $0.1 \mathrm{~kg}$. Height and weight were used to calculate BMI ( $\mathrm{kg}$ of body weight/height in meters $^{2}$ ). Predetermined categories classified BMI scores: underweight $<18.5 \mathrm{~kg} / \mathrm{m}^{2}$, normal weight $=18.5-24.9 \mathrm{~kg} / \mathrm{m}^{2}$, overweight $=25-29.9$ $\mathrm{kg} / \mathrm{m}^{2}$ and obese $\geq 30 \mathrm{~kg} / \mathrm{m}^{222}$. A foot-to-foot bioelectrical impedance analysis device (Tanita BF-556, Arlington Heights Illinois) was used to obtain body composition and report percent $(\%)$ body fat. American Council on Exercise ${ }^{23}$, any female with $\geq 32 \%$ body fat and any male with $\geq 25 \%$ body fat was considered obese.

\section{Biochemical}

Following a 12 hour fast, serum total cholesterol, low-density lipoprotein cholesterol (LDL-C), high-density lipoprotein cholesterol (HDL-C), triacylglycerol, and glucose were assayed using the portable Cholestech ${ }^{\circledR}$ (LDX system, Hayward California) machine. Total serum cholesterol $<200 \mathrm{mg} / \mathrm{dL}$, LDL-C $<100 \mathrm{mg} / \mathrm{dL}$, HDLC $>40 \mathrm{mg} / \mathrm{dL}$, triglycerides $<150 \mathrm{mg} / \mathrm{dL}$, glucose $<100 \mathrm{mg} / \mathrm{dL}$ are considered optimal metabolic-lipid profiles ${ }^{24}$.

\section{Clinical}

Blood pressure was measured after participants sat quietly for five minutes using an automatic blood pressure machine (Omron Healthcare Inc., Bannockburin Illinois). Systolic blood pressure (SBP) $<120 \mathrm{mmHg}$ and diastolic blood pressure (DBP) $<80 \mathrm{mmHg}$ was considered optimal. Systolic blood pressure $>130 \mathrm{mmHg}$ and 
DBP > $85 \mathrm{mmHg}$ was borderline high, while $\mathrm{SBP}>140 \mathrm{mmHg}$ and $\mathrm{DBP}>90 \mathrm{mmHg}$ was considered hypertensive.

\section{Cognitive Linguistic}

Cognitive-linguistic function was assessed using the Repeatable Battery for the Assessment of Neuropsychological Status (RBANS) ${ }^{25}$. The RBANS includes 12 subtests, with five index scores, summarizing: immediate memory, visuospatial/constructional, language, attention and delayed memory. The total score is the sum of the five index scores. Scoring is based on a standardized mean of 100 and a standard deviation of 15 ; a score $<70$ indicates suboptimal cognitive function. Swallowing Evaluation

The Swallowing SWAL-QOL is a 44-item survey where participants rate factors about 10 quality of life concepts related to swallowing, primarily in regards to eating and $\operatorname{diet}^{26,27}$. The highest possible score is 220 , the higher the score the better one's swallowing function.

\section{Dietary Intake and Nutritional Risk Assessment}

The Dietary Screening Tool (DST) is a 25-item questionnaire that is used to identify dietary patterns and nutritional risk in older adults ${ }^{28,29}$. Participants reported how frequently they consumed a food or type of food. A composite score was calculated based on subcomponents of the DST. The sub-components and point distribution included: whole fruit and juices (15 points), vegetables (15 points), lean proteins (10 points), added fats, sugars and sweets (25 points), dairy (10 points) and processed meats (10 points), and use of a dietary supplement (5 points). 
These sum-components are composited and total scores are defined for three different nutritional risk levels: $(<60)$ at risk, $(60-75)$ possible risk, and $(>75)$ not at risk $^{28}$. Categorization into three nutritional risk categories provides a way to determine if a patient needs a follow-up or nutrition assessment ${ }^{28}$. The DST Dietary intake was broken down based on point classification for the DST sub-components ${ }^{28}$ to explore specific areas contributing to low dietary quality. These sub-components were created to identify specific areas of the diet that may be problematic on an individual basis ${ }^{28}$.

Participants with fewer than $50 \%$ of total possible points for each subcomponent and if the participant did not currently take dietary supplement were considered low sub-scores. Less than $50 \%$ was selected as an exploratory marker to indicate infrequent/inadequate intake of whole grains, fruits, vegetables, dairy or lean proteins, and high consumption of processed meats, added sugars, fats and sweets.

\section{Physical Activity and Functioning}

The Physical Activity and Disability Survey (PADS) ${ }^{30,31}$ was used to assess physical activity levels. It covers a wide range of activities and includes six subscores: exercise, leisure-time physical activity (LTPA), general activity, therapy, employment, and wheelchair use. The PADS is coded based on intensity, type and amount of activity and can detect varying levels of physical activity ${ }^{32}$. Raw scores of $\leq 27$ indicate minimal, $28-42$ is minimal to moderate, $43-67$ is moderate, and $\geq 68$ indicates a high activity ${ }^{30}$.

The short physical performance battery $(\mathrm{SPPB})^{33}$ was completed to assess participants' global physical functioning and included usual gait speed, standing 
balance tests, and five repeated chair stands. SPPB scores are on a 12 point scale, the higher the score the better physical function. Scores 8-12 are considered "high functioning ${ }^{33}$."

A timed up and go (TUG) test was used to assess basic functional mobility ${ }^{34}$. It measures the time it takes for the participant to rise from a chair, walk three meters, turn around and walk back to the chair. Time was recorded in seconds, and the shorter amount of time, the better the score. The test was administered twice and the better score was recorded. A TUG score $>13.5$ is considered high risk for falls ${ }^{35}$

\section{Other Questionnaires}

A non-validated medical history questionnaire was be used to identify healthrelated conditions and how these conditions may impact health.

\section{Cardio-Metabolic Assessment}

Cardiovascular disease is the disease of the heart and/or blood vessels ${ }^{36}$. Traditional risk factors for CVD include modifiable and non-modifiable risk factors. Non-modifiable risk factors include age, sex and ethnicity. Modifiable risk factors include being overweight/obese, having hypertension, elevated blood glucose levels, and dyslipidemia ${ }^{37}$. As well lifestyle factors such as physical inactivity, tobacco use and a diet high in saturated fat and processed foods and low in fruits and vegetables and fiber ${ }^{37,38}$.

Cardiovascular risk factors were selected based on these risk factors but also unique factors that may impact CVD risk for those living with disability. These factors were grouped into eight categories, which included: 1$)$ age ( $>45$ years for men, $>55$ years for women), 2) anthropometrics (BMI, \%BF), 3) clinical (SBP and DBP), 4) 
biochemical (TC, HDL-C, TC/HDL-C ratio, LDL-C, TRG and Glucose), 5) diet (DST scores), 6) physical barriers (use of legs, arm or assistive device), activity (PADS scores) and functioning (SPPB and TUG scores), 7) smoking status, and 8) cognition. Those living with neurological disorders suffer physical and cognitive impairment that may disrupt activities of daily living (ADL); as a result physical barriers (such as partial or no use of arms and legs, as well as use of an assistive device) were examined due to the possibility they may promote a sedentary lifestyle. Cognitive function was also included as a CVD risk factor through examining total RBANS scores and three RBANS index scores (immediate memory, attention, delayed memory) $<70$.

\section{Statistical Analysis}

Statistical analysis were not hypothesis driven, but conducted to generate hypotheses and explore the population. Data were analyzed using SPSS, version 22.0 for Windows (IBM Corp. Summers, NY). Descriptive statistics were conducted and distribution of data was assessed through analyzing skewness and kurtosis. For data that were not normally distributed, proper statistical methods were used to account for this. Categorical variables are represented as numbers and percentages and continuous variables are reported as mean \pm standard deviation.

To analyze CVD risk factors, the participants were individually analyzed across the eight categories. The most frequent risk factors were then analyzed based on the variables within the eight CVD categories and reported as top CVD risk factors.

For normally distributed data, independent $t$-tests were conducted to determine if there were significant differences between groups regarding assessment variables. Cohen's $d$ was calculated to describe effect size for differences between groups in 
normally distributed variables $(0.2=$ small effect, $0.5=$ medium effect, $0.8=$ large effect). For data not normally distributed, Mann-Whitney U tests were used to analyze differences between groups and effect size was signified through calculating $r$ $(0.1=$ small effect, $0.3=$ medium effect, $0.5=$ large effect $)$. Differences between groups for categorical variables were identified using Fisher Exact Tests. Phi squared or Cramer's V were used to signify effect size $(0.1=$ small effect, $0.3=$ medium effect, 0.5=large effect). Pearson's R correlations were used with normally distributed variables, and Spearman Rho correlations were used as the non-parametric alternative. Differences between groups were significant when $\mathrm{p}=<0.05$. 


\section{RESULTS}

Demographic characteristics and results from specific assessment measures are summarized in Table 1. Of the four ABI participants two were diagnosed with stroke, one with a TBI and one participant had a diagnosis of TBI and stroke. An independent $t$-test found, those living with ABI were diagnosed significantly longer than those living with $\mathrm{PD}(\mathrm{p}=0.01, d=1.8)$. All participants self-identified as white/Caucasian and of non-Hispanic/Latino ethnicity. Two participants (both with ABI) were employed at the time of testing. The age range was 33 through 71 . Comorbidities amongst participants included musculoskeletal conditions (osteoporosis, arthritis), cancer, cardiovascular (coronary artery disease), previous head injury, and psychological disorders (bipolar). None reported endocrine dysfunction, such as thyroid disease or diabetes.

No significant correlation was found between RBANS scores and nutrition, cardio-metabolic, or physical assessments. As indicated by DST scores, three participants with PD were classified at nutritional risk and seven participants (4 PD and $3 \mathrm{ABI}$ ) were classified at possible nutrition risk (Table 2). Two participants with PD reported diet changes to soft, easy to chew foods, while all other participants reported to follow a "full normal diet," not modified in texture or consistency. All participants reported drinking thin liquids without any modifications.

Results from 10 DST sub-scores per participant are described in Table 3. When examining dietary components, $75 \%$ of participants were not consuming enough dairy products, and 50\% were frequently consuming added fats, sugars and sweets and/or not taking a dietary supplement. The majority of participants were consuming fruits, 
vegetables and whole grains regularly. On average, participants had inadequate subscores in three out of ten DST sub-categories.

Physical barriers, physical activity level and physical functioning for each participated are reported in Table 4. Six participants had partial use of arms and eight had partial use of legs, while seven participants reported to use an assistive device. The range of PADS scores for participants ranged from -12 to 311. Mean total TUG score was $12.1 \pm 3.2$ seconds. Physical barriers, physical activity level and physical functioning for each participated are reported in Table 4.

The secondary aim of this study was to analyze how compromised cognition, nutrition, and physical activity and functioning may increase CVD risk. Seven participants were taking medication to manage blood pressure and/or lipid profiles. Results of the RBANS revealed that three participants had total index scores $<70$ (1 PD, 2 ABI), three participants (1 PD, 2 ABI) had <70 Immediate Memory Scores, three ABI participants had $<70$ Attention scores and two PD and one ABI had $<70$ delayed memory scores. In total, five participants had cognitive impairment in one of these four areas. Typically, cognitive status is not classified as a CVD risk factor, however these tests have been included to explore the potential impact of impaired cognition associated with neurological disorders may have on CVD risk. Additionally, the presence of possible nutrition risk (Table 3) and compromised physical functioning (Table 4) may worsen overtime and evolve into a worse diet and sedentary lifestyle, factors that in turn can lead to CVD. The presence of nutrition and cardio-metabolic risk factors, including anthropometrics, clinical and biochemical values are reported for each participant in Table 2. 
Participants had three to six risk factors. The most common risk factors are highlighted in Figure 1. Body mass index scores ranged from $23.0 \mathrm{~kg} / \mathrm{m}^{2}$ to 33.3 $\mathrm{kg} / \mathrm{m}^{2}$. Additionally, 58.3\% participants had elevated SBP and/or DBP, and, $72.7 \%$ participants had at least one abnormal lipid or glucose level lab value (Table 2).

An exploratory aim of this study was to examine if there are differences between those living with $\mathrm{PD}$ and $\mathrm{ABI}$ across cognition, nutrition and physical activity and functioning. In addition to significantly higher total RBANS scores, those with PD scored significantly higher in language $(96.9 \pm 8.7,80.00 \pm 2.3, \mathrm{p}=0.004, d=2.66)$ and attention $(95.0 \pm 10.4,56.00 \pm 15.9, \mathrm{p}=0.000, d=2.90)$. There was no difference in DST or PADS scores between groups.

A Fisher's exact test found those with PD were more likely to have full use of arms $(\mathrm{p}=0.061, \mathrm{Phi}=0.707)$ and legs $(\mathrm{p}=0.208, \mathrm{Phi}=0.50)$, and less likely to use assistive devices $(\mathrm{p}=0.061, \mathrm{Phi}=0.598)$ with a large effect size (Table 4). Overall, TUG performance for those with PD was better, 11.1 \pm 2.5 seconds versus $14.2 \pm 3.8$ seconds ( $\mathrm{p}=0.112, d=0.96)$, with a large effect size. Participants with ABI had SPPB scores below eight. There was also no difference in anthropometrics, clinical or biochemical data in those living with PD versus ABI. 


\section{DISCUSSION}

This baseline study is the first of a 5-year observational study in those with neurological disorders to understand the rate and magnitude of change in this population, as well to help prevent comorbidities. This study is the first to examine cognition, nutrition, and physical activity and functioning together in those living with PD or ABI. Findings indicated those living with one of these neurological diagnoses present with deficits in cognition nutrition, cardio-metabolic and/or physical functioning. Our findings highlight the need for an interdisciplinary team to work with this population to help prevent CVD. The majority of our participants, were overweight/obese $(\mathrm{n}=9)$ and had DST scores $<75(\mathrm{n}=10)$. Additionally, 50\% performed sub-optimally in physical functioning assessments and all presented CVD risk factors.

A Pearson correlation found a negative correlation between total RBANS scores and months elapsed since diagnosis $(\mathrm{r}=-0.655, \mathrm{p}=0.021)$. The association between RBANS scores and time since diagnosis correlated with previous literature regarding cognitive decline in this population ${ }^{39,40}$. The significantly lower RBANS scores for those with ABI may be associated with the significantly longer time since diagnosis $(5.3 \pm 4.3$ vs. $14.3 \pm 5.6$ years, $\mathrm{p}=0.011)$.

While malnutrition with low body weight or eating difficulties may be present in these disease states ${ }^{3,5,41,42}$, none of our participants were underweight and only two reported to consume a "soft" modified texture diet. Ten out of twelve participants had $<75$ DST scores. A score between 60 and 75 indicates possible nutritional risk. Those with higher DST scores (a more healthful dietary pattern) have been associated with 
more favorable biomarkers, health status, nutrient dense diets and body compositions $^{28}$. As a result, we felt it was necessary to examine DST scores $<75$ overtime and identify participants with these scores needed improvements in dietary quality.

The frequent consumption of added fats, sugar and sweets (Table 3) may indicate those with cognitive and physical impairment are choosing convenience foods frequently. Nine out of twelve participants were not consuming diary frequently, and to optimize bone health, future dietary interventions should consider promoting consumption of low/reduced fat products high in calcium and vitamin D. As well as, encouraging the use of a daily multi-vitamin supplement, if appropriate, and an education of which foods provide appropriate amount of calories and nutrients for this population.

Low DST and general activity scores and their relationship suggests further investigation of disease-related eating barriers, such as ability to buy and prepare meals ${ }^{5,14,43}$. Altered satiety cues and change in appetite associated with TBI may also be present ${ }^{3,42}$. It also implies isolated activity time is less of a barrier than performing household tasks. Most participants were married or lived with family, and household work was performed by someone else. These findings are consistent with past research, which found $86 \%$ of those with $\mathrm{PD}$ were disabled from participating in ADL, but $88.8 \%$ had social support, and $64 \%$ participated in regular exercise/leisure time activity $^{44}$. Future physical activity interventions should target ways to help increase the ability to independently carry out more ADL, which may improve diet quality. 
Evidence shows physical activity can help reduce age-related physical and cognitive decline ${ }^{45-47}$. The presence of elevated exercise and LTPA activity and their correlation with SPPB scores may imply a protective effect of activity on participant's physical decline and should be examined over the next five years.

Due to the small sample size and the use of pharmacological medications to manage blood pressure and/or cholesterol levels by many participants (58.3\%), it is hard to speculate the risk factor with the biggest impact on the development of a cardiovascular event in those with neurological disorders. Despite the use of medication to manage lipid profiles and blood pressure, other CVD risk factors were still present and may lead to a CVD event. This can be highlighted by presence of elevated bodyweight and low dietary scores in many participants and shows the importance to continue to monitor and promote heart health in this population.

Research still needs to better understand the risk of CVD in those with PD and whether these is in fact a protective cardio-metabolic effect present in those with PD or an increased risk of a CVD event ${ }^{16-18,48,49}$. Both those with ABI and PD the presence of elevated BMI and \%BF, suboptimal DST scores and slight abnormality in clinical and biochemical values gives reason to continue to monitor those with one of these neurological disorders. Especially given the association with TBI and the development of cardio-metabolic alterations overtime ${ }^{33,42,50}$. Due to the small sample size of those living with stroke, it is difficult to compare participants and assess if the notion of the obesity paradox (those obese/overweight at the time of stroke have better functional outcomes ${ }^{12,19}$ ) exists a year or more after stroke. 
While more research is needed to draw conclusion regarding cardiovascular risk across these disease states, it is still important to monitor and treat cardiovascular risk factors present. Research notes those with multiple marginal risk factors are at risk for a CVD event within 10 years ${ }^{51}$. Those currently taking medication to treat hypertension, with suboptimal blood pressure (especially elevated SBP levels) are at more increased risk than those not taking medication with elevated blood pressure levels ${ }^{51}$. Four out of twelve of participants were currently taking blood pressure medication and presented with elevated/ pre-hypertensive SBP $(\geq 130 \mathrm{mmHg})$.

Despite the small sample size, the biggest difference between those living with $\mathrm{ABI}$ or PD were differences in cognitive-linguistic deficits. Cognitive-linguistic complications are common across diseases ${ }^{39,52-56}$, however for PD, older age at disease onset, depression, male gender, motor symptom severity, and advanced disease are risk factors for cognitive impairment ${ }^{40}$. Cognitive symptoms usually appear within 15 years of PD diagnosis ${ }^{57,58}$. Only one participant with PD had a low total RBANS scores. The two participants with stroke had total RBANS scores $>70$ while the two TBI participants had scores < 70. Both TBI participants had low RBANS index scores for immediate memory, and attention, which is consistent with the nature of the disease $^{39}$. However, PD progresses, it is likely issues with cognition, nutrition and physical activity and functioning may become more pronounced than those living with ABI.

\section{Study Strengths and Limitations}

This is the first study to complete combined assessments of cognition, nutrition, and physical activity and functioning in those living with PD or ABI. This 
interdisciplinary study obtained both subjective and objective data via validated tools to assess the study sample and generate hypotheses.

While this study is novel, it is not without limitations. The small sample size and homogeneity of participants does not allow wide generalizability for those living with PD or ABI. Participants were predominantly well educated and of white/Caucasian decent, and recruited on a voluntary basis. As a result, participants likely had an interest and motivation to improve health status. Finally, since there were a larger number of PD participants than anticipated, obtaining Hoehn and Yahr classifications to identify severity of disability in $\mathrm{PD}^{59}$ would strengthen results.

Future research should expand recruitment across the three disease states, to compare differences between PD, TBI and stroke, rather than just PD and ABI. This will allow a better understanding of how cognition, nutrition and physical functioning differs across the three diseases. Research should also expand recruitment to include healthy, age-matched controls, to provide insight on how living with neurological disorders compare to the healthy population. Once a more complete understanding of the population is established, well-defined recommendations and interventions can be developed and tested to improve treatment of those with PD and ABI. 


\section{CONCLUSION}

Suboptimal cognition, dietary quality, physical functioning, and cardio-metabolic risk factors are frequently reported in patients with neurological disorders. These findings confirmed the presence of cognitive, dietary and physical decline in our participant group and support the need for an interdisciplinary team to work with patients and caregivers to improve health and prevent further development of comorbidities in this population. 


\section{LITERATURE CITED}

1. Barichella M, Cereda E, Pezzoli G. Major nutritional issues in the management of Parkinson's disease. Mov Disord 2009;24:1881-92.

2. National Institue of Health. Traumatic Brain Injury: Hope Through Research. NIH Publication 2002; http://www.ninds.nih.gov/disorders/tbi/detail_tbi.htm. Accessed May 2, 2013.

3. Murphy MP, Carmine H. Long-term health implications of individuals with TBI: a rehabilitation perspective. NeuroRehabilitation 2012;31:85-94.

4. Lamb F, Anderson J, Saling M, Dewey H. Predictors of subjective cognitive complaint in postacute older adult stroke patients. Arch Phys Med Rehabil 2013;94:1747-52.

5. Westergren A. Nutrition and its relation to mealtime preparation, eating, fatigue and mood among stroke survivors after discharge from hospital - a pilot study. Open Nurs J 2008;2:15-20.

6. Parkinson's Disease Foundation. What is Parkinson's Disease? 2013; http://www.pdf.org/about_pd. Accessed November 1, 2013.

7. Porth CM, Matfin G. Pathophysiology: Concepts of Altered Health States. Williams \& Wilkins; 2009.

8. Driver S, Irwin K, Woolsey A, Pawlowski J. Creating an effective physical activity-based health promotion programme for adults with a brain injury. Brain Inj 2012;26:1482-92.

9. Faul M, Xu L, Wald MM. Traumatic brain injury in the United States: emergency department visits, hospitalizations and deaths 2002-2006. . Atlanta, GA: Centers for Disease Control and Prevention, National Center for Injury Prevention and Control 2010.

10. Kraukau K, Hansson A, Karlsson T, Nygren de Boussard C, Tengvar C, Borg J. Nutritional treatment of patients with severe traumatic brain injury during the first six months after injury Nutrition 2007;23:308-17.

11. Ott L, McClain C, Young B. Nutrition and severe brain injury. Nutrition 1989;5:75-9.

12. Scherbakov N, Dirnagl U, Doehner W. Body weight after stroke: lessons from the obesity paradox. Stroke 2011;42:3646-50.

13. Shen HC, Chen HF, Peng LN, et al. Impact of nutritional status on long-term functional outcomes of post-acute stroke patients in Taiwan. Arch Gerontol Geriatr 2011;53:e149-52. 
14. Medin J, Windahl J, von Arbin M, Tham K, Wredling R. Eating difficulties among patients 3 months after stroke in relation to the acute phase. $J$ Adv Nurs 2012;68:580-9.

15. Klose M, Juul A, Struck J, Morgenthaler NG, Kosteljanetz M, FeldtRasmussen U. Acute and long-term pituitary insufficiency in traumatic brain injury: a prospective single-centre study. Clin Endocrinol (Oxf) 2007;67:598606.

16. Barichella M, Marczewska A, Vairo A, Canesi M, Pezzoli G. Is underweightness still a major problem in Parkinson's disease patients? Eur J Clin Nutr 2003;57:543-7.

17. Cereda E, Cassani E, Barichella M, Caccialanza R, Pezzoli G. Anthropometric indices of fat distribution and cardiometabolic risk in Parkinson's disease. Nutr Metab Cardiovasc Dis 2013;23:264-71.

18. Cassani E, Cereda E, Barichella M, et al. Cardiometabolic factors and disease duration in patients with Parkinson's disease. Nutrition 2013;29:1331-5.

19. Doehner W, Schenkel J, Anker SD, Springer J, Audebert HJ. Overweight and obesity are associated with improved survival, functional outcome, and stroke recurrence after acute stroke or transient ischaemic attack: observations from the TEMPiS trial. Eur Heart J 2013;34:268-77.

20. Andersen KK, Olsen TS. Body mass index and stroke: overweight and obesity less often associated with stroke recurrence. J Stroke Cerebrovasc Dis 2013;22:e576-81.

21. Vemmos K, Ntaios G, Spengos K, et al. Association between obesity and mortality after acute first-ever stroke: the obesity-stroke paradox. Stroke 2011;42:30-6.

22. Center for Disease Control and Prevention: About Adult BMI. . 2011; http://www.cdc.gov/healthyweight/assessing/bmi/adult_bmi/index.html. Accessed May 2, 2013.

23. American Council on Exercise. Percent Body Fat Norms for Men and Women. $.2013 ;$

http://www.acefitness.org/?creative $=45247336884 \&$ device $=c \&$ network $=g \& m a$ tchtype=b\&gclid=CNi3ieq6jr0CFcFlOgodCVAAxQ. Accessed June 2, 2013.

24. Centers for Disease Control and Prevention. Cholesterol 2012. Accessed April 3, 2013.

25. Randolph C. Repeatable Battery for Assessment of Neurophyschological Status. Examiner's Manual San Antonio, TX: The Psychological Corporation 1998. 
26. McHorney CA, Martin-Harris B, Robbins J, Rosenbek J. Clinical validity of the SWAL-QOL and SWAL-CARE outcome tools with respect to bolus flow measures. Dysphagia 2006;21:141-8.

27. McHorney CA, Robbins J, Lomax K, et al. The SWAL-QOL and SWALCARE outcomes tool for oropharyngeal dysphagia in adults: III.

Documentation of reliability and validity. Dysphagia 2002;17:97-114.

28. Bailey RL. Dietary screening tool identifies nutritional risk in older adults The American Journal of Clinical Nutrition 2009;90:177-83.

29. Bailey RL, Mitchell DC, Miller CK, et al. A Dietary Screening Questionnaire Identifies Dietary Patterns in Older Adults The Journal of Nutrition 2007; ;137: :421-26.

30. Kayes NM, McPherson KM, Taylor D, Schluter PJ, Wilson BJ, Kolt GS. The Physical Activity and Disability Survey (PADS): reliability, validity and acceptability in people with multiple sclerosis. Clin Rehabil 2007;21:628-39.

31. Kayes NM, Schluter PJ, McPherson KM, Taylor D, Kolt GS. The Physical Activity and Disability Survey -- Revised (PADS-R): an evaluation of a measure of physical activity in people with chronic neurological conditions. Clin Rehabil 2009;23:534-43.

32. Rimmer JH, Riley BB, Rubin SS. A new measure for assessing the physical activity behaviors of persons with disabilities and chronic health conditions: the Physical Activity and Disability Survey. Am J Health Promot 2001;16:3442.

33. Guralnik JM, Simonsick EM, Ferrucci L, et al. A short physical performance battery assessing lower extremity function: association with self-reported disability and prediction of mortality and nursing home admission. J Gerontol 1994;49:M85-94.

34. Podsiadlo D, Richardson S. The timed "Up \& Go": a test of basic functional mobility for frail elderly persons. J Am Geriatr Soc 1991;39:142-8.

35. Shumway-Cook A, Brauer S, Woollacott M. Predicting the probability for falls in community-dwelling older adults using the Timed Up \& Go Test. Phys Ther 2000;80:896-903.

36. World Heart Federation. Cardiovascular disease risk factors 2011; http://www.world-heart-federation.org/press/fact-sheets/cardiovasculardisease-risk-factors/. Accessed February 12, 2014.

37. Lloyd-Jones DM, Leip EP, Larson MG, et al. Prediction of lifetime risk for cardiovascular disease by risk factor burden at 50 years of age. Circulation 2006;113:791-8. 
38. Bazzano LA, He J, Ogden LG, et al. Fruit and vegetable intake and risk of cardiovascular disease in US adults: the first National Health and Nutrition Examination Survey Epidemiologic Follow-up Study. Am J Clin Nutr 2002;76:93-9.

39. Katz DI, Ashley MJ, O'Shanick GJ, Connors SH. Cognitive rehabilitation: the evidence, funding and case for advocacy in brain injury. . McLean, VA: Brain Injury Association of America 2006.

40. Leroi I, McDonald K, Pantula H, Harbishettar V. Cognitive impairment in Parkinson disease: impact on quality of life, disability, and caregiver burden. J Geriatr Psychiatry Neurol 2012;25:208-14.

41. Sheard JM, Ash S, Silburn PA, Kerr GK. Prevalence of malnutrition in Parkinson's disease: a systematic review. Nutr Rev 2011;69:520-32.

42. Breed ST, Flanagan SR, Watson KR. The relationship between age and the self-report of health symptoms in persons with traumatic brain injury. Arch Phys Med Rehabil 2004;85:S61-7.

43. Andersson I, Sidenvall B. Case studies of food shopping, cooking and eating habits in older women with Parkinson's disease. J Adv Nurs 2001;35:69-78.

44. Ellis T, Cavanaugh JT, Earhart GM, et al. Factors associated with exercise behavior in people with Parkinson disease. Phys Ther 2011;91:1838-48.

45. Pahor M, Blair SN, Espeland M, et al. Effects of a physical activity intervention on measures of physical performance: Results of the lifestyle interventions and independence for Elders Pilot (LIFE-P) study. J Gerontol A Biol Sci Med Sci 2006;61:1157-65.

46. Lee Y, Back JH, Kim J, et al. Systematic review of health behavioral risks and cognitive health in older adults. Int Psychogeriatr 2010;22:174-87.

47. Balzi D, Lauretani F, Barchielli A, et al. Risk factors for disability in older persons over 3-year follow-up. Age Ageing 2010;39:92-8.

48. Nataraj A, Rajput AH. Parkinson's disease, stroke, and related epidemiology. Mov Disord 2005;20:1476-80.

49. Fall PA, Saleh A, Fredrickson M, Olsson JE, Granerus AK. Survival time, mortality, and cause of death in elderly patients with Parkinson's disease: a 9year follow-up. Mov Disord 2003;18:1312-6.

50. Prodam F, Gasco V, Caputo M, et al. Metabolic alterations in patients who develop traumatic brain injury (TBI)-induced hypopituitarism. Growth Horm IGF Res 2013;23:109-13. 
51. D'Agostino RB, Sr., Vasan RS, Pencina MJ, et al. General cardiovascular risk profile for use in primary care: the Framingham Heart Study. Circulation 2008;117:743-53.

52. Muslimovic D, Post B, Speelman JD, Schmand B. Cognitive profile of patients with newly diagnosed Parkinson disease. Neurology 2005;65:1239-45.

53. Kudlicka A, Clare L, Hindle JV. Pattern of executive impairment in mild to moderate Parkinson's disease. Dement Geriatr Cogn Disord 2013;36:50-66.

54. Kudlicka A, Clare L, Hindle JV. Executive functions in Parkinson's disease: systematic review and meta-analysis. Mov Disord 2011;26:2305-15.

55. Barker-Collo S, Feigin VL, Parag V, Lawes CM, Senior H. Auckland Stroke Outcomes Study. Part 2: Cognition and functional outcomes 5 years poststroke. Neurology 2010;75:1608-16.

56. van Rijsbergen MW, Mark RE, de Kort PL, Sitskoorn MM. The COMPlaints After Stroke (COMPAS) study: protocol for a Dutch cohort study on poststroke subjective cognitive complaints. BMJ Open 2013 Jan;3:e003599.

57. Centers for Disease Control and Prevention. Behavioral Risk Factor Surveillance System (BRFSS) Perceived Cognitive Impairment Module. 2013; http://www.cdc.gov/aging/healthybrain/brfss-faq.htm - q2. Accessed 14, January.

58. Hely MA, Morris JG, Reid WG, Trafficante R. Sydney Multicenter Study of Parkinson's disease: non-L-dopa-responsive problems dominate at 15 years. Mov Disord 2005;20:190-9.

59. Hoehn MM, Yahr MD. Parkinsonism: onset, progression and mortality. Neurology 1967;17:427-42. 
TABLES AND FIGURES

\begin{tabular}{|c|c|c|c|c|}
\hline & All $(n=12)$ & PD $(n=8)$ & $\mathrm{ABI}(\mathrm{n}=4)$ & Effect Size \\
\hline Age $(\text { years })^{\dagger}$ & $60.0 \pm 12.4$ & $65.5 \pm 5.0$ & $49.0 \pm 16.1$ & 0.54 \\
\hline Months Since Dx. & $99.3 \pm 75.5$ & $63.4 \pm 51.3$ & $171.0 \pm 66.7^{*}$ & 1.91 \\
\hline Gender $\%(\mathrm{n})^{\sharp}$ & & & & 0.250 \\
\hline Men & $66.7(8)$ & $75.0(6)$ & $50.0(2)$ & \\
\hline Women & $33.3(4)$ & $25.0(2)$ & $50.0(2)$ & \\
\hline Education Level \%(n) & & & & 0.463 \\
\hline HS Diploma & $25(3)$ & $12.5(1)$ & $50.0(2)$ & \\
\hline Bachelors & $16.6(2)$ & $25.0(2)$ & $0(0)$ & \\
\hline$\geq$ Graduate Degree & $58.3(7)$ & $62.5(5)$ & $50.0(2)$ & \\
\hline RBANS Total & $80.1 \pm 17.0$ & $87.1 \pm 14.6$ & $66.0 \pm 12.6^{*}$ & 2.455 \\
\hline Height (cm) & $170.1 \pm 9.2$ & $170.5 \pm 6.98$ & $169.4 \pm 14.1$ & 0.10 \\
\hline Weight (kg) & $78.4 \pm 15.0$ & $79.7 \pm 14.1$ & $75.7 \pm 18.7$ & 0.25 \\
\hline $\mathrm{BMI}\left(\mathrm{kg} / \mathrm{m}^{2}\right)$ & $26.8 \pm 3.0$ & $27.3 \pm 3.3$ & $26.0 \pm 2.4$ & 0.40 \\
\hline BMI Categories\%(n) & & & & 0.217 \\
\hline Normal & $25.0(3)$ & $25.0(2)$ & $25.0(1)$ & \\
\hline Overweight & $66.7(8)$ & $62.5(5)$ & $75.0(3)$ & \\
\hline $\begin{array}{l}\text { Obese } \\
\text { Body Fat }(\%)\end{array}$ & $\begin{array}{c}8.3(1) \\
30.0 \pm 6.5\end{array}$ & $\begin{array}{c}12.5(1) \\
29.9 \pm 6.7\end{array}$ & $\begin{array}{c}0(0) \\
30.1 \pm 7.2\end{array}$ & 0.02 \\
\hline $\mathrm{TC}(\mathrm{mg} / \mathrm{dL})^{\dagger}$ & $182.9 \pm 37.3(11)$ & $169.1 \pm 28.9(7)$ & $207.0 \pm 42.0(4)$ & 0.139 \\
\hline $\mathrm{TAG}(\mathrm{mg} / \mathrm{dL})^{\dagger}$ & $131.00 \pm 70.0(11)$ & $132.7 \pm 73.8(7)$ & $128.0 \pm 73.6(4)$ & 0.286 \\
\hline HDL-C $(\mathrm{mg} / \mathrm{dL})^{\dagger}$ & $48.6 \pm 20.4(10)$ & $43.7 \pm 12.7(7)$ & $60.0 \pm 33.5(3)$ & 0.109 \\
\hline LDL-C $(\mathrm{mg} / \mathrm{dL})^{\dagger}$ & $99.6 \pm 30.6(10)$ & $98.9 \pm 27.6(7)$ & $101.3 \pm 43.8(3)$ & 0.03 \\
\hline Glucose $(\mathrm{mg} / \mathrm{dL})^{\dagger}$ & $87.0 \pm 12.9(10)$ & $91.2 \pm 7.9(6)$ & $80.8 \pm 14.5(4)$ & 0.2365 \\
\hline $\mathrm{SBP}(\mathrm{mmHg})^{\dagger}$ & $133.7 \pm 17.0$ & $138.6 \pm 18.5$ & $124.0 \pm 8.8$ & 0.343 \\
\hline $\mathrm{DBP}(\mathrm{mmHg})^{\dagger}$ & $79.0 \pm 9.0$ & $80.3 \pm 9.9$ & $76.5 \pm 7.2$ & 0.196 \\
\hline DST & $64.3 \pm 12.4$ & $61.1 \pm 13.6$ & $70.8 \pm 7.0$ & 1.308 \\
\hline SWAL-Q̣OL & $188.0 \pm 20.6$ & $176.9 \pm 15.0$ & $210.3 \pm 6.1 *$ & 4.188 \\
\hline $\operatorname{PADS}^{\dagger} \mathrm{n}$ & $94.9 \pm 89.7$ & $89.7 \pm 99.6$ & $108.7 \pm 71.5$ & 0.143 \\
\hline SPPB d & $8.7 \pm 1.6$ & $9.3 \pm 1.0$ & $7.5 \pm 2.1$ & 1.996 \\
\hline
\end{tabular}

*Indicates statistically significant differences between PD and ABI groups $(\mathrm{p}<0.05)$. Notes: values provided for total number of participants and by disease state expressed as mean \pm standard deviation. Differences between groups for all normally distributed variables analyzed using independent $t$-tests, Cohen's d for effect size $(0.2=$ small effect, $0.5=$ medium effect, $0.8=$ large effect $)$. 'Between group differences conducted using Mann-Whitney U Test, effect size reported as $\mathrm{r}(0.1=$ small effect, $0.3=$ medium effect, $0.5=$ large effect). ${ }^{*}$ Between group differences for categorical variables provided using fisher exact test, effect size for fisher exact test using phi coefficient or Cramer's V $(0.10=$ small, 0.30 $=$ medium, large $=0.50)$. Abbreviations: Dx, diagnosis 
Table 2: Nutrition \& Cardio-Metabolic Risk Factors By Participants

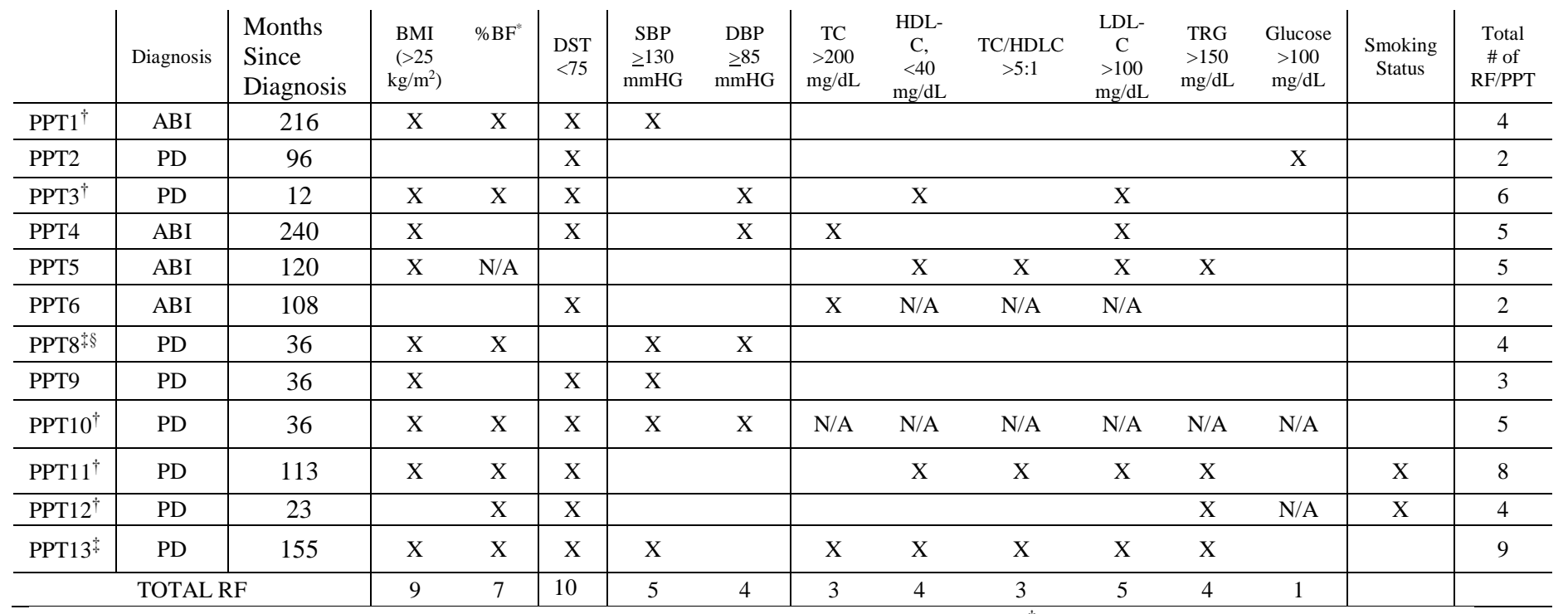

*Based on guidelines from American Council of Exercise, females with $\geq 32 \% \mathrm{BF}$ and males with $\geq 25 \% \mathrm{BF}$; ${ }^{\dagger}$ PPT currently takes blood pressure medication;

FPT currently takes blood pressure \& lipid lowering medication; ${ }^{\S}$ PPT had history of coronary artery disease. Abbreviations: BMI, Body Mass Index;

$\% \mathrm{BF}$, percent body fat; BP, blood pressure, TC, total cholesterol; HDL-C, high-density lipoprotein cholesterol; LDL-C, low-density lipoprotein cholesterol;

TRG, triglycerides; PADS, physical activity and disability scale; DST, dietary screening tool; RF, Risk Factors 
Table 3: DST Sub-Scores by Participant

\begin{tabular}{|c|c|c|c|c|c|c|c|c|c|c|}
\hline PPT & Diagnosis & $\begin{array}{l}\text { Fruit } \\
\text { \&Juice }\end{array}$ & Vegetables & $\begin{array}{l}\text { Whole } \\
\text { Grains }\end{array}$ & $\begin{array}{c}\text { Lean } \\
\text { Proteins }\end{array}$ & $\begin{array}{l}\text { Added } \\
\text { Fats, } \\
\text { Sugar, } \\
\text { Sweets }\end{array}$ & Dairy & $\begin{array}{c}\text { Processed } \\
\text { Meats }\end{array}$ & Supplement & $\begin{array}{l}\text { Total Sub- } \\
\text { Categories }\end{array}$ \\
\hline PPT1 & $\mathrm{ABI}$ & & & $X$ & $X$ & & & & $\mathrm{X}$ & 3 \\
\hline PPT2 & PD & & & & & $X$ & $\mathrm{X}$ & & $X$ & 3 \\
\hline PPT3 & PD & & & & $X$ & $X$ & $X$ & & $X$ & 4 \\
\hline PPT4 & ABI & & & & & $X$ & $X$ & $X$ & & 3 \\
\hline PPT5 & $\mathrm{ABI}$ & & & & & & & & & \\
\hline PPT6 & ABI & $\mathrm{X}$ & & & $\mathrm{X}$ & & $\mathrm{X}$ & & & 3 \\
\hline PPT8 & $\mathrm{PD}$ & & & & & & $\mathrm{X}$ & & & 1 \\
\hline РPT9 & PD & & $X$ & & $X$ & & $\mathrm{X}$ & & & 3 \\
\hline PPT10 & $\mathrm{PD}$ & & & & & $X$ & $\mathrm{X}$ & & $X$ & 3 \\
\hline PPT11 & $\mathrm{PD}$ & & & & & & $\mathrm{X}$ & & $\mathrm{X}$ & 2 \\
\hline PPT12 & PD & & $\mathrm{X}$ & $\mathrm{X}$ & & $\mathrm{X}$ & & & & 3 \\
\hline PPT13 & $\mathrm{PD}$ & $\mathrm{X}$ & $\mathrm{X}$ & $\mathrm{X}$ & & $X$ & $\mathrm{X}$ & $X$ & $\mathrm{X}$ & 7 \\
\hline Total: & & 2 & 3 & 3 & 4 & 6 & 9 & 2 & 6 & \\
\hline
\end{tabular}

Note: Check marks indicate fruit \& juice, vegetables, whole grains scores $\leq 7$ out of 15 points, lean protein, dairy, processed meats scores $\leq 5$ out of 10 , added fats, sugar, sweets $\leq 12$ out of 25 , and if the participant did not take a supplement. PPT 5 and 8 were not at nutritional risk. Abbreviations: PPT, participants; DST, dietary screening tool 
Table 4: Physical Barriers, Physical Activity and Physical Function

\begin{tabular}{|c|c|c|c|c|c|c|c|c|c|c|c|c|c|}
\hline \multirow[b]{2}{*}{ PPT } & \multirow[b]{2}{*}{$\begin{array}{l}\text { Diagnosi } \\
\mathrm{s}\end{array}$} & \multicolumn{4}{|c|}{ PHYSICAL BARRIERS } & \multicolumn{4}{|c|}{ ACTIVITY LEVELS } & \multicolumn{3}{|c|}{$\begin{array}{c}\text { PHYSICAL FUNCTION } \\
\text { MEASURES }\end{array}$} & \multirow{2}{*}{ Total RF } \\
\hline & & Arms & Legs & $\begin{array}{l}\text { Assistive } \\
\text { Device }\end{array}$ & $\begin{array}{c}\text { Fall } \\
\text { Frequency }\end{array}$ & $\begin{array}{c}\text { PADS } \\
\leq 42\end{array}$ & Exercise $^{\dagger}$ & $\mathrm{LTPA}^{\dagger}$ & $\begin{array}{l}\text { General } \\
\text { Activity }^{\dagger}\end{array}$ & $\begin{array}{c}\text { SPPB } \\
<8\end{array}$ & $\begin{array}{c}\text { Balance } \\
\leq 2\end{array}$ & $\begin{array}{c}\text { TUG } \\
\geq \\
13.5 \\
\text { sec }\end{array}$ & \\
\hline PPT1 & $\mathrm{ABI}$ & $\mathrm{X}$ & $\mathrm{X}$ & $\mathrm{X}$ & & & & $\mathrm{X}$ & & & $\mathrm{X}$ & & 5 \\
\hline PPT2 & $\mathrm{PD}$ & & $\mathrm{X}$ & $\mathrm{X}$ & $\mathrm{X}$ & & & $\mathrm{X}$ & $X$ & & $\mathrm{X}$ & & 6 \\
\hline PPT3 & $\mathrm{PD}$ & & $\mathrm{X}$ & $\mathrm{X}$ & & & & & & & & $\mathrm{X}$ & 3 \\
\hline PPT4 & ABI & $\mathrm{X}$ & $\mathrm{X}$ & $\mathrm{X}$ & & $\mathrm{X}$ & $\mathrm{X}$ & $\mathrm{X}$ & $\mathrm{X}$ & $\mathrm{X}$ & $\mathrm{X}$ & $\mathrm{X}$ & 10 \\
\hline PPT5 & $\mathrm{ABI}$ & $X$ & $\mathrm{X}$ & $\mathrm{X}$ & & & & & & $\mathrm{X}$ & & $X$ & 5 \\
\hline PPT6 & $\mathrm{ABI}$ & $\mathrm{X}$ & $X$ & $\mathrm{X}$ & & & & & $X$ & & & & 4 \\
\hline PPT8 & PD & & & & & & & & & & & & 0 \\
\hline PPT9 & $\mathrm{PD}$ & & & & & & & & $\mathrm{X}$ & & & & 1 \\
\hline PPT10 & $\mathrm{PD}$ & $\mathrm{X}$ & $\mathrm{X}$ & & & & & & $\mathrm{X}$ & & & & 3 \\
\hline PPT11 & PD & $\mathrm{X}$ & $\mathrm{X}$ & $\mathrm{X}$ & $\mathrm{X}$ & $\mathrm{X}$ & $\mathrm{X}$ & $\mathrm{X}$ & & & & $\mathrm{X}$ & 8 \\
\hline PPT12 & $\mathrm{PD}$ & & & & $\mathrm{X}$ & $\mathrm{X}$ & $\mathrm{X}$ & $\mathrm{X}$ & $\mathrm{X}$ & & & & 5 \\
\hline PPT13 & PD & & & & & & & & $\mathrm{X}$ & & & & 1 \\
\hline \multicolumn{2}{|c|}{ Total RF } & 6 & 8 & 7 & 3 & 3 & 3 & 5 & 7 & 2 & 3 & 4 & \\
\hline
\end{tabular}

Check marks indicate participants are at risk of poor physical function and activity level. Portray poor physical function and activity level. Physical barriers include if participant has partial use of arms or legs, uses an assistive device, and reports frequent falls. 'Indicates PPT does not participate in PADS sub-scores (exercise, leisure time, or general activity) and received a score of 0 or below. Abbreviations: PPT, participant; LTPA, Leisure-Time Physical Activity; RF, risk factor 
Figure 1: Most Common Nutrition, Cardio-Metabolic and Physical Risk Factors

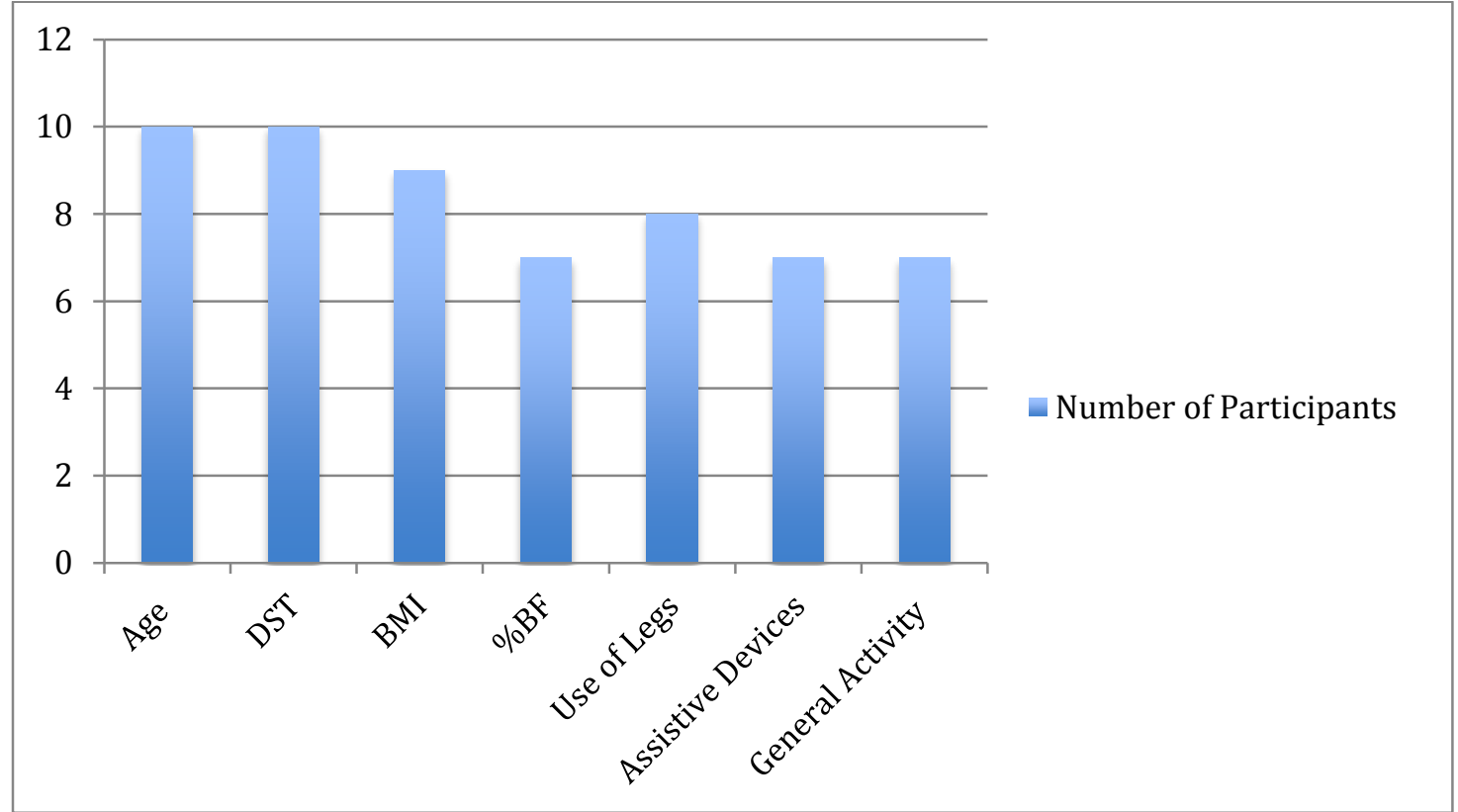




\section{APPENDICES}

Append A: Review of Literature 33

Appendix B: Extended Materials and Methods 98

Appendix C: Consent Form for Research ... 111

Appendix D: Assessment Materials 116 


\section{APPENDIX A: Review of Literature}

\section{Introduction}

Parkinson's disease (PD), traumatic brain injury (TBI), and stroke are neurological conditions that can result in lifelong challenges that affect physical, cognitive and psychosocial functioning $^{1-5}$, which in turn can jeopardize dietary intake and increase likelihood of nutritional and cardiovascular disease (CVD) risk. Traumatic brain injury and stroke are subtypes of acquired brain injury (ABI), a term used to describe structural damage to the brain ${ }^{6,7}$. Approximately $1,700,000$ and 795,000 people experience a TBI or stroke, respectively, every year in the United States (US) ${ }^{7,8}$. Parkinson's disease is a progressive, neurodegenerative, movement disorder that one million people in the US live with ${ }^{9}$. While these neurological diseases are each unique and have different long-term impacts, they have similar complications that can negatively impact nutritional status and dietary intake ${ }^{1,3,10}$.

Limited research exists examining the relationship between cognition, nutrition and physical activity in those with one of these neurological disorders. Research has examined long-term (a year or more following diagnosis) nutritional status of those living with $\mathrm{PD}{ }^{1,11,12}$. Unintentional weight loss is typical at the time of PD diagnosis and nutritional status declines as the disease progresses ${ }^{1}$. Meanwhile, nutritional status of patients in the acute stages of stroke and TBI has been assessed and malnutrition and muscle wasting are consistently reported ${ }^{13-16}$. Evidence indicates up to six months following a stroke and two months following a TBI are a high-risk time for malnutrition ${ }^{5,17}$, however very little research has examined nutritional status a year after. Since nutritional status is compromised in the acute phase after an ABI, long- 
term nutritional status is likely to be poor ${ }^{16}$. In addition to risk of poor nutritional status, physical disabilities associated with these neurological disorders ${ }^{3,18,19,20}$ warrant an assessment of physical activity and functioning. An assessment of both nutrition and physical activity will provide a clearer idea of if these neurological disorders are at increased risk of diet and exercise related comorbidities.

Research indicates there may be a protective cardio-metabolic effect of PD, even in those with PD that are overweight ${ }^{21,22}$. Meanwhile, those with TBI are at increased risk for significant weight change, as well diseases related to physical activity and diet, such as coronary heart disease (CHD) and metabolic syndrome, a disease marked by abdominal obesity, hypertension, dyslipidemia and insulin resistance ${ }^{3,23}$. Research indicates an obesity paradox seems to exist following stroke, decreasing risk of reoccurring stroke ${ }^{15,24}$, however a cardiovascular risk assessment of those living with stroke has not been completed.

Due to complications of neurological disorders, it is implied that nutritional imbalances can result in over-nutrition or under-nutrition ${ }^{1,3,5,17,23}$. While research has examined nutritional status in those with PD, limited research exists analyzing how cognition, nutrition and physical activity and functioning relate. Similar complications of these three disease states suggest research should examine long-term nutritional status of those with stroke and TBI, as well as cognition and physical activity. Due to this lack of research, a cross-sectional study including those living with PD, TBI and stroke is necessary to assess dietary quality, nutritional status, physical activity and physical functioning, as well as cardiovascular risk, and quality of life. 


\section{Parkinson's Disease}

The Definition, Prevalence and Effects of PD

Parkinson's Disease is a neurodegenerative, movement disorder caused by the death of dopamine cells ${ }^{9}$. Dopamine cells are the neurons that regulate motor function $^{25}$ and are concentrated in the substantia nigra, the area of the brain that controls movement ${ }^{26}$. In addition to motor symptoms (partial or full functional loss of a body part), those living with PD experience a variety of cognitive deficits, even during early stages of the disease ${ }^{27}$. The direct and indirect cost of total PD in the US is approximately $\$ 25$ billion per year ${ }^{9}$. Up to 60,000 new cases of PD occur annually in the US ${ }^{28}$ and once motor symptoms are apparent up to $80 \%$ of the dopamineproducing cells are dead ${ }^{26}$. These motor and non-motor symptoms develop overtime and impact daily activity ${ }^{1}$ and negatively impact quality of life ${ }^{27}$.

Parkinson's disease is one of the most common late-life (beginning in the sixth or seventh decade of life) neurodegenerative diseases, impacting up to $2.0 \%$ of people 60 years and older ${ }^{29}$. Men are one and a half times more likely to be diagnosed with PD than women ${ }^{9}$. Common motor impairments include bradykinesia (slowness of movement), akinesia (difficulty initiating movement), tremors, and rigidity ${ }^{30}$. The three commonly identified subtypes of PD are based on major motor symptoms: 1)

tremor dominant, 2) postural instability gait disorder and 3) akinetic-rigid ${ }^{31,32}$. Postural symptoms are more common in women, while symmetrical upper-disease related motor symptoms are more common in $\operatorname{men}^{33}$.

Parkinson's can be classified into a variety of different subtypes, usually based upon the dominant motor symptoms present. Parkinson's can also be identified in 
stages based on the Hoehn and Yahr scale $(\mathrm{HY})^{34}$. This one through five scale was developed to describe degree of disability and functional limitations related to $\mathrm{PD}^{34}$. Phase one describes early onset symptoms, while stage five would describe the final phases, where one is confined to a wheelchair or bed. The progression of the disease is usually marked by increased motor impairment ${ }^{9}$. These motor symptoms, as well as, non-motor symptoms, can impact dietary intake and compromise nutritional status ${ }^{35,36}$. Non-motor symptoms prevalent in PD include: cognitive impairment, neuropsychiatric symptoms, sleep disturbances, fatigue, gastrointestinal symptoms and sensory disturbances $^{37,38}$. Cognitive dysfunction can occur early in diagnosis ${ }^{39}$.

\section{Parkinson's Disease and Effects on Cognition}

Parkinson's disease is associated with a variety of cognitive deficits that appear in the earliest stages of the disease and continue to worsen as the disease progresses $^{27,37,38}$. Within 15 years of diagnosis, over $80 \%$ of those living with PD experience a form of cognitive impairment (deficiency in brain function that affects memory, language, perception, visuospatial aspects, ability to carry out tasks and judgment $)^{40}$ or dementia ${ }^{41}$. These alterations can interfere with everyday functioning ${ }^{27}$. Older age at disease onset, depression, male gender, severity of motor symptoms and advanced disease stage are risk factors for the development of mild cognitive impairment (MCI) for those with $\mathrm{PD}^{10}$. Evidence of MCI in the early stages of PD is associated with the incidence of dementia in later stages of $\mathrm{PD}^{42}$.

Cognitive symptoms associated with PD are mostly a result of the pathological changes within the brain, including changes in the dopaminergic pathway ${ }^{43}$. Dopaminergic drugs, such s levodopa (L-dopa), used to synthetically produce 
dopamine have been associated with improving cognition in PD patients, as well as negatively impacting cognition ${ }^{44,45}$. There are multiple reasons for cognitive changes in those with PD and many pathways are disrupted as a result of lack of dopamine deficiency. In addition to lack of dopamine, the presence of Lewy body production (abnormal aggregates of protein that develop inside nerve cells and interfere with signal conduction) and cell loss in the brain can also disrupt cognitive function ${ }^{39,46}$.

In those newly diagnosed with $\mathrm{PD}$, the most prominent cognitive issues are related to memory and executive functions $(\mathrm{EF})^{47}$. Executive function is the set of mental processes that help one connect past experience with present action ${ }^{48}$. Deficits with EF include difficulty with concept formation, decision-making, cognitive flexibility and selective attention $37,47,49$. Difficulties with EF can be attributed to damage of the frontal cortex as a result of $\mathrm{PD}^{47,49}$. A cross-sectional study examining the pattern of EF in 34 participants with mild to moderate PD, with a mean duration of 68.2 \pm 52.4 months, found nearly $45 \%$ of participants had a degree of EF impairment ${ }^{49}$.

Those living with PD have issues with dual-tasking, which are tasks that require simultaneous performance of at least two cognitive functions along with motor functions ${ }^{43}$. Wild and colleagues ${ }^{27}$ examined dual tasking, in those with PD $(n=18)$ versus healthy older adults $(n=18)$ and found that those with PD compromised the cognitive function tasks to focus on the motor task ${ }^{27}$. Poor dual tasking is also an indicator of impaired EF. These symptoms may contribute to a compromised quality of life and health status ${ }^{39,47}$, which in turn may impact one's ability to make proper dietary choices. 
In addition to compromised EF and memory, neuropsychiatric conditions, including depression, anxiety and apathy, often precede motor symptoms ${ }^{50}$. These conditions add significant burden to $\mathrm{PD}^{43}$ and impact quality of life ${ }^{51}$. Paranoid delusions, hallucinations, impulse control disorder, and addictive symptoms can result due to treatment and medications for $\mathrm{PD}^{43}$. These cognitive and neuropsychiatric impairments, combined with motor impairment, not only impact quality of life but have physiological side effects on the body that impact energy needs ${ }^{1}$.

\section{Physiological Side Effects and Energy Needs of PD}

Physiological side effects and energy needs vary depending on the stage of the disease $^{1,52}$ Unintentional weight loss preceding a PD diagnosis is common ${ }^{53}$, and weight then tends to increase immediately after diagnosis when treatment is initiated $^{1,52}$. The initial pre-diagnosis weight loss is attributed to the energy imbalance from the increase in energy expenditure as a result of motor symptoms, such as rigidity and dyskinesias (involuntary muscle movements) compared to reduced energy intake. A longitudinal, prospective study examined weight changes of 468 people with PD and found a mean weight loss of 5.2 pounds 10 years preceding diagnosis, but a fairly constant weight two to four years prior to diagnosis ${ }^{53}$. Physiological changes in PD can also impact desire to eat as a result of hyposmia (reduced ability to smell) and change in eating habits as a result of $\mathrm{PD}^{1,54}$. Generally, nutritional status declines as the disease progresses and resistance to various forms of available treatment develops (Figure A) ${ }^{1}$. However, findings have contradicted this decline in weight as a result of treatment ${ }^{52}$. 
Figure A:

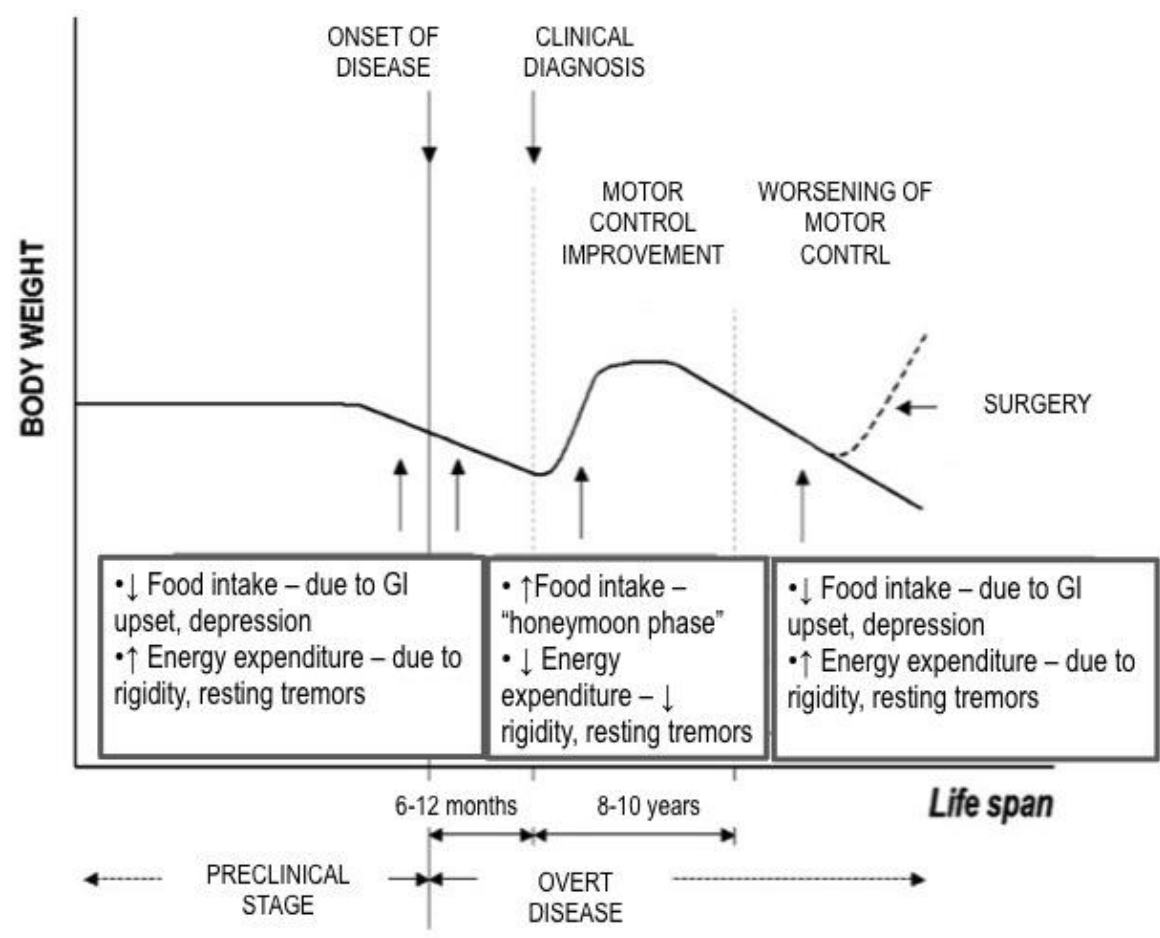

\section{Malnutrition and PD: Under-nutrition}

Malnutrition, or poor nutritional status, is defined as an imbalance of energy, macronutrients and/or micronutrients that results in compromised body shape, size and composition, function and clinical outcomes ${ }^{55}$. It includes under-nutrition, which results from insufficient intake to meet energy expenditure ${ }^{56}$, and over-nutrition, which is caused by excessive calorie intake and/or inadequate activity ${ }^{56}$. Proteinenergy malnutrition refers specifically to deficiency rather than an excess of protein and energy $\mathrm{y}^{36}$. It also can result in a lower quality of life and poorer health outcomes, which in turn can increase risk of falls, hospitalization and admittance to aged care facilities $^{36,57,58}$. Assessments of nutritional status determine if one is malnourished 
through examining anthropometrics, biochemical and clinical data, and dietary intake. Nutrition assessments of those living with PD typically find compromised nutritional status $^{11,12,59}$.

The average age of those diagnosed with PD is 60 years old ${ }^{60}$. Change in weight, particularly weight loss, during aging is typical ${ }^{61}$, yet it seems to be greater in those with $\mathrm{PD}^{62}$. Changed in total body weight in men and woman overtime varies. Typically, men gain weight until about the age of 55 and women until the age of 65; after this point in time weight loss is common. Weight loss in healthy aging adults occurs because of the loss of lean muscle tissue, which is replaced with fat ${ }^{61}$.

Under-nutrition is prevalent in those living with $\mathrm{PD}^{11,12,59}$, however it is difficult to determine how much of it is due to $\mathrm{PD}^{36}$. The majority of PD patients are elderly and as a result are also experiencing physiological changes associated with aging $^{61}$. In addition to weight loss, changes include reduction of digestive secretions, intestinal absorption, protein synthesis, and factors that decrease energy intake ${ }^{63}$; these factors include altered sense of smell and taste, loss of teeth and ill-fitting dental prostheses $^{63}$. A mean weight loss of 7.7 pounds during the 8 years following diagnosis of PD has been reported ${ }^{53}$. The study found energy intake to be similar between those with PD and those without PD shortly before diagnosis, but saw an increase in energy intake shortly after the diagnosis of $\mathrm{PD}^{53}$. This research implies that weight loss associated with PD can be due to an increase in energy expenditure unique to PD, that healthy adults to do not experience ${ }^{53}$.

Compared to age matched controls, research has found lower body mass index (BMI) scores in those with $\mathrm{PD}^{64}$. Other study have also found those with PD to have 
significantly lower BMI scores $\left(24.4 \pm 0.5 \mathrm{~kg} / \mathrm{m}^{2}\right)$ and percent body fat (\%BF) $(22.2 \% \pm 0.9)$ compared to age-matched controls without PD $\left(26.3 \pm 0.4 \mathrm{~kg} / \mathrm{m}^{2}\right.$, $24.6 \% \pm 0.9)^{62}$. The majority of these participants were in stage two of $\mathrm{PD}^{34,62}$. Motor and non-motor symptoms ${ }^{1,36}$ often compromise dietary intake in those living with $\mathrm{PD}^{36,59}$ and may also impact malnutrition. As PD progresses, a decreased response to treatment occurs and motor control declines ${ }^{1,65}$. Decline in motor control, such as the presence of dyskinesia and rigidity raises energy expenditure and can lead to negative energy balance and weight loss ${ }^{1}$. Physical changes and motor symptoms such as curve posture, shuffling gait and postural instability ${ }^{1}$ make buying, preparing and eating food independently difficult ${ }^{1,35,66}$. This development of chronic disabilities can interfere with activities of daily living (ADL), which include washing, dressing, eating and walking ${ }^{58}$. Those with PD lose the ability to eat independently due to decreased hand-mouth coordination and decline in fine movements to use utensils ${ }^{30,67}$. Motor symptoms can lead to a reduction in energy intake and weight ${ }^{1,66}$.

Non-motor symptoms can also cause a decline in dietary intake ${ }^{36}$ and includes depression, dementia, confusion, and apathy, as well as gastrointestinal symptoms; typical gastrointestinal symptoms include constipation, dysphagia (difficulty swallowing), early satiety, decreased gastric transit time, nausea, change in taste, loss of appetite and sialorrhea (excessive drooling), also cause a decline in dietary intake $\mathrm{e}^{1,36,68,69}$. A qualitative study examined food shopping, cooking and eating habits in older women with PD, and found decrease in sense of smell, appetite and taste in combination with issues transporting food to the mouth and swallowing were major issues associated with altering nutritional status ${ }^{70}$. Due to these barriers to meet 
nutrient and energy needs, those with PD are at increased for weight loss and loss of lean body mass ${ }^{36}$. Weight loss is a natural part of the aging process, yet seems to be more common and severe in those with $\mathrm{PD}^{62}$.

Research indicates lower body weight and barriers for inadequate dietary intake in this population, indicating under-nutrition is present in this population. Findings reveal a strong correlation between lower Mini Nutritional Assessment (MNA) scores and time since PD diagnosis ${ }^{65}$. A cross-sectional, population-based study, which included 135 PD cases in two regions of North East England, found that 21 of the 135 (15.4\%) participants were classified as malnourished ${ }^{11}$. The study also found that females with PD, were more likely to be severely malnourished (BMI $<18.5)$ than male counterparts ${ }^{11}$; this research is consistent to males and females without $\mathrm{PD}^{71}$.

Sheard and colleagues ${ }^{72}$ found similar results, where 19 of $125(13 \%)$ participants were considered moderately malnourished, and, females were more frequently malnourished and more likely to experience unintentional weight loss compared to males with PD. Malnourished males in this study had a significantly higher median BMI score (21.1 (range:19.5-33.2) kg/m²) compared to malnourished females (19.5 (range: $\left.17.7-21.6) \mathrm{kg} / \mathrm{m}^{2}\right)^{12}$. Males also had a significantly higher median waist circumference (86.75 (ranger: $78.9-116.0) \mathrm{cm}$ ) compared to females (73.5 (Range: $65.5-88.0) \mathrm{cm})^{12}$. Patient-Generated Subjective Global Assessments in this study suggest muscle wasting in malnourished men and women living with $\mathrm{PD}^{12}$. Due to the larger BMI scores and waist circumference in malnourished men with PD, accompanied by the presence of muscle wasting, these malnourished participants are 
likely suffer from sarcopenic obesity, while malnourished females may suffer from both muscle and fat $\operatorname{loss}^{12}$. Sarcopenia is the age-related loss of lean muscle mass and muscle function ${ }^{73-75}$. These results indicate that nutritional assessments for those living with PD are necessary. More research is needed to understand exactly why malnutrition occurs in this population and to help prevent malnutrition and sarcopenia, as well as to monitor how medications and treatment impact weight in this population.

Medications and treatment for PD may also impact weight and food choices $^{1,64,76}$. Dopaminergic treatment has been associated with a decrease in weight for those with PD who experience dyskinesia, common complication of L-dopa ${ }^{64}$. Lower BMI scores are associated with advanced PD patients taking higher dosages of L-dopa ${ }^{64}$. A common side effect of L-dopa is nausea and vomiting, to help limit this prescribed with carbidopa as to reduce symptoms of nausea and vomiting and help control PD symptoms. Reducing symptoms of nausea and vomiting, as well as seeking alternative treatments may help those with PD reduce risk of weight loss While undernutrition and weight loss are problematic for those with $\mathrm{PD}$, weight gain can also occur and is associated with PD treatment ${ }^{1}$.

\section{Malnutrition and PD: Over-nutrition}

Time of PD diagnosis is often associated with weight gain, because those living with PD begin treatment to control symptoms that promote weight loss ${ }^{1}$. While some research has found weight loss in response to treatment for PD, other research has reported weight gain as a result. For instance, surgical procedures to treat PD, such as deep brain stimulation (DBS) are associated with significant weight gain ${ }^{52,77}$. 
Pharmacological medications can also cause weight gain ${ }^{52,76}$. Dopamine agonists are medications that stimulate the parts of brain to believe it is receiving dopamine. Since they are not as potent as L-dopa, they are less likely to cause dyskinesia $^{78}$, which in turn would decrease energy expenditure associated with dyskinesia. They also can cause compulsive behaviors, include compulsive eating and undesirable weight gain ${ }^{76}$. In a report by Nirenberg and Waters ${ }^{76}$, seven cases of PD are described that experienced compulsive eating and undesired weight gain related to dopamine agonists, these participants saw an average $15 \%$ increase $(13 \mathrm{~kg} \pm 7 \mathrm{~kg})$ in body weight. Five of the seven participants decreased or discontinued dopamine agonists and self-reported a decrease in food cravings and weight ${ }^{76}$. Despite a small sample size findings suggest further research should evaluate the impact of dopamine agonists, weight status and dietary habits on those living with PD.

Another treatment that impacts weight is DBS, a surgical option for those with PD, and utilized by approximately 30,000 people with PD worldwide ${ }^{79}$. In this surgical procedure, an impulse generator is placed under the collarbone that provides an electrical impulse to the substantia nigra ${ }^{79}$. It typically is recommended for those with PD who have complications from medication such as dyskinesia and severe motor fluctuations, as well as those who no longer responding to pharmacological treatment $^{30}$. The procedure can effectively reduce motor symptoms, which allows for a decrease in pharmacological medications ${ }^{80}$. The effectiveness can reduce L-dopa dosage, in turn reducing negative side effects that impact dietary intake, such as nausea, vomiting, and involuntary movements associated with the medication. 
Deep brain stimulation is also associated with an increase in appetite and restoration of hormonal balance. As a result, DBS promotes significant weight gain $^{52,76,81}$. An investigation of weight gain in 30 PD patients receiving DBS found 29 participants (96.7\%) experienced weight gain within one year of treatment ${ }^{52}$; the mean weight gain was $9.3 \pm 6.2 \mathrm{~kg}^{52}$. Just over $46 \%$ reported increased weight within the first three months ${ }^{52}$. Additionally, $24 \%$ of participants reported weighing the most in their lifetime ${ }^{52}$. None of the participants experienced weight loss and there was a clear shift from being underweight and normal body weight to being overweight and obese $^{52}$.

Contradicting previous research, a higher prevalence of overweight and obesity in those with PD seems to exist compared to the general population ${ }^{63}$. Of 134 participants, $62 \%$ of participants were classified as obese or overweight, while $3 \%$ were classified as underweight ${ }^{63}$. The mean duration of PD was 10.6 \pm 5.3 years and mean age of participants was $65.9 \pm 8.9$ years ${ }^{63}$. In comparing these participants to the general population, there was a higher proportion of obese people living with PD than living without PD (25 vs. $14 \%)^{63}$. However there seems to be an inverse relationship between the course of PD and $\mathrm{BMI}^{63}$. This highlights that while under-nutrition and excessive weight loss are an issue for those living with PD, weight gain and obesity are also present. Excessive weight gain and obesity are risk factors for CVD and other chronic diseases $^{82}$

Both weight loss and weight gain has been observed in this population and it is understood that nutritional status in those with PD is likely compromised ${ }^{36}$ and to worsen as the disease progresses ${ }^{1}$. Consequently, a nutrition assessment, evaluation, 
monitoring and possible treatments should be included in the treatment plan for those with PD ${ }^{1}$. Additionally, neurological disorders, such as TBI and stroke, with similar cognitive and physical complications as $\mathrm{PD}$, may also experience malnutrition.

III. Traumatic Brain Injury

The Definition, Prevalence and the Effects of TBI.

Traumatic brain injury occurs from an external mechanical force, such as a jolt or blow to the brain, that causes brain dysfunction ${ }^{83}$. There are two types of severe TBI's, closed and penetrating ${ }^{84}$. A closed TBI is caused by movement of the brain within the skull and can be caused by falls, motor vehicle accidents, or being struck with an object ${ }^{84}$. Penetrating head injuries are caused when a foreign object enters the skull and includes being struck with a sharp object or a firearm injury ${ }^{84}$.

Each year, approximately 1.7 million people in the US endure a TBI and about 275,000 are hospitalized ${ }^{8}$. In the US, the total annual economic cost of TBI is $\$ 60$ billion $^{85}$. Those sustaining a TBI is bimodal, occurring primarily in younger or older adults $^{86}$. Older adults have the highest rates of TBI hospitalizations and deaths ${ }^{8,87}$. The leading cause of TBI is falls (35\%), followed by motor vehicle-related injuries (17\%) and a strike or blow to the head (workplace or sports-related injuries) $(16.5 \%)^{8}$. However, approximately $21 \%$ of the causes are unknown ${ }^{8}$. Amongst, military personnel, one in six U.S. service members deployed in support of Operation Enduring Freedom (OEF) or Operation Iraqi Freedom (OIF), sustained a $\mathrm{TBI}^{88}$.

Complications following TBI persist as time progresses ${ }^{89}$. Up to 5.3 million people $(1.7 \%)$ in the US live with long-term disabilities as a result of a $\mathrm{TBI}^{85}$, making TBI the leading cause of disabilities. Long-term disability is defined as the loss of one 
or more physical or mental functions ${ }^{85}$. A model created to predict long-term disability following TBI hospitalization found about $43.3 \%$ of a population based sample sustained long-term disability ${ }^{90}$; findings highlight side-effects of TBI are a serious public health issue in the US ${ }^{90}$.

Following TBI, chronic, late emerging health implications can occur and include neurologic, mobility, endocrine, swallowing and gastrointestinal issues ${ }^{3}$. Breed and colleagues ${ }^{86}$ examined those who sustained a TBI up to four years ago, and noted that younger and older adults with TBI reported musculoskeletal issues more frequently than those living without TBI. In addition to physical impairment, acquired cognitive impairments as a result of TBI can impede everyday activities and interfere with productivity, independence as well as safety ${ }^{91}$. As a result, it is essential to manage the effects of TBI and analyze how cognition, nutritional status and physical function are impacted a year or more after injury.

\section{TBI and Effects on Cognition}

The cognitive effects following a TBI can last a life-time ${ }^{86}$. Neurological difficulties following TBI include seizures, spasticity, balance difficulties, loss of urinary control, communicative impairment, and chronic headaches ${ }^{89}$. Individuals who sustain brain injuries frequently have trouble with concentration, memory, perception, attention, social interaction, managing emotions, problem solving, and decision making ${ }^{91}$. These complications can interfere with multiple aspects of all aspects of daily activity ${ }^{91}$. A study analyzing functional status among OEF/OIF veterans with a history of TBI found reduced functional status was strongly correlated with poorer cognitive function ${ }^{92}$, particularly related to motor function, processing 
speed and executive function ${ }^{92}$. These impairments highlight TBI's impacts cognitive functions related to carrying out ADL and to make decisions.

Cognitive complications in those living with TBI change over time. However, research indicates after a mild to severe TBI, cognition improvement occurs during the first two years, but remains impaired beyond this point ${ }^{93}$. During the early recovery phases, people seem to have problems with arousal, attention and memory ${ }^{91}$. Although problems with attention and memory persist overtime, particular difficulties with executive function, attention and cognitive control mechanisms become more prominent $^{91}$. A longitudinal study followed older adults with TBI for 12 months following injury, finding poor processing speed, verbal, memory, language and executive function compared to older adults without $\mathrm{TBI}^{94}$. Traumatic brain injury is also associated with increase risk for PD and other neurodegenerative diseases ${ }^{95,96}$.

Furthermore, older adults with closed TBI tend to have issues with naming and word fluency under timed conditions, as well as with verbal and visual memory ${ }^{97}$. Impaired cognitive function in this population seems to exacerbate other health related issues $^{3}$ and the Brain Injury Association of American recognizes additional research is necessary to further understand the disease and develop clinical guidelines and modifications ${ }^{91}$. Additionally, how these cognitive issues impact dietary intake, nutritional status and whether they promote nutritional risk needs to be further examined.

Physiological Side Effects and Energy Needs of TBI

Research has extensively examined the physiological side effects and impact on nutritional status during the acute phase of TBI, from time of diagnosis to six 
months ${ }^{10,11}$. The body undergoes hyper-metabolic, hyper-catabolic, and hyperdynamic responses ${ }^{13}$. These physiological responses are not only a result of the injury, but due to unfavorable secondary events from $\mathrm{TBI}^{98}$. These secondary events include fever, increased intracranial pressure, and seizures ${ }^{98}$ Consequently, following a TBI the body's energy expenditure and nitrogen excretion increase ${ }^{14}$. This increased energy expenditure results in a catabolic state, increasing muscle breakdown as well as negative effects on immune function and morbidity ${ }^{99}$. Energy and protein needs increase and meeting these requirements is imperative to prevent and prolong muscle wasting and excessive weight loss ${ }^{13}$. To treat those with a TBI during the acute phase, early nutrition support decreases risk for morbidity and mortality ${ }^{100,101}$.

A retrospective study explored nutritional treatment (parenteral and enteral nutrition) and outcomes up to six months after a $\mathrm{TBI}^{13}$. A nutrition assessment found $68 \%$ participants exhibited signs of malnutrition during this time period, with up to $29 \%$ body weight $\operatorname{loss}^{13}$. This study revealed that in most participants weight continued to decrease one to two months after injury ${ }^{13}$, highlighting the increase in energy expenditure and importance of adequate nutrition during the immediate stages. However, what happens beyond this point in those living with a TBI needs to be further examined.

\section{Malnutrition and TBI: Under-nutrition}

Nutritional status following the acute phase of a TBI has not been extensively examined. Research has been reported immediately following a TBI and found those living with TBI seem to reach lowest weight two months after injury ${ }^{13}$. Research has 
also examined nutritional status up to six months after injury, typically this time is the rehabilitation stage $\mathrm{e}^{13}$.

While research has not examined nutritional status in those living with TBI a year or more, chronic complications following a TBI may compromise dietary intake and lead to poor nutritional status ${ }^{3}$. Self-reported chronic issues of TBI include changes in weight and appetite, sensory changes, swallowing problems, chronic pain and dystonia (a neurological movement disorder) ${ }^{3}$. Due to similar chronic symptoms in those living with PD and TBI, there is reason to assesses the impact physical and cognitive disabilities, including depression associated with $\mathrm{TBI}^{3}$, has on nutritional status and ability to buy and prepare food. This is especially true since research has shown physical and cognitive disabilities impact dietary intake and promote difficulty preparing meals in those living with $\mathrm{PD}^{1,36,68,69,70}$.

In a systematic review, Murphy and Carmine $^{3}$ note dysphagia is common immediately following a TBI, and can persist or even worsen overtime. Achieving adequate nutrition and hydration can be a lifelong challenge for those living with TBI and dysphagia ${ }^{3}$. Compared to the general population, those with TBI are two and a half times more likely to die of digestive disorders ${ }^{102}$. The most common digestive disorders include gastro-esophageal reflux disease, which occurs when acid re-enters the esophagus due to irregular relaxation of the lower esophageal sphincter. It can cause heartburn, regurgitation, dysphagia, aspiration pneumonia, chest pain and nausea ${ }^{3}$. While, gastrointestinal disorders can cause a decrease in dietary intake and weight loss, it is often caused by obesity, use of steroid medication and hiatal hernia ${ }^{3}$. 


\section{Malnutrition \& TBI: Over-nutrition}

A common late-onset complication of TBI is weight gain ${ }^{3}$. Excessive weight gain associated with TBI can be due TBI's impact on metabolism and hormone production, memory, self-regulation, mobility, altered satiety cues, and appetite altering medications ${ }^{3,86}$. Weight gain for those with disabilities significantly increases risk for CVD, diabetes, functional dependence, and immobility ${ }^{3}$. Weight gain in TBI is associated with metabolic syndrome, which can lead to stroke, retinopathy, peripheral artery disease, diabetes and cardiovascular disease ${ }^{3,86}$.

Additionally, TBI is associated with post-traumatic hypopituitarism (PTHP) (decrease in the release of pituitary hormones to regulate homeostasis in the body); approximately $25 \%$ of long-term survivors have post-traumatic hypopituitarism ${ }^{103}$. The number of people with PTHP after a TBI is a concerned because the condition is associated with increase in weight and metabolic imbalances up to two months after a $\mathrm{TBI}^{104}$. The pituitary gland is a vital link between the nervous system and endocrine system and releases hormones that impact metabolism and other life processes ${ }^{105}$. It is often undiagnosed in those with TBI because of the underlying primary diagnosis of TBI, but can be treated with hormone replacement therapy ${ }^{103}$. Klose and colleagues ${ }^{23}$ found those with TBI and PTHP have higher body compositions and BMI compared to those without PTHP up to 12 months after injury. An increase in BMI from three months $\left(27.1 \pm 5.7 \mathrm{~kg} / \mathrm{m}^{2)}\right.$ after injury to 12 months $\left(29.3 \pm 5.7 \mathrm{~kg} / \mathrm{m}^{2}\right)$ was found ${ }^{23}$. Those with PTHP were also older, and had a more severe TBI. What happens beyond this point regarding weight and body composition needs to be examined. 
Weight change is a common theme in those living with $\mathrm{TBI}^{23}$. Hibbard and colleagues $^{89}$ found those living with TBI for a year or more reported unintentional weight loss or gain greater than ten pounds. However, to our knowledge, the research has not examined long-term (12 or more months following TBI) weight status and dietary intake in people with TBI. How diet, as well as physical inactivity, plays a role in weight gain and if weight gain continues overtime needs to be examined. Since research indicates nutritional status and weight change occurs in TBI, a form of ABI, it is likely that changes also occur in those living with other forms of ABI, such as stroke.

IV. Stroke

The Definition, Prevalence and Effects of Stroke

A stroke results when the brain's blood supply is blocked or when a blood vessel in the brain bursts ${ }^{106}$. The American Heart Association (AHA) estimates that someone in the US has a stroke every 40 seconds $^{82}$. By 2030 , nearly $4 \%$ of the US is projected to have experienced a stroke, and there will be an additional 3.4 million people with stroke compared to in $2012^{107}$. Stroke is the fourth leading cause of death $^{106}$ and $80 \%$ of stroke can be prevented ${ }^{106}$. Maintaining a healthy diet and exercising are to ways to help prevent a stroke ${ }^{108}$. Eating five servings of fruits and vegetables per day has been found to lower risk of stroke by $30 \%{ }^{108}$. Additionally, a meta-analysis found those who had high physical activity levels had a $27 \%$ lower risk of stroke ${ }^{109}$. Stroke occurs mostly in adults over the age of $65^{7}$. Women ages 55-75 have a one in five chance of stroke, while male counterparts have a one in six chance $^{110}$; each year approximately 55,000 more women than men have a stroke ${ }^{111}$. 
Although age-specific stroke rates are high in men, women have much higher incidences at older ages due to the longer life expectancy in women ${ }^{112}$.

The total annual direct and indirect costs of stroke are forecasted to increase to $\$ 240.67$ billion by 2030 , an increase of $129 \%^{107}$. Immediately following a stroke, at least $40 \%$ of stroke survivors have moderate disabilities and up to $30 \%$ have severe disabilities ${ }^{113}$. A stroke may impact psychological, physical, social and cognitive function ${ }^{114}$. These complications can alter a person's life and increase risk of being institutionalized, becoming psychotic or depressed, or of dying ${ }^{114}$. Of a 180 people over 65 years old, six months after stroke, 50\% had hemiparesis, $46 \%$ had altered cognitive function, $35 \%$ had symptoms of depression, $30 \%$ were unable to walk without assistance, and $19 \%$ had aphasia ${ }^{19}$. Similar to PD and TBI, side effects of stroke impact physical and cognitive function and may also lead to assistance with $\mathrm{ADL}^{115}$, as well as a decrease in dietary intake and quality overtime.

\section{Stroke and Effects on Cognition}

Cognitive-linguistic deficits following a stroke reduces functional outcome for at least five years after stroke in some individuals ${ }^{116}$. Assessments of cognitivelinguistic function after stroke assess memory, information processing speed, visuoperceptual/construction ability, $\mathrm{EF}$, attention, language and depression ${ }^{114,117}$. Impaired memory, poor concentration and mental slowness are the most common cognitive complaints after a stroke ${ }^{118,119}$. The functional status of 126 stroke patients was examined, (mean age 76.9 \pm 10 years) at baseline (2-3 weeks after stroke) and 13 months following event of stroke ${ }^{120}$. Findings concluded cognitive function at baseline 
was an independent and significant predictor of long-term functional outcome and degree of disability after stroke ${ }^{120}$.

Subjective cognitive complaints in 25 older adult stroke patients (mean age $67 \pm 10$ years) were assessed three to nine months after stroke and revealed $90 \%$ of participants reported cognitive issues or impairment ${ }^{4}$. Another study found attention, language, construction and reasoning the most affected cognitive limitations, where orientation was least affected ${ }^{121}$. Depression was the main variable that made a significant independent contribution to the prediction of subjective cognitive complaint ${ }^{4}$. In general, cognitive decline, is associated with risk for functional decline in $\mathrm{ADL}^{122}$, which can impact dietary intake and physical activity level. Whether these cognitive issues in junction with physiological side effects of stroke impact dietary intake and physically activity level, as well as increases risk of reoccurring stroke must be assessed.

\section{Physiological Side Effects and Energy Needs of Stroke}

Similar to TBI, the physiological side effects and impact of nutritional status during the acute phase of stroke has been thoroughly examined ${ }^{15,123}$. Following a stroke the body is in a hyper-catabolic state, which increases energy needs ${ }^{15,16}$. These energy needs are usually not met and as a result, fat and muscle tissue wasting and weight loss occurs (Figure B) ${ }^{15}$. The body's response to stroke leads to functional decline and the depletion of energy stores ${ }^{15}$. People who experience tissue wasting may also experience cachexia (dramatic weight loss and muscle wasting) ${ }^{124}$ or sarcopenia, which can contribute to a poorer prognosis after stroke ${ }^{15}$. 
Figure B:

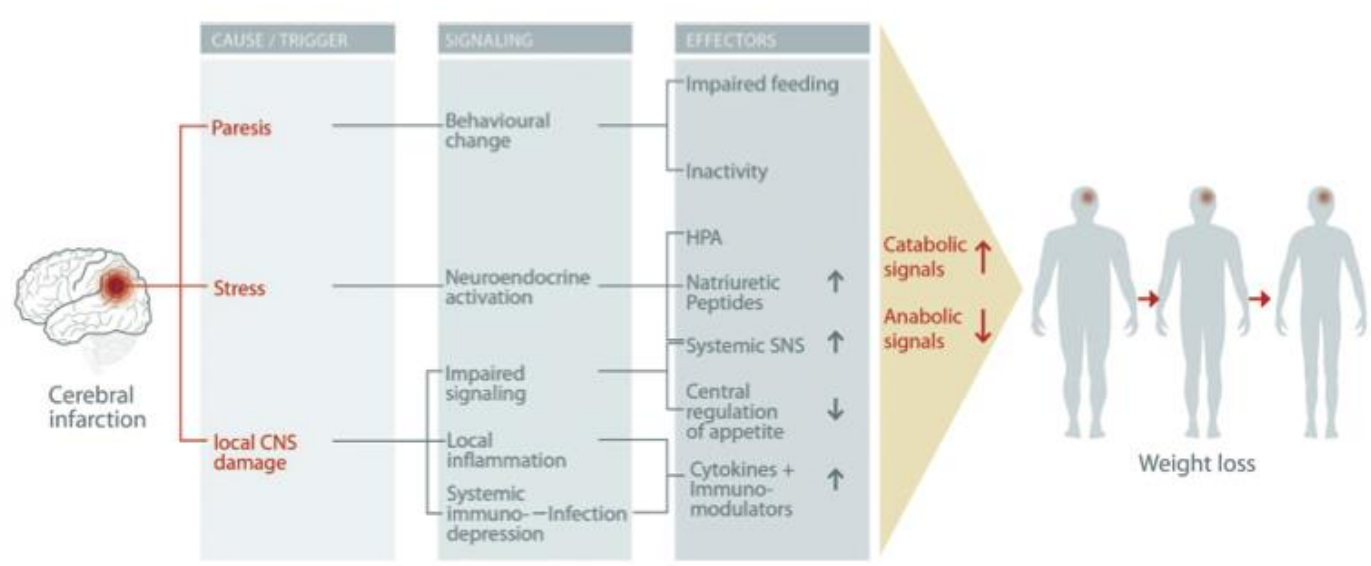

Malnutrition and Stroke: Under-Nutrition

In addition to weight loss from this hyper-metabolic state, persons in the acute phase of stroke are susceptible to weight loss due to fever, local central nervous system damage, and cytokines and oxygen-free radical build-up due damage of the blood vessel lining ${ }^{15}$. Impaired feeding and dysregulation of appetite can also promote weight loss following a stroke ${ }^{15}$. Finally, inactivity due to paralysis, can promote weight loss due to a loss of lean muscle mass ${ }^{15,125}$, and severely interfere with one's ability to prepare meals. As a result, malnutrition can result from inadequate intake of kilocalories, protein and/or nutrients the body requires for maintenance and repair ${ }^{115}$. Malnutrition as a result of stroke can negatively impact physical and social well-being and quality of life ${ }^{126}$.

Decline in nutritional status during the acute phase of stroke is highlighted in a prospective, descriptive study examining the risk and prevalence of malnutrition of 23 participants $^{123}$. At baseline, 21 of 23 participants were considered well-nourished, however significantly more participants were malnourished or at risk of becoming 
malnourished ten days later ${ }^{123}$. Based on MNA scores, after ten days, eight participants $(35 \%)$ were well-nourished, nine (39\%) were at risk of malnutrition and six $(26 \%)$ were malnourished ${ }^{123}$. The MNA not only exams anthropometrics, but also includes a dietary questionnaire, as well as a global and subjective assessment. While MNA scores indicated decline in nutritional status, there was no significant change in weight and BMI scores between these two time periods ${ }^{123}$. Despite a small sample size, this decline in nutritional status highlights rapid changes that occur during the acute phase of stroke.

Impaired feeding during the acute phases of stroke can be due dysphagia, and up to $65 \%$ of people with stroke experience dysphagia ${ }^{126}$. Many regain functional swallowing usually within the first month following a stroke ${ }^{127}$, however, for some, dysphagia is still present six months after stroke ${ }^{128}$. Dysphagia can compromise food and fluid intake, which can alter consciousness and promote physical weakness. The physical weakness experienced post-stroke can also negatively impact swallowing. Complications from dysphagia can also increase length of hospital stay, rehabilitation time, and result in a poorer long-term outcome ${ }^{126}$.

Change in consciousness, difficulty swallowing, inadequate food and fluid intake, and an increased in energy expenditure as a result of stroke can result in severe malnutrition ${ }^{15,126}$. Whether nutritional status improves or further declines after the acute phase needs to be more closely examined. Since nutritional status is likely to decline in the acute stage, where there is closer monitoring over dietary intake, it is necessary to examine what happens to nutritional status in people with stroke as time progresses. 
Westergren $^{5}$ found stroke survivors who self-reported low energy levels, were more prone to poor nutritional status, since they may stop eating before daily energy needs are meet. Research has examined nutritional status in the month following a stroke, and found chronic disabilities that interfere with ADL related to eating including purchasing groceries, preparing food, and eating ${ }^{5}$. Eating difficulties, barriers that negatively interfere with the preparation and intake of food and fluids ${ }^{129}$, are common among stroke survivors and negatively impact dietary intake, as well as quality of life ${ }^{123,130}$. Eating difficulties (sitting position, managing food on plate, transporting food to mouth, opening and closing mouth, manipulating food in mouth, swallowing, food consumption, alertness and eating speed) related to stroke were observed.

A comparison of eating difficulties and nutritional status in the acute phase (the days immediately following stroke) was compared with nutritional status three months after stroke. The research found that majority of baseline eating difficulties, observed continued three months later. Inadequate food intake, increased in 22 participants in the acute phase to 32 participants post intervention ${ }^{17}$. Despite these observations, nutritional status, based on total MNA scores, significantly improved three months after a stroke ${ }^{17}$. The contradiction of improved MNA scores compared to the observed inadequate food intakes, suggests nutritional status in those with stroke needs to be examined more thoroughly, and that the MNA may not be an effective tool in assessing nutritional status overtime in this population.

Other research has highlighted malnutrition to be an issue beyond the rehabilitation phase and up to six months after stroke compared to the acute 
phase $^{131,132}$. Six months after stroke $82 \%$ of women and $78 \%$ of men with eating disabilities did not meet energy requirements. Nutritional status, male gender, age, and stroke severity at admission were significant risk factors for poorer functional outcomes six months post-stroke ${ }^{16}$. Weight loss as little as three kilograms or more following a stroke has been an independent predictor of adverse outcomes following stroke $^{133}$, this weight loss has been found to occur up to a year ${ }^{134}$. As a result, malnutrition during acute stroke is considered a potentially modifiable factor that should be corrected and monitored to help improve long-term functional ${ }^{16}$. Whether weight loss continues to persist after a year following stroke must also be assessed, especially since many eating difficulties are associated with stroke ${ }^{135}$..

Eating difficulties following a stroke highlights that individualized therapy after stroke to improve eating ability is imperative ${ }^{135}$. More research is needed to understand whether malnutrition persists a year or more after stroke, as well as preventing stroke reoccurrence. Additionally, due to the susceptibility of malnutrition in the months following a stroke, an obesity paradox exists. While, being overweight/obese increases risk of stroke, $22 \%$ and $64 \%$ respectively ${ }^{136}$, research has found an obesity paradox following a stroke ${ }^{137}$. Being overweight or obese at the time of stroke seems to result in better long-term functional outcomes for those living with stroke $^{137}$.

\section{Malnutrition and Stroke: Over-nutrition}

An obesity paradox seems to exist with stroke patients, in that mortality seems to be lower in obese patients ${ }^{137}$. Those who are underweight at the time of stroke seem to have more complications and poorer survival than those who are of normal 
weight or overweight when assessed six months after stroke ${ }^{138}$. The underlying cause of this paradox is currently unknown, but supported from research with large study populations $^{139}$. The notion of the obesity paradox and stroke is often attributed to the catabolic imbalances and inflammatory state immediately following a stroke that causes weight loss ${ }^{15}$. This weight loss also causes muscle tissue wasting, which impairs recovery after stroke ${ }^{15}$.

While obesity increases risk of a first-time stroke, however, those who are overweight or obese post-stroke, are less likely to have a reoccurring stroke in the years following stroke ${ }^{139,140}$. Through examining data form the Danish Stroke Registry, Andersen and Olsen ${ }^{140}$ found as BMI increases, the risk of a stroke reoccurring decreased, despite age, sex, stroke severity or cardiovascular risk profile. Underweight patients more likely had a history of a previous stroke ${ }^{140}$. However, other research indicates, normal weight patients were more likely to have a reoccurring stroke ${ }^{24}$. This is a concern since research implicates compromised dietary intake in six months following ${ }^{129}$, which can promote a further decline in weight.

The obesity paradox seems to persist as time following a stroke progresses. A prospective study examined stroke survivors up to 30 months after stroke or a transient ischemic attack, and found overweight and obese participants to be at the lowest rink for the following endpoints: morbidity, mortality, and poor functional outcomes ${ }^{24}$. Those positive outcome measures were found the most in obese or very obese, while underweight participants were at the highest risk for all endpoints ${ }^{24}$.

Overall, existing research supports obesity paradox and stroke, however a recent study examining stroke rehabilitation outcomes, slightly contradicts the idea of 
obesity paradox ${ }^{141}$. The relationship between functional independence measurement (FIM) scores, including cognitive and motor sub-scores, and BMI scores for those in stroke rehabilitation was examined and those considered overweight had the highest motor and cognitive sub-scores ${ }^{141}$. There was no significance differences between motor FIM sub-scores between groups, but the overweight group had significantly higher cognitive sub-scores compared to the obese group ${ }^{141}$. No significant differences were found between normal weight stroke participants and underweight or overweight participants for cognitive sub-scores ${ }^{141}$. Whether this holds true beyond the rehabilitation phase has not been assessed, and highlights the need to develop proper guidelines for weight status and dietary intake following a stroke. Especially since research has found an association between obesity and poor cognition in the aging population $^{142}$.

Due to mixed results, more research is needed understand how to help optimize health and prevent a reoccurring stroke or other forms of chronic disease. Research regarding the obesity paradox and stroke contradicts current guidelines to reduce body weight after stroke ${ }^{15}$, and clearer guidelines are needed to promote optimal weight status in this population, especially long-term (a year or more) after stroke. Stroke is a cardiovascular event, and as a result it is important to continue to assess the cardiovascular risk of this population to prevent the occurrence of another cardiovascular event. Due to the similarities this neurological condition has with TBI and PD, the cardiovascular health of these populations must also be examined. V. Overall Cardiovascular Risk 
Across these three disease states research varies as to whether or not those living with neurological conditions such as PD, TBI and stroke are at increased CVD risk $^{3,52,63,143}$ and this may be due to change in lifestyle following diagnosis as well as physiological impacts of the disease. Cardiovascular disease is the leading cause of death in the United States ${ }^{144}$. It is the disease of the heart and/or blood vessels and often results from atherosclerosis, which is the hardening of the arteries ${ }^{145}$. Modifiable CVD risk factors include being overweight or obese, having hypertension, elevated blood glucose levels, and dyslipidemia ${ }^{146}$. As well as life style choices such as physical inactivity, tobacco use and a diet high in saturated fat and processed foods and low in fruits, vegetables and fiber ${ }^{146,147}$.

To assess if one is overweight or obese, $\mathrm{BMI}$ and $\% \mathrm{BF}$ are indicators. Body mass index is calculated from weight and height and can serve as an indicator of body fatness ${ }^{148}$. Body mass index is classified according to predetermined categories: underweight $=<18.5 \mathrm{~kg} / \mathrm{m}^{2}$, normal weight $=18.5-24.9 \mathrm{~kg} / \mathrm{m}^{2}$, overweight $=25-29.9$ $\mathrm{kg} / \mathrm{m}^{2}$ and obese $\geq 30 \mathrm{~kg} / \mathrm{m}^{2}{ }^{148}$. According to the American Council on Exercise ${ }^{149}$, any female with $\geq 32 \% \mathrm{BF}$ and any male with $\geq 25 \% \mathrm{BF}$ are considered obese.

Blood pressure is a clinical risk factor for CVD. Systolic blood pressure (SBP) $>120 \mathrm{mmHg}$ and diastolic blood pressure (DBP) >80 $\mathrm{mmHg}$ are considered suboptimal. When diagnosing for metabolic syndrome, SBP $\geq 135 \mathrm{mmHg}$ and DBP $\geq 85 \mathrm{mmHg}$ are used; these levels are considered pre-hypertensive ${ }^{150}$. Hypertension can be caused by lifestyle factors such as a high sodium diet, obesity and physical inactivity $^{151}$. Suboptimal serum levels are also a risk factor for cardiovascular disease and can be affected by poor diet and physical activity ${ }^{152}$. Total serum cholesterol $>200$ 
$\mathrm{mg} / \mathrm{dL}$, low density lipoprotein cholesterol (LDL-C) $>100 \mathrm{mg} / \mathrm{dL}$, high-density lipoprotein cholesterol (HDL-C) $<40 \mathrm{mg} / \mathrm{dL}$, and triglycerides $>150 \mathrm{mg} / \mathrm{dL}$ are used to describe those with dyslipidemia ${ }^{153}$. Dyslipidemia can lead hardening of the arteries overtime, which can lead to $\mathrm{CVD}^{154}$. Hyperglycemia is marked by fasting blood sugar $>100 \mathrm{mg} / \mathrm{dL}^{150}$ and can indicate insulin resistance, metabolic syndrome, pre--diabetes $(110-125 \mathrm{mg} / \mathrm{dL})$ or diabetes $(>126 \mathrm{mg} / \mathrm{dL})^{155}$.

The development of clinical and biochemical CVD risk factors are impacted by diet and physical activity. An inverse relationship has been found with fruit and vegetable consumption and the risk of $\mathrm{CVD}^{147}$. Consuming fruits and vegetables $>3$ times a day compared to once a day was associated with a $27 \%$ lower stroke incidence, a $42 \%$ lower stroke mortality, and a $27 \%$ lower cardiovascular disease mortality ${ }^{147}$. Increasing fiber intake, which can be found in fruits and vegetables and whole grain products, has also been found to reduce modifiable CVD risk factors such as dyslipidemia, diabetes and being overweight ${ }^{156-159}$. Physical inactivity can also negatively impact blood pressure, lipid profiles, fasting blood glucose and weight, which in turn can lead to a cardiovascular event ${ }^{160}$.

In addition to modifiable risk factors that can increase risk of CVD, Nonmodifiable CVD risk factors include age, gender, race and family history ${ }^{145}$. Risk of developing heart disease increases with aging ${ }^{145}$. Men are at greater risk of heart disease than pre-menopausal women, however once women are post-menopausal risk is similar across both genders ${ }^{145}$. African Americans seem to be at greater risk for developing $\mathrm{CVD}^{161}$. Finally, risk also increases if a first-degree relative had a cardiovascular event before the age of $55^{145}$. To assess and treat these risk factors, the 
American Heart Association and American College of Cardiology developed 10-year and lifetime risk estimates using algorithms for the development of atherosclerotic cardiovascular disease (Figure C) ${ }^{162}$. As described previously, those living with PD, TBI or stroke experience changes in physical and cognitive function ${ }^{3}$, which can not only impact nutritional status and dietary, but also promote a sedentary lifestyle, which may increase the risk of CVD in this population.

Research indicates those living with neurological conditions such as PD, TBI and stroke may be at increased CVD risk because they have one or more of these modifiable risk factors, such as a sedentary lifestyle, elevated lipid profiles or inadequate diets ${ }^{3,52,63,143}$. As described earlier, neurological conditions can impact dietary intake, especially for those living alone. Generally, older men living alone are at risk of malnutrition and need a supportive environment to provide optimal dietary intake and help compromise cardiovascular health ${ }^{163}$. A recent study analyzed the daily eating events among older men living with PD, stroke or rheumatoid arthritis and found that men living alone used more convenience foods such as instant and readyto-eat foods, compared to those who lived with a significant other ${ }^{163}$. Convenient foods are often higher in sodium, sugar and fat compared to fresh, homemade meals and can increase risk for chronic disease, including $\mathrm{CVD}^{164}$. 
Figure C:

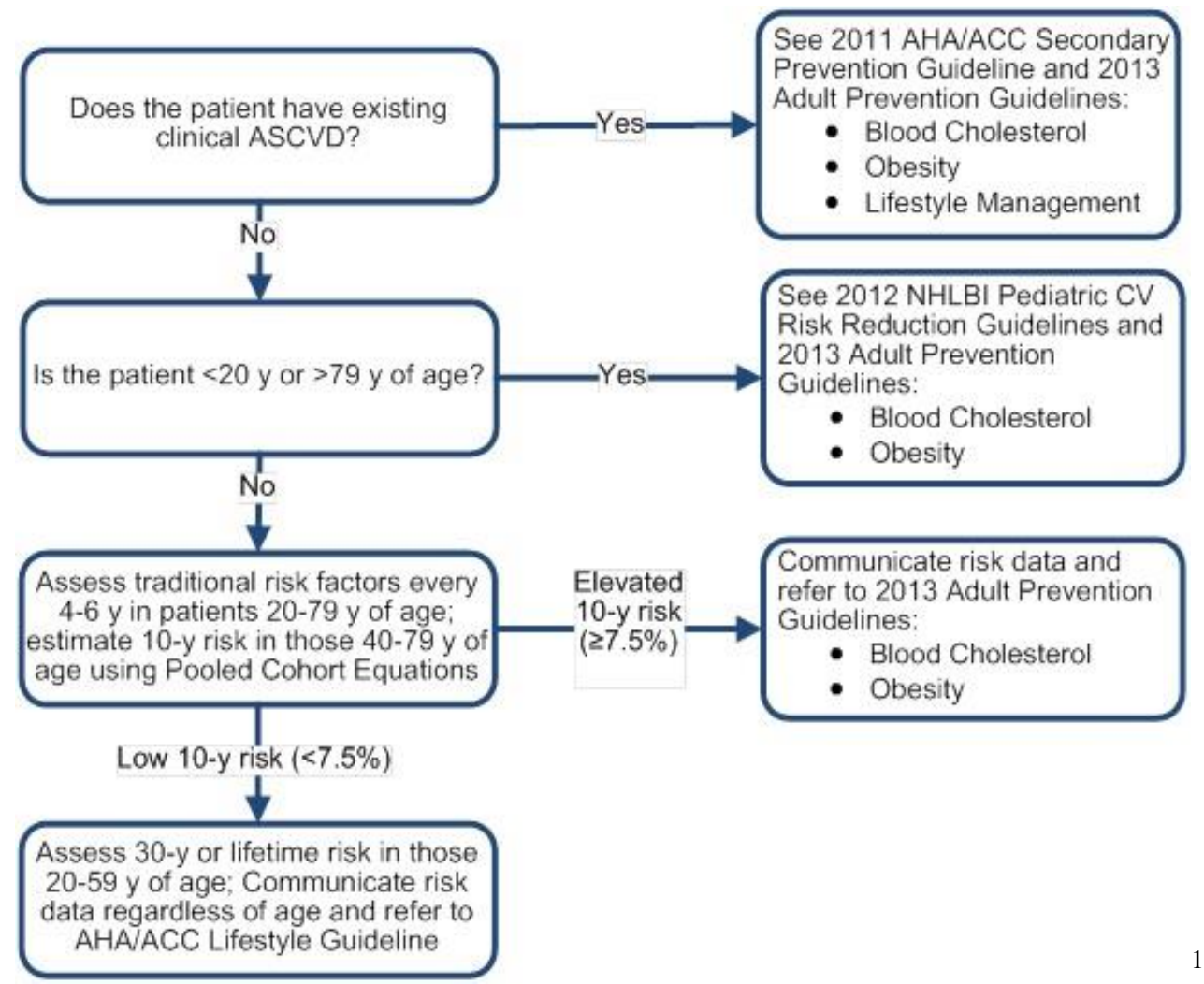

While poor dietary intake may increase cardiovascular risk in those with stroke and $\mathrm{PD}$, limited research exists regarding the dietary intake of those living with TBI. A late-onset complication of TBI is weight gain which can be a result from hormone and metabolic imbalances, as well as changes in mobility, self-regulation, altered satiety cues, and from medications that alter appetite ${ }^{3,86}$. Weight gain can lead to metabolic syndrome, which seems to develop in many of those living with $\mathrm{TBI}^{3}$. Metabolic syndrome is associated with excess food consumption, which can greatly be due to larger portion sizes, convenience foods and the availability of foods high in

\footnotetext{
1 Algorithm developed by The American Heart Association and American College of Cardiology to estimate 10-year and lifetime risks for the development of atherosclerotic cardiovascular disease (ASCVD)
} 
saturated and trans fats and added sugars ${ }^{165,166}$. The prevalence of metabolic syndrome can also increase risk for the development of CVD in this population ${ }^{3}$. Yet, the prevalence of those with TBI who have CVD or may be at risk for CVD has yet to be assessed.

Meanwhile, the prevalence of overweight and obesity seems to change throughout the course of PD, depending on the stage of PD and side effects of medications ${ }^{1}$. Research has found a lower prevalence rate of stroke in those with PD compared to the general population ${ }^{167}$. The mechanism behind this is not fully understood. There seems to be a higher prevalence of those overweight and obese with PD compared to the general population, however being overweight/obese with PD does not seem to increase risk for $\mathrm{CVD}^{168}$. While, research has found this association, the mechanism is still not quit understood, and as result monitoring weight is necessary to help prevent other declines associated with excessive weight gain.

Besides weight, research has also analyzed lipid profiles in those with PD. The relationship between cardio-metabolic risk factors and duration of PD has been examined to find that the longer one is living with PD, the better HDL-C levels are ${ }^{22}$. An inverse relationship of the TC-to-HDL-C ratio was also observed ${ }^{22}$. Research has also examined the effect of lipid profiles on those with TBI. Hypopituitarism is a common side effect following TBI and those living with TBI and PTHP frequently present metabolic alterations that include altered glucose levels, insulin resistance and hypertriglyceridemia and dyslipidemia ${ }^{169}$. 
In a total risk assessment, patients with a TBI appear to be at significantly increased risk for stroke ${ }^{170}$, as well as diabetes mellitus, hypertension, atrial fibrillation and CVD $^{3,16,89,170-172}$. Those with PTHP twelve months after TBI, had a higher total and LDL-cholesterol, as well as significantly higher BMI $\left(23.9 \pm 3.4 \mathrm{~kg} / \mathrm{m}^{2}\right.$ vs. $27.1 \pm$ $\left.29.3 \mathrm{~kg} / \mathrm{m}^{2}\right)$, waist circumference $(84 \pm 10 \mathrm{~cm}$ vs. $102 \pm 18 \mathrm{~cm})$ and total and abdominal FM compared to those TBI patients with intact pituitary function ${ }^{23}$. Mean BMI score for insufficient pituitary TBI patients increased significantly from three months to 12 months following injury, from $27.1 \mathrm{~kg} / \mathrm{m}^{2}$ to $29.3 \mathrm{~kg} / \mathrm{m}^{2}$. Additionally, total cholesterol significantly increased from $174.1 \pm 46.4 \mathrm{mg} / \mathrm{dL}$ to $208.8 \pm 27.1$ in those with insufficient pituitary function ${ }^{104}$. For those without PTHP, mean BMI scores remained stable and within normal limits, and total cholesterol levels saw a modest decrease $^{23}$. This study highlights the presence of cardiovascular risk in those with PTHP and TBI 12 months following injury, however what happens to weight status in TBI patients without and without PTHP beyond a year needs to be assessed.

When enough cardiovascular risk factors are present, this can lead to a cardiovascular event. Traumatic brain injury is associated with increased risk of stroke, a population based study followed those living with TBI for 5 years after injury, and found TBI patients had 10.21 times, 4.61 times and 2.32 times greater risk of stroke compared to non-TBI patients at 3 months, one year and five years post diagnosis ${ }^{170}$. At three months following TBI diagnosis, 675 strokes occurred in those with TBI, while only 207 cases were reported in non-TBI patients ${ }^{170}$. This study speculates the increase risk of stroke in those with TBI can be from the disturbance of blood supply to the brain post TBI, the formation of an atherosclerotic blood vessel 
due to the sudden impact after a TBI, or an increase in intracranial pressure and blood pressure post $\mathrm{TBI}^{170}$. Antipsychotic drugs used to treat TBI may also increase risk of stroke $^{173}$. The presence of cardiovascular risk factors previously described in this population $^{3,23}$, as well as the role diet and physical inactivity plays in developing CVD risk factors may also increase risk of stroke. As a result a more thorough assessment to understand the relationship between TBI and a stroke event is warranted. Additionally, since both TBI and stroke are forms of ABI, the presence of CVD risk factors in TBI give warrant an examination of CVD risk $\mathrm{n}$ those living with stroke.

Whether those living with stroke remain at cardiovascular risk following event of stroke needs to be assessed. As described earlier, an obesity paradox seems to exist following stroke, and is associated with a decrease risk in stroke reoccurrence ${ }^{143}$. The AHA proposed guidelines to prevent stroke reoccurrence, target similar modifiable and non-modifiable risk factors associated with CVD prevention ${ }^{174}$. The guidelines note that while obesity increases risk of stroke, no study has found weight reduction to reduce risk of stroke recurrence ${ }^{174}$. Additionally, Andersen and Olsen ${ }^{140}$ found patients with recurrent stroke are more often men, underweight and have a history of heart attack, atrial fibrillation, and hypertension. This study highlights the negative correlation between BMI and stroke recurrence based on an odds ratio (OR) (Figure D) ${ }^{140}$. It also highlights that risk factors for stroke and other cardiovascular events continue to exist in those following stroke if lifestyle modifications are not made.

A final modifiable risk factor that increases the chances of developing CVD is smoking tobacco. Smoking increases risk for coronary heart disease and stroke by two to four times ${ }^{175}$; it can also reduce blood flow to legs and $\operatorname{skin}^{175}$. The prevalence 
of smoking amongst those with neurological diseases and the influence it has on cardiovascular health in this population needs to thoroughly be examined. In addition to lifestyle choices, such as smoking tobacco, physical activity and function are associated with cardiovascular risk. Due to the nature of these three diseases, physical activity level may be limited. Physical impairment can promote a sedentary lifestyle and weight gain, but also negatively impact lean body mass.

Figure D:

140

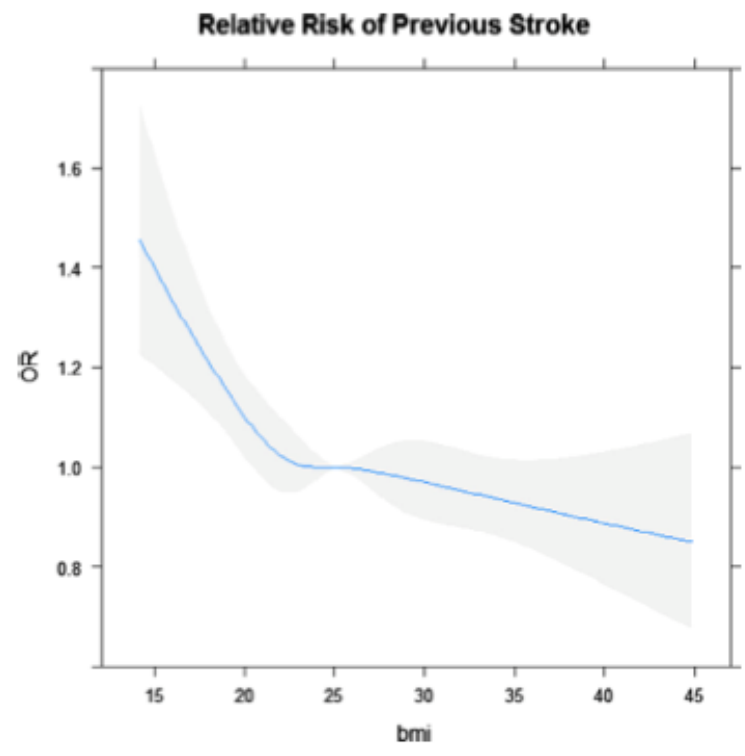

VI. Physical Activity and Physical Function

Physical activity is bodily movement by the skeletal muscles that results in energy expenditure ${ }^{176}$. It includes leisure time activities, such as sports and exercise, and $\mathrm{ADL}^{176}$. Physical activity curtails risk of mortality and morbidity ${ }^{160}$. Health benefits of physical activity have been well documented, including weight management, and preventing and treating cardiovascular disease and musculoskeletal 
disorders ${ }^{160}$. Physical activity promotes good physical health status, as well as mood and cognitive function, which can improve quality of life ${ }^{177}$. Evidence shows physical activity can help reduce age-related physical and cognitive decline ${ }^{178-180}$. A recent study examined the impact of a physical and leisure activity programmed on community-dwelling older adults and found the intervention had improvement in areas of cognition, specifically in abstract reasoning ability, a common initial symptom of dementia ${ }^{181}$, as well as significant in QOL.

Physical activity greatly relates to physical function, which is one's ability to carry out tasks related to activities of daily living, as well as quality of life ${ }^{182}$. Limited physical function can be due compromised upper and lower extremity function ${ }^{122}$. Compromised physical function can interfere with performing different tasks such as walking, climbing stairs, lifting heavy objects, picking up an object off the floor ${ }^{183}$, bathing, dressing, eating and cleaning ${ }^{184}$. A decline in physical function may lead to sedentary behaviors, which combined with excess calorie intake, can increase risk for obesity $^{185}$. Obesity is further associated with functional limitations ${ }^{186}$.

Many older adults develop sarcopenic-obesity, and this increase in body fat and decrease in muscle mass has been found to accelerate decline in physical function ${ }^{183,187}$. To treat and prevent complications of sarcopenic-obesity, incorporating physical activity can increase muscle mass and decrease fat mass, and in turn enhance physical function ${ }^{188}$. However, low BMI scores are also associated with compromised physical function, resulting in increased risk of falls and inability to carry out $\mathrm{ADL}^{189}$. 
Guidelines for physical activity have been created to promote optimal health benefits ${ }^{190}$. The 2008 Physical Activity Guidelines for Americans ${ }^{190}$ recommends adults participate in at least 150 minutes of moderate-intensity or 75 minutes per week of vigorous activity. This includes aerobic and muscle strengthening activity. Those living with chronic disease that follow physical activity guidelines can lower mortality by $46 \%$, meanwhile adults without chronic disease following these guidelines can lower mortality by $27 \%{ }^{191}$. The same guidelines pertain to those adults living with disability, including neurological disorders ${ }^{190}$. Research has found exercise to help lessen the burden of mobility related issues of $\mathrm{PD}^{192}$; those with PD who exercise have a better quality of life, walking ability, balance, strength, flexibility, and cardiovascular fitness levels ${ }^{192}$.

Despite these health benefits, some adults living with disability may not be able to meet these guidelines due to cognitive and physical impairment. For those living with disability, any degree of activity can provide health benefits and curtail functional decline ${ }^{193}$. Physicians can modify physical activity recommendations for those unable to meet guidelines ${ }^{193}$, but realities of these neurological disorders must be recognized to help this population overcome barriers of the disease that may deter participation in physical activity.

Physical and cognitive disabilities associated with neurological diseases can greatly impact physical function, which may decrease physical activity level and can also result in a decline in quality of life and depression ${ }^{3,4,39,194}$. A decline in physical activity is a risk factor for decline in physical function and can further inhibit mobility ${ }^{122}$. Consequently, those living with PD, TBI or stroke are at risk for sedentary 
behaviors and further induced functional decline, especially since these diseases can greatly impact movement of arms and legs ${ }^{185}$.

Motor and non-motor motor symptoms associated with PD may impact physical activity and function. . A reduction in physical function can also reduce ADL such as housekeeping, preparing meals, and ability to travel in the community ${ }^{195}$. Additionally, Wild and colleague's ${ }^{27}$ dual task study, revealed people with PD had a shorter gait due to difficulty with performing a cognitive task in conjunction with a motor task. Additionally, those with PD that had postural instability and gait difficulty reported worse health-related quality ${ }^{38}$. Changes highlight the impact both motor and non-motor symptoms have on PD, resulting in life-style changes.

Physical and cognitive changes experienced in this population may also increase risk for falling. Falls not only impact well-being, but can result in severe injuries ${ }^{196}$. Factors that increase risk for falls include older age, body composition, number of chronic diseases, muscle strength, functional mobility, balance, and fear of falling ${ }^{197-199}$. Targeting these risk factors by promoting physical activity that targets muscle strength and balance may help to prevent falls in this population, as well as those with other neurological disorders.

Extensive research indicates those with PD and stroke are at increased risk for falls ${ }^{200,201}$. Approximately $60 \%$ of those living with PD fall yearly ${ }^{202}$. Predicting falls in those with PD are associated with history of previous falls, disease severity, poor balance, reduced mobility, freezing of gait and reduced leg strength ${ }^{203,204}$. Similar physical limitation following a stroke also increase risk of falling ${ }^{205}$, and it is one of the most common complications following a stroke ${ }^{206}$. 
Following a stroke, impaired dynamic balance is associated with frequent falls three weeks after stroke ${ }^{205}$. Those who experience falling after a stroke show lower cognitive and physical functions, compared to those who did not fall, which highlights falling may impact cognitive and physical function ${ }^{205}$. This loss of balance, combined with fear of falling, may promote a sedentary lifestyle and decline in physical activity level.

Additionally, immediately following a stroke, walking dysfunction is common, as well as fatigue and lack of energy ${ }^{5}$. To treat these symptoms rehabilitation is usually followed after a stroke. Research also reveals rehabilitation post stroke is a key time to assess cognitive function, and that stroke-related cognitive impairment can limit functional gains during stroke rehabilitation ${ }^{200}$. Also, despite rehabilitation physical limitations can persist or re-occur ${ }^{20,130}$. Six months following a stroke, among 206 participants, $75 \%$ experience upper limb/motor impairment ${ }^{130}$. Research has also found three to nine months following a year-long rehabilitation, those living with chronic stroke seem likely to redevelop symptoms of walking dysfunction ${ }^{207-209}$. Additionally, research has found gait seems to worsen in the later years post stroke ${ }^{20}$, which can present challenges with balance, an increase in energy expenditure, risk of injury and decrease activity levels ${ }^{20}$. These findings insinuate rehabilitation exercises beyond the rehabilitation phase may be necessary to promote and maintain optimal physical function in those living with chronic stroke.

The literature also implies those living with TBI may be at increase risk for falling ${ }^{3,7}$. This can be due to changes in strength, endurance and balance ${ }^{210}$, as well as diminished motor-planning and attention, pain and weight gain ${ }^{3}$. All of these factors 
are inter-related and can promote poor physical function and low physical activity levels. While a decline in mobility is a part of the natural aging process, it seems to happen more rapidly in those living with $\mathrm{TBI}^{3}$.

Those who sustain a TBI are also more likely to experience muscular and orthopedic symptoms compared to nondisabled people ${ }^{86}$. Change in mobility, pelvis, limb and vertebrae fractures and other physical traumas that occur at the time of injury can also have long-term consequence and can re-emerge overtime, thus decreasing physical function and activity level and promoting weight gain ${ }^{3}$. Pain and stiffness in the joints may also deter physical activity in this population ${ }^{3}$. If this population continues to be sedentary and obesity develops, pain can become more pronounced, as research has found an association between obesity and joint and muscle pain ${ }^{211}$. Since over-nutrition has also been found in those with PD and stroke these issues may also occur in these neurological disorders as well.

As previously described, those with PD, TBI or stroke can suffer from underand over-nutrition. As a result, both physical inactivity and being obese are associated with decline in physical function and associated risk factors, such as the development of metabolic syndrome, CVD, and diabetes ${ }^{193}$. Being underweight can result in muscle wasting and poor physical function ${ }^{18}$. As previously described those with disability that are underweight may have issues with eating and swallowing which can also promote decline in physical function ${ }^{129}$.

Issues of physical function are prevalent in all three of these disease states and can further negatively impact health and quality of life. While, functional decline is a natural part of aging, it is more severe for those living with neurological conditions 
and other chronic diseases ${ }^{193}$. A recent cohort study examined factors associated with changes in physical function in older Chinese adults and found the main cause of functional decline was chronic disease; older persons with chronic conditions, such as stroke, PD, diabetes, and osteoporosis were more likely to experience a decline in physical function over the four year study period ${ }^{193}$. This study highlights that while chronic diseases increase the likelihood of disability, information regarding effective management of these disabling conditions is limited ${ }^{193,212}$. Research has also yet to examine the role of combining nutrition, cognition and physical activity in this population and how it can positively improve health outcomes.

Cognitive decline associated with these disease states can also impact physical activity level and physical functioning. Even mild levels of cognitive impairment have been found to increase disability and overall functional impairment ${ }^{10}$. Those with cognitive impairment may not be able to effectively perform meaningful tasks, which is hypothesized to be closely linked to inability to carry out $\mathrm{ADL}^{213}$. Besides poor cognition, psychological issues associated with these neurological disorders, including fear of falling is recognized as a factor that may deter older adults susceptible to falls from being physically active ${ }^{198}$.

While existing barriers can lead deter physical activity and promote decline in physical functioning, certain factors in this population have been found to help curtail this decline. A recent study examining factors that impact exercise behavior of 260 participants living with PD contradicts this ${ }^{214}$. The study found that those who participated in exercise had less severe motor impairment, fewer depressive symptoms, and few issues with physical mobility. Through a multivariate logistic 
regression, this cross sectional study found the degree of physical impairments, activity limitation and participation restrictions were not significantly associated with exercise behavior, but self-efficacy and belief regarding capabilities to exercise were $^{214}$.

Regardless of disease severity, those with higher self-efficacy were more than twice as likely to participate in routine exercise compared to those with low selfefficacy $^{214}$. A higher education level and older age also was associated with increased likelihood to partake in exercise ${ }^{214}$. The majority of participants $(86 \%)$ had mobility related issues that disabled them from participating ADL, but $88.8 \%$ of participants had a social support system at home to assist them ${ }^{214}$. This highlights that the main source of physical activity for this population is from planned exercise and leisure activity, as opposed through independently carrying out ADL. Findings also imply that promoting an increase activity in this population may be most effective through encouraging exercise and leisure time activity.

A limitation of this study was that the majority of participants only had mildto-moderate PD. Additionally, due to the cross-sectional study design, causality as to whether exercise promotes high self-efficacy or high self-efficacy promotes exercise needs to be monitored overtime ${ }^{214}$. How the progression of the disease impacts selfefficacy, willingness to exercise overtime, and whether exercise overtime can help delay the progression of the disease must also be assessed ${ }^{214}$.

Never the less, the findings of Ellis and colleagues ${ }^{214}$, reveal an understanding of factors that promotes physical activity can help provide vital information on how to promote physical activity and provide clearer recommendations for those living with 
neurological disorders. Physical inactivity can result in a further decline in physical function. Decline in physical function can promote muscle loss, as well as a decline in quality of life. While research has identified barriers that may promote a sedentary lifestyle, research has not examined the physical activity level of those living with one of these neurological conditions overtime. Doing so will help understand how and why ability to participate in exercise changes overtime. An assessment of physical activity levels and physical function of this population overtime can provide a better understanding of the diseases, and help create clearer recommendations and specialized programs for individuals throughout life. Doing so will not only decrease risk of developing other comorbidities associated with a sedentary lifestyle, but also help improve quality of life $\mathrm{e}^{160}$.

VII. Quality of Life

The World Health Organization (WHO) defines quality of life (QOL) as one's perception of their position in life in relation to the culture and value system in which they live $e^{215}$. The long-term disabilities of these neurological diseases greatly impact QOL $^{3,4,58}$. Quality of life has been shown to be lower in those with PD compared to age-matched healthy controls as well as compared to those with other disease entities such as diabetes ${ }^{216}$. A recent study, examined resilience, or one's ability to "bounce back" following an event or diagnosis, in those with PD. Results found that those with higher resilience scores, had better physical and mental quality of life and lesser disability $^{217}$. However, no correlation was found between disease severity and resilience scores ${ }^{217}$. Depression and mild cognitive impairment in those with PD is also correlated with a poorer nutritional status, indicating a worse QOL ${ }^{1,36,68,69}$. Those 
living with TBI and stroke also experience mental and physical side effects, which can also experience changes in $\mathrm{QOL}^{72}$.

Those with TBI often experience side-effects that compromise well-being, such a bowel and bladder incontinence, sleep disorders, psychiatric diseases and sexual dysfunction ${ }^{218}$. Additionally, Siponkoski and colleagues ${ }^{219}$ examined the quality of life of those with TBI that received intensive multidisciplinary residential rehabilitation treatment for up to 15 years post injury, and found quality of life was related to age at time of injury, depression, anxiety, amount of assistance needed, and education level ${ }^{219}$. Results also found that QOL remained stable over time and that those with milder injuries had a lower QOL $^{219}$. Traumatic brain injuries can impact long-term functional outcomes in older adults, however more information is needed to identify the specific, long-term post TBI side effects have on ADL, especially in older adults $^{28}$. Jacobsson and Lexell ${ }^{220}$ examined life satisfaction in those living with TBI six to fifteen years after injury and found those with a higher life satisfaction had fewer emotional disturbances and better social participation, as well as a longer time post injury and a more severe injury sustained later in life. It appears cohabiting and higher productivity levels also helps improve life satisfaction ${ }^{220}$. Findings indicate life satisfaction can improve with time and highlight factors that can impact life satisfaction. Both studies indicate more severe cognitive impairment seems to be associated with greater QOL and life satisfaction ${ }^{219,220}$. The reasoning for this, as well as the impact disease severity has on other health parameters, needs to be further investigated. 
Quality of life is also impacted in those with stroke, which can be exhibited by eating difficulties and inability to perform activities of daily living ${ }^{5}$. Research also consistently finds women seem to have less favorable outcomes after stroke than men, more difficulty with ADL, depression and overall lower QOL ${ }^{112}$. This lower QOL in women could be due to worse mobility, pain/discomfort, and anxiety and depression observed up to 12 months after stroke ${ }^{221}$. Research suggests that quality of life is often compromised in those living with PD, TBI and stroke, and as a result depression is a common side-effect of those living with one of these neurological conditions $^{38,37,219}$. Fatigue and sleep disturbances are common side effects of these three neurological conditions that can greatly impact quality of life ${ }^{86}$. A decline in quality of life can negatively impact nutritional status, as well as physical activity and function.

VII. Conclusion

Parkinson's disease, TBI and stroke are three neurological diseases that impact cognitive and physical function as well as nutritional status and risk of CVD. Research suggests dietary intake and nutritional status can be compromised due to the complications of these neurological conditions ${ }^{3,16,65}$. How nutritional status and physical activity level are impacted a year or more after diagnosis in those living with one of these diseases must be assessed to understand the difference between each disease and to acquire an understanding in treating those living long-term with PD, TBI or stroke. Assessing how nutritional status and physical activity level impact risk for cardiovascular disease, physical function and quality of life must also be assessed. Due to the prevalent research of weight loss and eating difficulties associated with one 
of these neurological disorders, research also indicates those living with neurological conditions may be at risk for malnutrition ${ }^{1,13-16}$ a year or more after diagnosis. It is necessary to examine how disabilities increase rate of nutritional and cardiovascular risk. It is also necessary to examine how cognition, nutrition and physical functioning interact in those living with neurological disorders and impact quality of life.

\section{References}

1. Barichella M, Cereda E, Pezzoli G. Major nutritional issues in the management of Parkinson's disease. Mov Disord 2009;24:1881-92.

2. National Institue of Health. Traumatic Brain Injury: Hope Through Research. NIH Publication 2002; http://www.ninds.nih.gov/disorders/tbi/detail_tbi.htm. Accessed May 2, 2013.

3. Murphy MP, Carmine H. Long-term health implications of individuals with TBI: a rehabilitation perspective. NeuroRehabilitation 2012;31:85-94.

4. Lamb F, Anderson J, Saling M, Dewey H. Predictors of subjective cognitive complaint in postacute older adult stroke patients. Arch Phys Med Rehabil 2013;94:1747-52.

5. Westergren A. Nutrition and its relation to mealtime preparation, eating, fatigue and mood among stroke survivors after discharge from hospital - a pilot study. Open Nurs J 2008;2:15-20.

6. Porth CM, Matfin G. Pathophysiology: Concepts of Altered Health States. Williams \& Wilkins; 2009.

7. Driver S, Irwin K, Woolsey A, Pawlowski J. Creating an effective physical activity-based health promotion programme for adults with a brain injury. Brain Inj 2012;26:1482-92.

8. Faul M, Xu L, Wald MM. Traumatic brain injury in the United States: emergency department visits, hospitalizations and deaths 2002-2006. . Atlanta, GA: Centers for Disease Control and Prevention, National Center for Injury Prevention and Control 2010.

9. Parkinson's Disease Foundation. What is Parkinson's Disease? 2013; http://www.pdf.org/about_pd. Accessed November 1, 2013. 
10. Leroi I, McDonald K, Pantula H, Harbishettar V. Cognitive impairment in Parkinson disease: impact on quality of life, disability, and caregiver burden. J Geriatr Psychiatry Neurol 2012;25:208-14.

11. Jaafar AF, Gray WK, Porter B, Turnbull EJ, Walker RW. A cross-sectional study of the nutritional status of community-dwelling people with idiopathic Parkinson's disease. BMC Neurol 2010;10:124.

12. Sheard JM, Ash S, Mellick GD, Silburn PA, Kerr GK. Malnutrition in a sample of community-dwelling people with Parkinson's disease. PLoS One 2013;8:e53290.

13. Kraukau K, Hansson A, Karlsson T, Nygren de Boussard C, Tengvar C, Borg J. Nutritional treatment of patients with severe traumatic brain injury during the first six months after injury Nutrition 2007;23:308-17.

14. Ott L, McClain C, Young B. Nutrition and severe brain injury. Nutrition 1989;5:75-9.

15. Scherbakov N, Dirnagl U, Doehner W. Body weight after stroke: lessons from the obesity paradox. Stroke 2011;42:3646-50.

16. Shen HC, Chen HF, Peng LN, et al. Impact of nutritional status on long-term functional outcomes of post-acute stroke patients in Taiwan. Arch Gerontol Geriatr 2011;53:e149-52.

17. Medin J, Windahl J, von Arbin M, Tham K, Wredling R. Eating difficulties among patients 3 months after stroke in relation to the acute phase. J Adv Nurs 2012;68:580-9.

18. Broadwin J, Goodman-Gruen D, Slymen D. Ability of fat and fat-free mass percentages to predict functional disability in older men and women. J Am Geriatr Soc 2001;49:1641-5.

19. Kelly-Hayes M, Beiser A, Kase CS, Scaramucci A, D'Agostino RB, Wolf PA. The influence of gender and age on disability following ischemic stroke: the Framingham study. J Stroke Cerebrovasc Dis 2003;12:119-26.

20. Patterson KK, Gage WH, Brooks D, Black SE, Mcllroy WE. Changes in gait symmetry and velocity after stroke: a cross-sectional study from weeks to years after stroke. Neurorehabil Neural Repair 2010;24:783-90.

21. Cereda E, Cassani E, Barichella M, Caccialanza R, Pezzoli G. Anthropometric indices of fat distribution and cardiometabolic risk in Parkinson's disease. Nutr Metab Cardiovasc Dis 2013;23:264-71. 
22. Cassani E, Cereda E, Barichella M, et al. Cardiometabolic factors and disease duration in patients with Parkinson's disease. Nutrition 2013;29:1331-5.

23. Klose M, Juul A, Struck J, Morgenthaler NG, Kosteljanetz M, FeldtRasmussen U. Acute and long-term pituitary insufficiency in traumatic brain injury: a prospective single-centre study. Clin Endocrinol (Oxf) 2007;67:598-606.

24. Doehner W, Schenkel J, Anker SD, Springer J, Audebert HJ. Overweight and obesity are associated with improved survival, functional outcome, and stroke recurrence after acute stroke or transient ischaemic attack: observations from the TEMPiS trial. Eur Heart J 2013;34:268-77.

25. Mayo Clinic. Parkinson's disease. 2012; http://www.mayoclinic.com/health/parkinsons-disease/DS00295. Accessed November 1, 2013.

26. Natioanl Parkinson Foundation. What is Parkinson's Disease ? 2013; http://www.parkinson.org/Parkinson-s-Disease/PD-101/What-is-Parkinson-sdisease. Accessed October, 2013.

27. Wild LB, de Lima DB, Balardin JB, et al. Characterization of cognitive and motor performance during dual-tasking in healthy older adults and patients with Parkinson's disease. J Neurol 2013;260:580-9.

28. Lecours A, Sirois MJ, Ouellet MC, Boivin K, Simard JF. Long-term functional outcome of older adults after a traumatic brain injury. J Head Trauma Rehabil 2012;27:379-90.

29. Sweeney P. Parkinson's Disease. 2013; http://www.clevelandclinicmeded.com/medicalpubs/diseasemanagement/neuro logy/parkinsons-disease/.

30. Nutt JG, Wooten GF. Clinical practice. Diagnosis and initial management of Parkinson's disease. N Engl J Med 2005;353:1021-7.

31. Jankovic J, McDermott M, Carter J, et al. Variable expression of Parkinson's disease: a base-line analysis of the DATATOP cohort. The Parkinson Study Group. Neurology 1990;40:1529-34.

32. Marras C, Lang A. Parkinson's disease subtypes: lost in translation? J Neurol Neurosurg Psychiatry 2013;84:409-15.

33. Szewczyk-Krolikowski K, Tomlinson P, Nithi K, et al. The influence of age and gender on motor and non-motor features of early Parkinson's disease: 
Initial findings from the Oxford Parkinson Disease Center (OPDC) discovery cohort. Parkinsonism Relat Disord 2013.

34. Hoehn MM, Yahr MD. Parkinsonism: onset, progression and mortality. Neurology 1967;17:427-42.

35. Lorefat B, Ganowiak W, Wissing U, Granerus AK, Unosson M. Food habits and intake of nutrients in elderly patients with Parkinson's disease. Gerontology 2006;52:160-8.

36. Sheard JM, Ash S, Silburn PA, Kerr GK. Prevalence of malnutrition in Parkinson's disease: a systematic review. Nutr Rev 2011;69:520-32.

37. Kudlicka A, Clare L, Hindle JV. Pattern of executive impairment in mild to moderate Parkinson's disease. Dement Geriatr Cogn Disord 2013;36:5066.

38. Duncan GW, Khoo TK, Yarnall AJ, et al. Health-related quality of life in early Parkinson's disease: The impact of nonmotor symptoms. Mov Disord 2013.

39. Kudlicka A, Clare L, Hindle JV. Quality of life, health status and caregiver burden in Parkinson's disease: relationship to executive functioning. Int J Geriatr Psychiatry 2013.

40. Centers for Disease Control and Prevention. Behavioral Risk Factor Surveillance System (BRFSS) Perceived Cognitive Impairment Module. 2013; http://www.cdc.gov/aging/healthybrain/brfss-faq.htm - q2. Accessed 14, January.

41. Hely MA, Morris JG, Reid WG, Trafficante R. Sydney Multicenter Study of Parkinson's disease: non-L-dopa-responsive problems dominate at 15 years. Mov Disord 2005;20:190-9.

42. Litvan I, Aarsland D, Adler CH, et al. MDS Task Force on mild cognitive impairment in Parkinson's disease: critical review of PD-MCI. Mov Disord 2011;26:1814-24.

43. Connolly B, Fox SH. Treatment of Cognitive, Psychiatric, and Affective Disorders Associated with Parkinson's Disease. Neurotherapeutics 2013.

44. Cools R, Barker RA, Sahakian BJ, Robbins TW. Enhanced or impaired cognitive function in Parkinson's disease as a function of dopaminergic medication and task demands. Cereb Cortex 2001;11:1136-43. 
45. Peran P, Nemmi F, Meligne D, et al. Effect of levodopa on both verbal and motor representations of action in Parkinson's disease: a fMRI study. Brain Lang 2013;125:324-9.

46. Dauer W, Przedborski S. Parkinson's disease: mechanisms and models. Neuron 2003;39:889-909.

47. Muslimovic D, Post B, Speelman JD, Schmand B. Cognitive profile of patients with newly diagnosed Parkinson disease. Neurology 2005;65:1239-45.

48. National Center for Learning Disabilities. What is Executive Function? . 2013; http://www.ncld.org/types-learning-disabilities/executive-functiondisorders/what-is-executive-function. Accessed December 2, 2013.

49. Kudlicka A, Clare L, Hindle JV. Executive functions in Parkinson's disease: systematic review and meta-analysis. Mov Disord 2011;26:2305-15.

50. Postuma RB, Aarsland D, Barone P, et al. Identifying prodromal Parkinson's disease: pre-motor disorders in Parkinson's disease. Mov Disord 2012;27:617-26.

51. Schrag A, Jahanshahi M, Quinn N. What contributes to quality of life in patients with Parkinson's disease? J Neurol Neurosurg Psychiatry 2000;69:308-12.

52. Barichella M, Marczewska AM, Mariani C, Landi A, Vairo A, Pezzoli G. Body weight gain rate in patients with Parkinson's disease and deep brain stimulation. Mov Disord 2003;18:1337-40.

53. Chen H, Zhang SM, Hernan MA, Willett WC, Ascherio A. Weight loss in Parkinson's disease. Ann Neurol 2003;53:676-9.

54. Uc EY, Struck LK, Rodnitzky RL, Zimmerman B, Dobson J, Evans WJ. Predictors of weight loss in Parkinson's disease. Mov Disord 2006;21:9306.

55. Malnutrition Advisory Group. Guidelines for Detection and Management of Malnutrition. . Maidenhead, UK: British Association for Paretneral and Enteral Nutrition (BAPEN) 2000.

56. Escott-Stump S. Nutrition and Diagnosis - Related Care. 7th Edition ed. Baltimore, MD: Lippincott Williams \& Wilkins 2011:602-03.

57. Martineau J, Bauer JD, Isenring E, Cohen S. Malnutrition determined by the patient-generated subjective global assessment is associated with poor outcomes in acute stroke patients. Clin Nutr 2005;24:1073-7. 
58. Martignoni E, Citterio A, Zangaglia R, et al. How parkinsonism influences life: the patients' point of view. Neurol Sci 2011;32:125-31.

59. Wang G, Wan $Y$, Cheng $Q$, et al. Malnutrition and associated factors in Chinese patients with Parkinson's disease: Results from a pilot investigation. Parkinsonism Relat Disord 2010;16:119-23.

60. The Michael J. Fox Foundation. What Is Parkinson's? 2013; https://http://www.michaeljfox.org/page.html?what-is-parkinsonsinfographic. Accessed November 2, 2013.

61. MedlinePlus. Aging Changes in Body Shape. 2013; http://www.nlm.nih.gov/medlineplus/ency/article/003998.htm. Accessed April 2, 2013.

62. Beyer PL, Palarino MY, Michalek D, Busenbark K, Koller WC. Weight change and body composition in patients with Parkinson's disease. J Am Diet Assoc 1995;95:979-83.

63. Barichella M, Marczewska A, Vairo A, Canesi M, Pezzoli G. Is underweightness still a major problem in Parkinson's disease patients? Eur J Clin Nutr 2003;57:543-7.

64. Bachmann CG, Zapf A, Brunner E, Trenkwalder C. Dopaminergic treatment is associated with decreased body weight in patients with Parkinson's disease and dyskinesias. Eur J Neurol 2009;16:895-901.

65. Barichella M, Villa MC, Massarotto A, et al. Mini Nutritional Assessment in patients with Parkinson's disease: correlation between worsening of the malnutrition and increasing number of disease-years. Nutr Neurosci 2008;11:128-34.

66. Abbott RA, Cox M, Markus H, Tomkins A. Diet, body size and micronutrient status in Parkinson's disease. Eur J Clin Nutr 1992;46:879-84.

67. Bachmann CG, Trenkwalder C. Body weight in patients with Parkinson's disease. Mov Disord 2006;21:1824-30.

68. Edwards LL, Pfeiffer RF, Quigley EM, Hofman R, Balluff M. Gastrointestinal symptoms in Parkinson's disease. Mov Disord 1991;6:151-6.

69. Pfeiffer RF. Gastrointestinal dysfunction in Parkinson's disease. Lancet Neurol 2003;2:107-16.

70. Andersson I, Sidenvall B. Case studies of food shopping, cooking and eating habits in older women with Parkinson's disease. J Adv Nurs 2001;35:69-78. 
71. Johansson Y, Bachrach-Lindstrom M, Carstensen J, Ek AC. Malnutrition in a home-living older population: prevalence, incidence and risk factors. A prospective study. J Clin Nurs 2009;18:1354-64.

72. Sheard JM, Ash S, Mellick GD, Silburn PA, Kerr GK. Markers of disease severity are associated with malnutrition in Parkinson's disease. PLoS One 2013;8:e57986.

73. Forbes SC, Little JP, Candow DG. Exercise and nutritional interventions for improving aging muscle health. Endocrine 2012;42:29-38.

74. Janssen I. The epidemiology of sarcopenia. Clin Geriatr Med 2011;27:35563.

75. Hughes VA, Frontera WR, Roubenoff R, Evans WJ, Singh MA. Longitudinal changes in body composition in older men and women: role of body weight change and physical activity. Am J Clin Nutr 2002;76:473-81.

76. Nirenberg MJ, Waters C. Compulsive eating and weight gain related to dopamine agonist use. Mov Disord 2006;21:524-9.

77. Montaurier C, Morio B, Bannier S, et al. Mechanisms of body weight gain in patients with Parkinson's disease after subthalamic stimulation. Brain 2007;130:1808-18.

78. Parkinson's Disease Foundation. Prescription Medications. 2014; http://www.pdf.org/parkinson_prescription_meds - dopamine. Accessed December 15, 2013.

79. Parkinson's Disease Foundation. Surgical Treatments 2014; http://www.pdf.org/en/surgical_treatments. Accessed January 4, 2014.

80. National Institute of Neurological Disorders and Stroke. NINDS Deep Brain Stimulation for Parkinson's Disease Information Page. 2012; http://www.ninds.nih.gov/disorders/deep_brain_stimulation/deep_brain_stimul ation.htm. Accessed December 2, 2013.

81. Kashihara K. Weight loss in Parkinson's disease. J Neurol 2006;253 Suppl 7:VII38-41.

82. Go AS, Mozaffarian D, Roger VL, et al. Heart disease and stroke statistics-2013 update: a report from the American Heart Association. Circulation 2013;127:e6-e245.

83. Mayo Clinic. Traumatic Brain Injury. 2012; http://www.mayoclinic.com/health/traumatic-brain-injury/DS00552. Accessed July 132013. 
84. Centers for Disease Control and Prevention. Traumatic Brain Injury 2013; http://www.cdc.gov/traumaticbraininjury/. Accessed May 2, 2013.

85. Coronado VG, Xu L, Basavaraju SV, et al. Surveillance for traumatic brain injury - related deaths - United States, 1997-2007. Centers for Disease Control: Morbidity and Mortality Weekly 2011;60:1-32.

86. Breed ST, Flanagan SR, Watson KR. The relationship between age and the self-report of health symptoms in persons with traumatic brain injury. Arch Phys Med Rehabil 2004;85:S61-7.

87. Coronado VG, Thurman DJ, Greenspan AI, Weissman BM. Epidemiology In: Jallo J, Loftus CM, eds. Neurotrauma and critical care:brain. New York, NY: Thieme; 2009:3-19.

88. Terrio H, Brenner LA, Ivins BJ, et al. Traumatic brain injury screening: preliminary findings in a US Army Brigade Combat Team. J Head Trauma Rehabil 2009;24:14-23.

89. Hibbard MR, Uysal S, Sliwinski M, Gordon WA. Undiagnosed health issues in individuals with traumatic brain injury living in the community. J Head Trauma Rehabil 1998;13:47-57.

90. Selassie AW, Zaloshnja E, Langlois JA, Miller T, Jones P, Steiner C. Incidence of long-term disability following traumatic brain injury hospitalization, United States, 2003. J Head Trauma Rehabil 2008;23:123-31.

91. Katz DI, Ashley MJ, O'Shanick GJ, Connors SH. Cognitive rehabilitation: the evidence, funding and case for advocacy in brain injury. . McLean, VA: Brain Injury Association of America 2006.

92. Ettenhofer ML, Melrose RJ, Delawalla Z, Castellon SA, Okonek A. Correlates of functional status among OEF/OIF veterans with a history of traumatic brain injury. Mil Med 2012;177:1272-8.

93. Schretlen DJ, Shapiro AM. A quantitative review of the effects of traumatic brain injury on cognitive functioning. Int Rev Psychiatry 2003;15:341-9.

94. Rapoport MJ, Herrmann N, Shammi P, Kiss A, Phillips A, Feinstein A. Outcome after traumatic brain injury sustained in older adulthood: a oneyear longitudinal study. Am J Geriatr Psychiatry 2006;14:456-65.

95. Bower JH, Maraganore DM, Peterson BJ, McDonnell SK, Ahlskog JE, Rocca WA. Head trauma preceding PD: a case-control study. Neurology 2003;60:1610-5. 
96. Dunnett SB, Bjorklund A. Prospects for new restorative and neuroprotective treatments in Parkinson's disease. Nature 1999;399:A329.

97. Goldstein FC, Levin HS, Presley RM, et al. Neurobehavioural consequences of closed head injury in older adults. J Neurol Neurosurg Psychiatry 1994;57:961-6.

98. Becker DP, Miller JD, Ward JD, Greenberg RP, Young HF, Sakalas R. The outcome from severe head injury with early diagnosis and intensive management. J Neurosurg 1977;47:491-502.

99. Wolach B, Sazbon L, Gavrieli R, Broda A, Schlesinger M. Early immunological defects in comatose patients after acute brain injury. J Neurosurg 2001;94:706-11.

100. Rapp RP, Young B, Twyman D, et al. The favorable effect of early parenteral feeding on survival in head-injured patients. J Neurosurg 1983;58:906-12.

101. Sacks GS, Brown RO, Teague D, Dickerson RN, Tolley EA, Kudsk KA. Early nutrition support modifies immune function in patients sustaining severe head injury. JPEN J Parenter Enteral Nutr 1995;19:387-92.

102. Harrison-Felix CL, Whiteneck GG, Jha A, DeVivo MJ, Hammond FM, Hart DM. Mortality over four decades after traumatic brain injury rehabilitation: a retrospective cohort study. Arch Phys Med Rehabil 2009;90:1506-13.

103. Agha A, Thompson CJ. Anterior pituitary dysfunction following traumatic brain injury (TBI). Clin Endocrinol (Oxf) 2006;64:481-8.

104. Klose M, Watt T, Brennum J, Feldt-Rasmussen U. Posttraumatic hypopituitarism is associated with an unfavorable body composition and lipid profile, and decreased quality of life 12 months after injury. J Clin Endocrinol Metab 2007;92:3861-8.

105. Turley SM. Endocrinology. Medical Language 2nd Edition ed. Upper Saddle River, New Jersey Pearson Education 2011:712-14.

106. American Stroke Association. Stroke- Preventable, beatable, curable. . 2013; http://www.heart.org/idc/groups/heartpublic/@wcm/@adt/documents/downloadable/ucm_443967.pdf. Accessed April 2, 2013. 
107. Ovbiagele B, Goldstein LB, Higashida RT, et al. Forecasting the future of stroke in the United States: a policy statement from the American Heart Association and American Stroke Association. Stroke 2013;44:2361-75.

108. National Stroke Association. Physical Activity and Healthy Diet 2014; http://www.stroke.org/site/PageServer?pagename=eathealthy. Accessed August 12, 2013.

109. Lee CD, Folsom AR, Blair SN. Physical activity and stroke risk: a metaanalysis. Stroke 2003;34:2475-81.

110. Seshadri S, Beiser A, Kelly-Hayes M, et al. The lifetime risk of stroke: estimates from the Framingham Study. Stroke 2006;37:345-50.

111. Kleindorfer DO, Khoury J, Moomaw CJ, et al. Stroke incidence is decreasing in whites but not in blacks: a population-based estimate of temporal trends in stroke incidence from the Greater Cincinnati/Northern Kentucky Stroke Study. Stroke 2010;41:1326-31.

112. Reeves MJ, Bushnell CD, Howard G, et al. Sex differences in stroke: epidemiology, clinical presentation, medical care, and outcomes. Lancet Neurol 2008;7:915-26.

113. Finestone HM, Foley NC, Woodbury MG, Greene-Finestone L. Quantifying fluid intake in dysphagic stroke patients: a preliminary comparison of oral and nonoral strategies. Arch Phys Med Rehabil 2001;82:1744-6.

114. Barker-Collo S, Feigin V. The impact of neuropsychological deficits on functional stroke outcomes. Neuropsychol Rev 2006;16:53-64.

115. Bailey RL, Mitchell DC, Miller CK, et al. A Dietary Screening Questionnaire Identifies Dietary Patterns in Older Adults The Journal of Nutrition 2007; ;137: :421-26.

116. Barker-Collo S, Feigin VL, Parag V, Lawes CM, Senior H. Auckland Stroke Outcomes Study. Part 2: Cognition and functional outcomes 5 years poststroke. Neurology 2010;75:1608-16.

117. van Rijsbergen MW, Mark RE, de Kort PL, Sitskoorn MM. The COMPlaints After Stroke (COMPAS) study: protocol for a Dutch cohort study on poststroke subjective cognitive complaints. BMJ Open 2013 Jan;3:e003599.

118. Hochstenbach J, Prigatano G, Mulder T. Patients' and relatives' reports of disturbances 9 months after stroke: subjective changes in physical functioning, cognition, emotion, and behavior. Arch Phys Med Rehabil 2005;86:1587-93. 
119. Duits A, Munnecom T, van Heugten C, van Oostenbrugge RJ. Cognitive complaints in the early phase after stroke are not indicative of cognitive impairment. J Neurol Neurosurg Psychiatry 2008;79:143-6.

120. Wagle J, Farner L, Flekkoy K, et al. Early post-stroke cognition in stroke rehabilitation patients predicts functional outcome at 13 months. Dement Geriatr Cogn Disord 2011;31:379-87.

121. Wendel K, Risberg J, Pessah-Rasmussen H, Stahl A, Iwarsson S. Long-term cognitive functional limitations post stroke: objective assessment compared with self-evaluations and spouse reports. Int J Rehabil Res 2008;31:231-9.

122. Stuck AE, Walthert JM, Nikolaus T, Bula CJ, Hohmann C, Beck JC. Risk factors for functional status decline in community-living elderly people: a systematic literature review. Soc Sci Med 1999;48:445-69.

123. Mosselman MJ, Kruitwagen CL, Schuurmans MJ, Hafsteinsdottir TB. Malnutrition and risk of malnutrition in patients with stroke: prevalence during hospital stay. J Neurosci Nurs 2013;45:194-204.

124. Mahan LM, Escott-Stump S. Medical Nutrition Therapy for Cancer. Krause's Food and Nutrition Therapy. 12th Edition ed. Philadelphia, PA: Saunders Elsevier; 2008:968.

125. Jorgensen L, Jacobsen BK. Changes in muscle mass, fat mass, and bone mineral content in the legs after stroke: a 1 year prospective study. Bone 2001;28:655-9.

126. Sura L, Madhavan A, Carnaby G, Crary MA. Dysphagia in the elderly: management and nutritional considerations. Clin Interv Aging 2012;7:287-98.

127. Smithard DG, O'Neill PA, Parks C, Morris J. Complications and outcome after acute stroke. Does dysphagia matter? Stroke 1996;27:1200-4.

128. Smithard DG, Smeeton NC, Wolfe CD. Long-term outcome after stroke: does dysphagia matter? Age Ageing 2007;36:90-4.

129. Westergren A, Karlsson S, Andersson P, Ohlsson O, Hallberg IR. Eating difficulties, need for assisted eating, nutritional status and pressure ulcers in patients admitted for stroke rehabilitation. J Clin Nurs 2001;10:257-69.

130. Perry L, McLaren S. An exploration of nutrition and eating disabilities in relation to quality of life at 6 months post-stroke. Health \& Social Care in the Community 2004;12:288-97. 
131. Westergren A, Ohlsson O, Hallberg IR. Eating difficulties in relation to gender, length of stay, and discharge to institutional care, among patients in stroke rehabilitation. Disabil Rehabil 2002;24:523-33.

132. Crary MA, Carnaby-Mann GD, Miller L, Antonios N, Silliman S. Dysphagia and nutritional status at the time of hospital admission for ischemic stroke. J Stroke Cerebrovasc Dis 2006;15:164-71.

133. Hafer-Macko CE, Ryan AS, Ivey FM, Macko RF. Skeletal muscle changes after hemiparetic stroke and potential beneficial effects of exercise intervention strategies. J Rehabil Res Dev 2008;45:261-72.

134. Jonsson AC, Lindgren I, Norrving B, Lindgren A. Weight loss after stroke: a population-based study from the Lund Stroke Register. Stroke 2008;39:918-23.

135. Jacobsson C, Axelsson K, Norberg A, Asplund K, Wenngren BI. Outcomes of individualized interventions in patients with severe eating difficulties. Clin Nurs Res 1997;6:25-44.

136. Strazzullo P, D'Elia L, Cairella G, Garbagnati F, Cappuccio FP, Scalfi L. Excess body weight and incidence of stroke: meta-analysis of prospective studies with 2 million participants. Stroke 2010;41:e418-26.

137. McAuley PA, Blair SN. Obesity paradoxes. J Sports Sci 2011;29:773-82.

138. Collaboration FT. Poor nutritional status on admission predicts poor outcomes after stroke: observational data from the FOOD trial. Stroke 2003;34:1450-6.

139. Vemmos K, Ntaios G, Spengos K, et al. Association between obesity and mortality after acute first-ever stroke: the obesity-stroke paradox. Stroke 2011;42:30-6.

140. Andersen KK, Olsen TS. Body mass index and stroke: overweight and obesity less often associated with stroke recurrence. J Stroke Cerebrovasc Dis 2013;22:e576-81.

141. Burke DT, Al-Adawi S, Bell RB, Easley K, Chen S, Burke DP. The Effect of Body Mass Index on Stroke Rehabilitation. Arch Phys Med Rehabil In Press 2014.

142. Doruk H, Naharci MI, Bozoglu E, Isik AT, Kilic S. The relationship between body mass index and incidental mild cognitive impairment, Alzheimer's disease and vascular dementia in elderly. J Nutr Health Aging 2010;14:834-8. 
143. Kim BJ, Lee SH, Jung KH, et al. Dynamics of obesity paradox after stroke, related to time from onset, age, and causes of death. Neurology 2012;79:856-63.

144. Centers for Disease Control and Prevention. Heart Disease Facts and Statistics. . 2012; http://www.cdc.gov/heartdisease/statistics.htm. Accessed January 1, 2014.

145. World Heart Federation. Cardiovascular disease risk factors 2011; http://www.world-heart-federation.org/press/fact-sheets/cardiovasculardisease-risk-factors/. Accessed February 12, 2014.

146. Lloyd-Jones DM, Leip EP, Larson MG, et al. Prediction of lifetime risk for cardiovascular disease by risk factor burden at 50 years of age. Circulation 2006;113:791-8.

147. Bazzano LA, He J, Ogden LG, et al. Fruit and vegetable intake and risk of cardiovascular disease in US adults: the first National Health and Nutrition Examination Survey Epidemiologic Follow-up Study. Am J Clin Nutr 2002;76:93-9.

148. Center for Disease Control and Prevention: About Adult BMI. . 2011; http://www.cdc.gov/healthyweight/assessing/bmi/adult_bmi/index.html. Accessed May 2, 2013.

149. American Council on Exercise. Percent Body Fat Norms for Men and Women. . 2013;; http://www.acefitness.org/?creative $=45247336884 \&$ device $=c \&$ network $=g \& m a$ tchtype $=$ b\&gclid=CNi3ieq6jr0CFcFlOgodCVAAxQ. Accessed June 2, 2013.

150. American Heart Association. Symptoms and Diagnosis of Metabolic Syndrome. . 2011;

https://http://www.heart.org/HEARTORG/Conditions/More/MetabolicSyndr ome/Symptoms-and-Diagnosis-of-MetabolicSyndrome_UCM 301925_Article.jsp. Accessed February 2, 2014.

151. Center for Disease Control and Prevention. High Blood Pressure. 2013; http://www.cdc.gov/bloodpressure/. Accessed May 16, 2013.

152. Huffman MD, Capewell S, Ning H, Shay CM, Ford ES, Lloyd-Jones DM. Cardiovascular health behavior and health factor changes (1988-2008) and projections to 2020: results from the National Health and Nutrition Examination Surveys. Circulation 2012;125:2595-602.

153. Centers for Disease Control and Prevention. Cholesterol 2012. Accessed April 3, 2013. 
154. van der Wulp MY, Verkade HJ, Groen AK. Regulation of cholesterol homeostasis. Mol Cell Endocrinol 2013;368:1-16.

155. American Diabetes Association. Diagnosing Diabetes and Learning About Prediabetes. 2014; http://www.diabetes.org/diabetesbasics/diagnosis/?loc=db-slabnav. Accessed January 5, 2014.

156. Ning H, Van Horn L, Shay CM, Lloyd-Jones DM. Associations of dietary fiber intake with long-term predicted cardiovascular disease risk and C-reactive protein levels (from the National Health and Nutrition Examination Survey Data [2005-2010]). Am J Cardiol 2014;113:287-91.

157. Levitan EB. Invited commentary: dietary fiber, estradiol, and cholesterol. Am J Epidemiol 2011;173:157-9; discussion 60-1.

158. Tabatabai A, Li S. Dietary fiber and type 2 diabetes. Clin Excell Nurse Pract 2000;4:272-6.

159. Howarth NC, Saltzman E, Roberts SB. Dietary fiber and weight regulation. Nutr Rev 2001;59:129-39.

160. Centers for Disease Control and Prevention. Physical Activity and Health. . 2011; http://www.cdc.gov/physicalactivity/everyone/health/index.html. Accessed February 2, 2014.

161. McGruder HF, Malarcher AM, Antoine TL, Greenlund KJ, Croft JB. Racial and ethnic disparities in cardiovascular risk factors among stroke survivors: United States 1999 to 2001. Stroke 2004;35:1557-61.

162. Goff DC, Jr., Lloyd-Jones DM, Bennett G, et al. 2013 ACC/AHA Guideline on the Assessment of Cardiovascular Risk: A Report of the American College of Cardiology/American Heart Association Task Force on Practice Guidelines. Circulation 2013.

163. Kullberg K, Aberg AC, Bjorklund A, Ekblad J, Sidenvall B. Daily eating events among co-living and single-living, diseased older men. J Nutr Health Aging 2008;12:176-82.

164. Moubarac JC, Martins AP, Claro RM, Levy RB, Cannon G, Monteiro CA. Consumption of ultra-processed foods and likely impact on human health. Evidence from Canada. Public Health Nutr 2013;16:2240-8.

165. Bowman SA, Vinyard BT. Fast food consumption of U.S. adults: impact on energy and nutrient intakes and overweight status. J Am Coll Nutr 2004;23:163-8. 
166. Mirmiran P, Bahadoran Z, Delshad H, Azizi F. Effects of energy-dense nutrient-poor snacks on the incidence of metabolic syndrome: $\mathrm{A}$ prospective approach in Tehran Lipid and Glucose Study. Nutrition 2013.

167. Nataraj A, Rajput AH. Parkinson's disease, stroke, and related epidemiology. Mov Disord 2005;20:1476-80.

168. Fall PA, Saleh A, Fredrickson M, Olsson JE, Granerus AK. Survival time, mortality, and cause of death in elderly patients with Parkinson's disease: a 9-year follow-up. Mov Disord 2003;18:1312-6.

169. Prodam F, Gasco V, Caputo M, et al. Metabolic alterations in patients who develop traumatic brain injury (TBI)-induced hypopituitarism. Growth Horm IGF Res 2013;23:109-13.

170. Chen YH, Kang JH, Lin HC. Patients with traumatic brain injury: population-based study suggests increased risk of stroke. Stroke 2011;42:2733-9.

171. Glenn MB. Sudden cardiac death and stroke with the use of antipsychotic medications: implications for clinicians treating individuals with traumatic brain injury. J Head Trauma Rehabil 2010;25:68-70.

172. Romero JR, Morris J, Pikula A. Stroke prevention: modifying risk factors. Ther Adv Cardiovasc Dis 2008;2:287-303.

173. Gill SS, Rochon PA, Herrmann N, et al. Atypical antipsychotic drugs and risk of ischaemic stroke: population based retrospective cohort study. BMJ 2005;330:445.

174. Furie KL, Kasner SE, Adams RJ, et al. Guidelines for the prevention of stroke in patients with stroke or transient ischemic attack: a guideline for healthcare professionals from the american heart association/american stroke association. Stroke 2011;42:227-76.

175. U.S. Department of Health and Human Services. The Health Consequences of Smoking: A Report of the Surgeon General. . 2004 http://www.cdc.gov/tobacco/data_statistics/sgr/2004/. Accessed February 2, 2014.

176. Caspersen CJ, Powell KE, Christenson GM. Physical activity, exercise, and physical fitness: definitions and distinctions for health-related research. Public Health Rep 1985;100:126-31.

177. Reuter I. Aging, physical activity, and disease prevention 2012. J Aging Res 2012;2012:373294. 
178. Pahor M, Blair SN, Espeland M, et al. Effects of a physical activity intervention on measures of physical performance: Results of the lifestyle interventions and independence for Elders Pilot (LIFE-P) study. J Gerontol A Biol Sci Med Sci 2006;61:1157-65.

179. Lee Y, Back JH, Kim J, et al. Systematic review of health behavioral risks and cognitive health in older adults. Int Psychogeriatr 2010;22:174-87.

180. Balzi D, Lauretani F, Barchielli A, et al. Risk factors for disability in older persons over 3-year follow-up. Age Ageing 2010;39:92-8.

181. Kamegaya T, Araki Y, Kigure H, Long-Term-Care Prevention Team of Maebashi C, Yamaguchi H. Twelve-week physical and leisure activity programme improved cognitive function in community-dwelling elderly subjects: a randomized controlled trial. Psychogeriatrics 2014.

182. Thorpe RJ, Jr., Koster A, Kritchevsky SB, et al. Race, socioeconomic resources, and late-life mobility and decline: findings from the Health, Aging, and Body Composition study. J Gerontol A Biol Sci Med Sci 2011;66:1114-23.

183. Rolland Y, Lauwers-Cances V, Cristini C, et al. Difficulties with physical function associated with obesity, sarcopenia, and sarcopenic-obesity in community-dwelling elderly women: the EPIDOS (EPIDemiologie de l'OSteoporose) Study. Am J Clin Nutr 2009;89:1895-900.

184. Villareal DT, Chode S, Parimi N, et al. Weight loss, exercise, or both and physical function in obese older adults. N Engl J Med 2011;364:1218-29.

185. Rimmer JH, Rowland JL. Health promotion for people with disabilities: implications for empowering the person and promoting disability-friendly environments. . American Journal of Lifestyle Medicine 2008;2:409-20.

186. Jensen GL. Obesity and functional decline: epidemiology and geriatric consequences. Clin Geriatr Med 2005;21:677-87, v.

187. Delmonico MJ, Harris TB, Lee JS, et al. Alternative definitions of sarcopenia, lower extremity performance, and functional impairment with aging in older men and women. J Am Geriatr Soc 2007;55:769-74.

188. Frimel TN, Sinacore DR, Villareal DT. Exercise attenuates the weight-lossinduced reduction in muscle mass in frail obese older adults. Med Sci Sports Exerc 2008;40:1213-9.

189. Crogan NL, Pasvogel A. The influence of protein-calorie malnutrition on quality of life in nursing homes. J Gerontol A Biol Sci Med Sci 2003;58:15964. 
190. U.S. Department of Health and Human Services. 2008 Physical Activity Guidelines for Americans Washington, DC2008

191. Schoenborn CA, Stommel M. Adherence to the 2008 adult physical activity guidelines and mortality risk. Am J Prev Med 2011;40:514-21.

192. Kwakkel G, de Goede CJ, van Wegen EE. Impact of physical therapy for Parkinson's disease: a critical review of the literature. Parkinsonism Relat Disord 2007;13 Suppl 3:S478-87.

193. Chen CM, Chang WC, Lan TY. Identifying factors associated with changes in physical functioning in an older population. Geriatr Gerontol Int 2014.

194. Suzuki T, Sonoda S, Misawa K, Saitoh E, Shimizu Y, Kotake T. Incidence and consequence of falls in inpatient rehabilitation of stroke patients. Exp Aging Res 2005;31:457-69.

195. Krebs HI, Mernoff S, Fasoli SE, Hughes R, Stein J, Hogan N. A comparison of functional and impairment-based robotic training in severe to moderate chronic stroke: a pilot study. NeuroRehabilitation 2008;23:81-7.

196. Homann B, Plaschg A, Grundner M, et al. The impact of neurological disorders on the risk for falls in the community dwelling elderly: a casecontrolled study. BMJ Open 2013;3:e003367.

197. Tseng SZ, Wang RH. Quality of life and related factors among elderly nursing home residents in Southern Taiwan. Public Health Nurs 2001;18:304-11.

198. Suzuki M, Ohyama N, Yamada K, Kanamori M. The relationship between fear of falling, activities of daily living and quality of life among elderly individuals. Nurs Health Sci 2002;4:155-61.

199. Baker PS, Bodner EV, Allman RM. Measuring life-space mobility in community-dwelling older adults. J Am Geriatr Soc 2003;51:1610-4.

200. Lamb SE, Ferrucci L, Volapto S, et al. Risk factors for falling in homedwelling older women with stroke: the Women's Health and Aging Study. Stroke 2003;34:494-501.

201. Paul SS, Canning CG, Sherrington C, Lord SR, Close JC, Fung VS. Three simple clinical tests to accurately predict falls in people with Parkinson's disease. Mov Disord 2013;28:655-62.

202. Pickering RM, Grimbergen YA, Rigney U, et al. A meta-analysis of six prospective studies of falling in Parkinson's disease. Mov Disord 2007;22:1892-900. 
203. Latt MD, Lord SR, Morris JG, Fung VS. Clinical and physiological assessments for elucidating falls risk in Parkinson's disease. Mov Disord 2009;24:1280-9.

204. Ashburn A, Stack E, Pickering RM, Ward CD. Predicting fallers in a community-based sample of people with Parkinson's disease. Gerontology 2001;47:277-81.

205. Cho K, Lee G. Impaired dynamic balance is associated with falling in poststroke patients. Tohoku J Exp Med 2013;230:233-9.

206. Moroz A, Bogey RA, Bryant PR, Geis CC, O'Neill BJ. Stroke and neurodegenerative disorders. 2. Stroke: comorbidities and complications. Arch Phys Med Rehabil 2004;85:S11-4.

207. Wade DT, Collen FM, Robb GF, Warlow CP. Physiotherapy intervention late after stroke and mobility. BMJ 1992;304:609-13.

208. Stuart M, Benvenuti F, Macko R, et al. Community-based adaptive physical activity program for chronic stroke: feasibility, safety, and efficacy of the Empoli model. Neurorehabil Neural Repair 2009;23:726-34.

209. Pang MY, Eng JJ, Dawson AS, McKay HA, Harris JE. A community-based fitness and mobility exercise program for older adults with chronic stroke: a randomized, controlled trial. J Am Geriatr Soc 2005;53:1667-74.

210. O'Suilleabhain P, Dewey RB, Jr. Movement disorders after head injury: diagnosis and management. J Head Trauma Rehabil 2004;19:305-13.

211. Stone AA, Broderick JE. Obesity and pain are associated in the United States. Obesity (Silver Spring) 2012;20:1491-5.

212. Glasgow RE, Orleans CT, Wagner EH. Does the chronic care model serve also as a template for improving prevention? Milbank Q 2001;79:579-612, iv-v.

213. Alladi S, Meena AK, Kaul S. Cognitive rehabilitation in stroke : therapy and techniques. Neurol India 2002;50 Suppl:S102-8.

214. Ellis T, Cavanaugh JT, Earhart GM, et al. Factors associated with exercise behavior in people with Parkinson disease. Phys Ther 2011;91:1838-48.

215. WHO. The World Health Organization Quality of Life assessment (WHOQOL). 1995. 
216. Karlsen KH, Larsen JP, Tandberg E, Maland JG. Quality of life measurements in patients with Parkinson's disease: A community-based study. Eur J Neurol 1998;5:443-50.

217. Robottom BJ, Gruber-Baldini AL, Anderson KE, et al. What determines resilience in patients with Parkinson's disease? Parkinsonism Relat Disord 2012;18:174-7.

218. Masel BE, DeWitt DS. Traumatic brain injury: a disease process, not an event. J Neurotrauma 2010;27:1529-40.

219. Siponkoski ST, Wilson L, von Steinbuchel N, Sarajuuri J, Koskinen S. Quality of life after traumatic brain injury: Finnish experience of the QOLIBRI in residential rehabilitation. J Rehabil Med 2013;45:835-42.

220. Jacobsson L, Lexell J. Life satisfaction 6-15 years after a traumatic brain injury. J Rehabil Med 2013;45:1010-5.

221. Bushnell CD, Reeves MJ, Zhao X, et al. Sex differences in quality of life after ischemic stroke. Neurology 2014. 


\section{Appendix B: Extended Methodology}

\section{Subjects}

Twelve participants were included in the study and consisted of eight males and four females between ages 33 and 71. At baseline, a total of 15 subjects were recruited. Participants were eligible if they were diagnosed with Parkinson's disease (PD), traumatic brain injury (TBI) or stroke for at least 12 months and were between the ages of 18 to 85 . Participants were required to have a means of transportation to one of the URI Speech and Hearing Clinic locations.

This research was conducted as a sub-study of a longitudinal, observational study examining the cognition, nutritional status, physical activity level and physical functioning of those living with neurological disorders. Both received approval from URI's Institutional Review Board (IRB), Longitudinal Study of Communication, Nutrition and Physical Activity, IRB HU1314-006. Participants were recruited via announcements, brochures, and word-of-mouth. Brochures were provided to physician offices, hospitals, rehabilitation centers and health professionals to aid in recruitment as well as to those clients participating in URI's Department of Communicative Disorder's LOUD Crowd and Gateway Wellness Café. Study staff explained the research project to potential participants. If a potential participant was eligible and interested, they signed two copies of an informed consent. This sub-study only included baseline assessments, but participants consented to participate in a five-year longitudinal study with assessments every six months. Participants were then assigned identification numbers for data management that did not include any identifying numbers or letters. 
The study utilized baseline data collected from November and December 2013. Written data was stored in a locked file cabinet in 203 Fernwood on the URI campus. Electronic data with identified information was stored on a computer in 203 Fernwood and password protected and encrypted. De-identified data sets (identifying information like name address, email and telephone numbers removed) were stored on password protected computers in Ranger 301 (Lofgren's lab) and 214 Independence Square (Delmonico’s lab).

\section{Protocol Overview}

Participants reported to a URI Speech and Hearing Clinic location for baseline assessments. Baseline assessments were conducted on two separate occasions. After signing informed consent, participants completed cognitive, nutrition, and physical function assessments. Participants fasted 12-hours prior to the assessment, but were encouraged to drink water during this fast. During the assessment, a 12-hour fasting blood sample was collected, as well as blood pressure. Nutritional status was examined using assessment tools that reflect dietary quality, anthropometrics, body composition and biochemical values.

All questionnaires were administered to participants by study staff. The following surveys related to cognitive-linguistic capacity, nutrition and physical functioning and physical activity were completed: The Repeatable Battery for the Assessment of Neuropsychological Status (RBANS) ${ }^{1}$, the Swallowing Quality of Life Survey (SWAL-QOL) ${ }^{2,3}$, the Dietary Screening Tool (DST) ${ }^{4,5}$, and Physical Activity and Disability Survey (PADS) ${ }^{6,7}$. Other questionnaires included: a medical history questionnaire, 14-item Resilience Questionnaire ${ }^{8,9}$, and the Satisfaction with Life 
Scale (SWLS) $)^{10,11}$. To assess physical function the short physical performance battery $(\mathrm{SPPB})^{12}$ and the timed up and go (TUG) ${ }^{13}$ test was used. Assessments took approximately $3 \frac{1}{1} 2$ hours to complete per participant.

\section{Anthropometrics}

Trained study staffed obtained all measurements using standard procedures. Height $(\mathrm{cm})$ and weight $(\mathrm{kg})$ were measured using a stadiometer (Webb City, MO, USA). Height was rounded to the nearest $0.5 \mathrm{~cm}$ and weight was rounded to the closest $0.1 \mathrm{~kg}$. Height and weight value was used to calculate BMI ( $\mathrm{kg}$ of body weight/height in meters ${ }^{2}$ ). Body mass index was classified according to predetermined categories: underweight $<18.5 \mathrm{~kg} / \mathrm{m}^{2}$, normal weight $=18.5-24.9 \mathrm{~kg} / \mathrm{m}^{2}$, overweight $=$ $25-29.9 \mathrm{~kg} / \mathrm{m}^{2}$ and obese $\geq 30 \mathrm{~kg} / \mathrm{m}^{2} 14$.

A foot-to-foot bioelectrical impedance analysis device (Tanita BF-556, Arlington Heights, Illinois) was used to obtain body composition. This is a portable, battery-operated device that uses a very low electrical current (battery powered, 50 $\mathrm{kHz}$ ) to estimate fat mass and percentage body fat. This test is a valid and reliable tool to measure body composition ${ }^{15}$. According to the American Council on Exercise ${ }^{16}$, any female with $\geq 32 \%$ body fat and any male with $\geq 25 \%$ body fat was considered obese. Even though risk for this test is minimal, participants with a pacemaker were not tested.

\section{Biochemical Markers}

Serum total cholesterol, low-density lipoprotein cholesterol (LDL-C), highdensity lipoprotein cholesterol (HDL-C), triacylglycerol (TRG), and glucose were obtained using a finger stick (Cholestech ${ }^{\circledR}$ LDX system, Hayward California). Prior to 
obtaining blood markers, participants were instructed to abstain from eating or drinking for 12 hours. However, unlimited water intake was permitted and encouraged during the 12 hour fast. Forty microliters of blood was drawn from the participant's finger by trained personnel using a lancet, collected into a capillary tube, put into a cartridge, and assayed using the portable Cholestech $^{\circledR}(\mathrm{LDX}$ system, Hayward California) machine. The study staff used universal precautions and standardized protocols. Participants with total serum cholesterol $<200 \mathrm{mg} / \mathrm{dL}, \mathrm{LDL}-\mathrm{C}$ $<100 \mathrm{mg} / \mathrm{dL}, \mathrm{HDL}-\mathrm{C}>40 \mathrm{mg} / \mathrm{dL}$, and TRG $<150 \mathrm{mg} / \mathrm{dL}$ will have a serum lipid panel within normal limits ${ }^{17}$. A clinical diagnosis of high biochemical values include $\mathrm{TC} \geq 240 \mathrm{mg} / \mathrm{dL}, \mathrm{HDL}-\mathrm{C}<40 \mathrm{mg} / \mathrm{dL}, \mathrm{LDL}-\mathrm{C} \geq 160 \mathrm{mg} / \mathrm{dL}$, and TRG $\geq 200^{17}$. Fasting blood glucose $<100 \mathrm{mg} / \mathrm{dL}$ was considered normal, $100-125 \mathrm{mg} / \mathrm{dL}$ impaired, and $\geq$ $126 \mathrm{mg} / \mathrm{dL}$ was considered high.

\section{Blood Pressure}

Trained study staff measured blood pressures ${ }^{18}$. Participants sat quietly for five minutes and the cuffed arm was supported at heart level. Blood pressure was measured using an automatic blood pressure machine (Omron Healthcare Inc., Bannockburin Illinois). Blood pressure was taken twice or until readings were within $2 \mathrm{mg} / \mathrm{dl}$ and the readings were averaged together. Systolic blood pressure $<120 \mathrm{mmHg}$ and diastolic blood pressure $<80 \mathrm{mmHg}$ were considered within normal limits. Systolic

blood pressure $>130 \mathrm{mmHg}$ and diastolic blood pressure $>85 \mathrm{mmHg}$ were considered borderline high, while $\mathrm{SBP}>140 \mathrm{mmHg}$ and $\mathrm{DBP}>90 \mathrm{mmHg}$ was considered hypertensive. 


\section{Questionnaires}

Due to cognitive difficulties, the described questionnaires were to chosen to decrease labor intensity for the population of interest. To reduce error and inaccuracy, short questionnaires validated in elderly populations, neurological conditions or physical disabilities were selected.

\section{Cognitive-Linguistic}

To measure attention, language, memory, constructional and visual-spatial abilities, the RBANS was used ${ }^{1}$. It includes 12 subtests, with five index scores, summarizing: immediate memory, visuospatial/constructional, language, attention and delayed memory. The total score is the sum of all the index scores. Scoring is based on a mean of 100 and a standard deviation of 15 , and a score $<70$ indicates suboptimal cognitive function. The test takes approximately 30 minutes to complete and is intended to assess adults ages 20-89.

\section{Swallowing Evaluation}

The SWAL-QOL is a 44-item survey where participants rate factors about 10 quality of life concepts related to swallowing ${ }^{2,3}$. Specifically, participants were asked how swallowing problems affect their daily lives, especially in regards to eating and $\operatorname{diet}^{2,3}$. The highest possible score is 220 , the higher the score the better one's swallowing function. The SWAL-QOL took approximately 10 minutes to complete.

\section{Dietary Quality \& Nutrition Risk Assessment}

Participants completed the DST. This 25-item questionnaire is used to identify dietary patterns and nutritional risk in older adults ${ }^{4,5}$. Participants reported how frequently they consumed a food or type of food, as well as different dietary practices. 
The sub-components and point distribution included: whole fruit and juices (15 points), vegetables (15 points), lean proteins (10 points), Added fats, sugars and sweets (25 points), dairy (10 points) and processed meats (10 points), and use of a dietary supplement (5 points).

Based on these responses a composite score was calculated and correlated with three different nutritional risk levels; $(<60)$ at risk, (60-75) possible risk, and $(>75)$ not at risk ${ }^{4}$. Categorization into three nutritional risk categories provides a way to determine if a patient needs a follow-up or nutrition assessment ${ }^{4}$. The DST Dietary intake was broken down based on point classification for the DST sub-components ${ }^{4}$ to explore specific areas contributing to low dietary quality. These sub-components were created to identify specific areas of the diet that may be problematic on an individual basis $^{4}$. Cut points were set based upon if the participant had a score of approximately $50 \%$ or less of possible points for each sub-component. Participants with fewer than $50 \%$ of total possible points for each sub-component and if the participant did not currently take dietary supplement were considered low sub-scores. Less than $50 \%$ was selected as an exploratory marker to indicate infrequent/inadequate intake of whole grains, fruits, vegetables, dairy or lean proteins, and high consumption of processed meats, added sugars, fats and sweets.

This survey took approximately 10-15 minutes for the study staff to complete with each individual participant. While the DST has not been validated in those living with neurological disorders, it has been validated in older adults and is a capable of characterizing the overall dietary patterns of the older adult population ${ }^{4}$. 


\section{Physical Activity Survey}

The PADS was used to measure activity level. This survey is a validated and reliable source to measure physical activity in those who are sedentary and disabled $^{6,19}$. This tool covers a wide range of activities and includes six sub-scores: exercise, leisure-time physical activity (LTPA), general activity, therapy, employment, and wheelchair use. Scores increase as physical activity increases. The PADS is coded based on intensity, type and amount of activity, and can detect varying levels of physical activity ${ }^{19}$. Raw scores of $0-27$ indicate minimal, 28-42 is minimal to moderate, 43-67 is moderate, and $>68$ indicates an extreme level of activity ${ }^{6}$. This survey took about 20 minutes complete.

\section{Physical Functioning Assessment}

The SPPB ${ }^{12}$ was completed to assess participants' global physical functioning and included timed measures of usual gait speed, standing balance tests, and repeated five chair stands. For the balance tests participants were asked to maintain their feet in side-by-side, semitandem, and tandem stances for 10 seconds each. To assess walking speed participants walked four meters at their usual pace. Walking speed was performed twice, and the faster time was recorded. During the chair test participants stood up from sitting position with their arms folded across their chest. If the participant were able to perform this task, they were instructed to stand up and sit down five times as quickly as possible. The time to perform this task was recorded. SPPB scores are reported out of 12, and each sub score ranges from zero to four, and the higher the score the better lower physical function. Scores 8-12 are considered "high functioning ${ }^{12}$. 
A timed up and go (TUG) test was used to assess basic functional mobility ${ }^{13}$. It measures the time it takes for the participant to raise from a chair, walk three meters, turn around and walk back to the chair. The shorter amount of time, the better the score. Time was recorded in seconds, the test was administered twice and the better score was recorded. Those with TUG scores $>13.5$, are considered high risk for falls ${ }^{20}$

\section{Other Questionnaires}

\section{Past Medical History Questionnaire}

To identify health-related conditions and how these conditions may impact health, a non-validated medical history questionnaire will be used. Topics covered will include neurological, endocrine and cardiovascular health. Ten minutes were allotted to recite and complete this survey for each participant.

\section{Resilience}

The 14-item Resilience Scale ${ }^{8,9}$ measured resiliency. Resiliency is one's ability to recover from a physiological or psychological event ${ }^{8,9}$. It is a validated and reliable tool that has found a significant correlation between resilience, morale, depression and overall life satisfaction in older adults ${ }^{9}$. Questions are answered on a Likert scale from one to seven, where participants reflect on their belief that their life has meaning, sense of uniqueness, and ability to exist alone and manage their lives; higher scores are associated with greater degrees of resiliency ${ }^{8,9}$. It took approximately five minutes to complete. Total possible scores range from 14 to 98 , and a higher score indicates higher levels of resilience.

\section{Life Satisfaction}


The SWLS, a five-item questionnaire, was used to obtain overall life satisfaction ${ }^{10}$. It is used to measure global life satisfaction by asking participants to make a broad judgment of their life ${ }^{10}$. This questionnaire is answered on a Likert scale that ranges from one to seven ${ }^{10,11}$. Total possible score ranges from five to 35 , and the higher the score, the greater life satisfaction.

\section{Cardio-Metabolic Assessment}

Cardio risk factors were selected, and grouped into eight categories based upon modifiable and non-modifiable risk factors. These eight selected categories included: 1.) age (>45 years for men, $>55$ years for women), 2.) anthropometrics (BMI, \%BF) 3.) clinical (SBP and DBP), 4.) biochemical (TC, HDL-C, TC/HDL-C ratio, LDL-C, TRG and Glucose), 5.) diet (DST scores), 6.) physical barriers (use of legs, arm or assistive device), activity (PADS scores) and functioning (SPPB and TUG scores), 7.) smoking status, and 8.) cognition (RBANS scores). Those living with neurological disorders suffer physical and cognitive impairment that may disrupt activities of daily living (ADL); as a result physical barriers (such as partial or no use of arms and legs, as well as use of an assistive device) were examined due to the possibility they may promote a sedentary lifestyle. Cognitive function was also included as a CVD risk factor through examining total RBANS scores and three RBANS index scores (immediate memory, attention, delayed memory) $<70$.

\section{Statistical Analysis}

This is the first analysis of this study, and therefore statistical analysis were not hypothesis driven, but conducted to generate hypothesis and explore the population. 
Collected data was analyzed using SPSS, version 22.0 for Windows (IBM Corp. Summers, NY). Descriptive statistics were conducted and distribution of data was assessed through analyzing skewness and kurtosis. For data that was not normally distributed, proper statistical methods were used to account for this. Categorical variables are represented as numbers and percentages and continuous variables are reported as mean \pm standard deviation.

To analyze CVD risk factors, the participants were individually analyzed across the eight categories. The most frequent risk factors were then analyzed based on the variables within the eight CVD categories and reported as top CVD risk factor.

For all normally distributed data, independent t-tests were conducted to determine if there were significant differences between groups regarding assessment variables. Cohen's $d$ was calculated to describe effect size for differences between groups in normally distributed variables $(0.2=$ small effect, $0.5=$ medium effect, $0.8=$ large effect). For data not normally distributed, Mann-Whitney U tests were used to analyze differences between groups and effect size was signified through calculating $r$ $(0.1=$ small effect, $0.3=$ medium effect, $0.5=$ large effect $)$. Between group differences for categorical variables were identified using Fisher Exact Tests. Phi coefficient or Cramer's V were used to signify effect size $(0.1=$ small effect, $0,3=$ medium effect, $0.5=$ large effect). Pearson's R Correlations were used for normally distributed variables, and Spearman Rho Correlations were used as the non-parametric alternative. Significance for all analyses was set at $\mathrm{p}<0.05$. 


\section{Power Calculation}

An A-priori power analysis found that a sample of $28 \mathrm{PD}$ participants and 14 ABI participants would find significant difference between groups and SPPB scores.

To find significant differences between groups and DST scores, an A-priori power analysis suggests 63 PD participants and 31 ABI participants are needed.

\section{Resources Required}

Funding for this research was provided by URI's Department of Communicative Disorders. Supplies provided by the Department of Nutrition and Food Sciences included: computers, printers, computer software, paper and physical assessment equipment. Personnel to conduct the study were supplied by the Departments of Communicative Disorders, Kinesiology, and Nutrition and Food Sciences. No other university resources will be required for this study.

\section{References}

1. Randolph C. Repeatable Battery for Assessment of Neurophyschological Status. Examiner's Manual San Antonio, TX: The Psychological Corporation 1998.

2. McHorney CA, Martin-Harris B, Robbins J, Rosenbek J. Clinical validity of the SWAL-QOL and SWAL-CARE outcome tools with respect to bolus flow measures. Dysphagia 2006;21:141-8.

3. McHorney CA, Robbins J, Lomax K, et al. The SWAL-QOL and SWALCARE outcomes tool for oropharyngeal dysphagia in adults: III. Documentation of reliability and validity. Dysphagia 2002;17:97-114.

4. Bailey RL. Dietary screening tool identifies nutritional risk in older adults The American Journal of Clinical Nutrition 2009;90:177-83.

5. Bailey RL, Mitchell DC, Miller CK, et al. A Dietary Screening Questionnaire Identifies Dietary Patterns in Older Adults The Journal of Nutrition 2007; ;137: :421-26. 
6. Kayes NM, McPherson KM, Taylor D, Schluter PJ, Wilson BJ, Kolt GS. The Physical Activity and Disability Survey (PADS): reliability, validity and acceptability in people with multiple sclerosis. Clin Rehabil 2007;21:628-39.

7. Kayes NM, Schluter PJ, McPherson KM, Taylor D, Kolt GS. The Physical Activity and Disability Survey -- Revised (PADS-R): an evaluation of a measure of physical activity in people with chronic neurological conditions. Clin Rehabil 2009;23:534-43.

8. Wagnild GM. The Resilience Scale User's Guide. 2009; http://www.resiliencecenter.com.

9. Wagnild GM, Young HM. Development and psychometric evaluation of the Resilience Scale. J Nurs Meas 1993;1:165-78.

10. Diener E, Emmons RA, Larsen RJ, Griffin S. The Satisfaction With Life Scale. J Pers Assess 1985;49:71-5.

11. Pavot W, Diener E, Colvin CR, Sandvik E. Further validation of the Satisfaction with Life Scale: evidence for the cross-method convergence of well-being measures. J Pers Assess 1991;57:149-61.

12. Guralnik JM, Simonsick EM, Ferrucci L, et al. A short physical performance battery assessing lower extremity function: association with self-reported disability and prediction of mortality and nursing home admission. J Gerontol 1994;49:M85-94.

13. Podsiadlo D, Richardson S. The timed "Up \& Go": a test of basic functional mobility for frail elderly persons. J Am Geriatr Soc 1991;39:142-8.

14. Center for Disease Control and Prevention: About Adult BMI. . 2011; http://www.cdc.gov/healthyweight/assessing/bmi/adult_bmi/index.html. Accessed May 2, 2013.

15. Ritchie JD, Miller CK, Smiciklas-Wright H. Tanita foot-to-foot bioelectrical impedance analysis system validated in older adults. J Am Diet Assoc 2005;105:1617-9.

16. American Council on Exercise. Percent Body Fat Norms for Men and Women. 2013;

http://www.acefitness.org/?creative $=45247336884 \&$ device $=c \&$ network $=g \& m a$ tchtype $=$ b\&gclid=CNi3ieq6jrOCFcFlOgodCVAAxQ. Accessed June 2, 2013.

17. Centers for Disease Control and Prevention. Cholesterol 2012. Accessed April 3, 2013.

18. Centers for Disease Control and Prevention. High Blood Pressure 2013; http://www.cdc.gov/bloodpressure/. Accessed May 13, 2013. 
19. Rimmer JH, Riley BB, Rubin SS. A new measure for assessing the physical activity behaviors of persons with disabilities and chronic health conditions: the Physical Activity and Disability Survey. Am J Health Promot 2001;16:3442.

20. Shumway-Cook A, Brauer S, Woollacott M. Predicting the probability for falls in community-dwelling older adults using the Timed Up \& Go Test. Phys Ther 2000;80:896-903. 
Appendix C: Consent Form for Research

\title{
Longitudinal Study of Communication, Nutrition and Physical Activity
}

\author{
Leslie A. Mahler, $\mathrm{PhD}$, Principal Investigator \\ Ingrid Lofgren, $\mathrm{PhD}$, co-Investigator \\ Matthew Delmonico, PhD, co-Investigator \\ CONSENT FORM FOR RESEARCH: Participant \\ Version 2: July 30, 2013
}

The University of Rhode Island

Department of Communicative Disorders

25 W Independence Square, Suite I

Kingston, RI 02881

\section{Purpose of the Consent:}

You have been invited to take part in a research project described below. The purpose of the consent form you are about to read is to provide you with details about the research study and to inform you of your rights if you agree to participate in the study. Your participation is completely up to you. The researcher will explain the project to you in detail. You should feel free to ask questions. If you have more questions later you can call, Dr. Leslie Mahler, the person mainly responsible for this study, at 401874-2490. You may also contact Dr. Ingrid Lofgren at 401-874-5706 or Dr. Matthew Delmonico at 401-874-5440, who are co-Investigators on the study. You must be at least 18 years old, speak English, and have neurological diagnosis of traumatic brain injury, stroke, or Parkinson disease to be in this research project.

\section{Description of the project:}

This is a research project designed to look at communication, nutrition, and physical activity characteristics of adults who have a stroke, traumatic brain injury or Parkinson disease. All evaluations will be conducted at one of two University of Rhode Island locations; in Independence Square on the Kingston Campus at 25 West Independence Way, Kingston or in Independence Square at 500 Prospect Street in Pawtucket.

You are being asked to be in this study because we want to determine the long-term impact of neurological disorders on communication, nutrition, and physical activity. We are looking for 200 people who have a stroke, traumatic brain injury or Parkinson disease to participate in this project. Participation in this study is entirely your choice.

If you decide to take part in this study, you should understand that the evaluations are investigational and you may not experience any benefit from participation. Participation may also involve additional risks as listed in the Potential Risks and Discomforts section. The consent form will help make sure you understand the tasks 
included in the study before you decide whether you want to take part in the study. You may also quit the study at any time.

\section{What will be done:}

If you agree to take part in this study, you will be asked to complete up to 11 evaluations over five years. Evaluations will take place every six months. The evaluations will include a variety of tasks such as reading sentences and describing a picture, an assessment of how your muscles move, a cognitive screening, an interview, a clinical swallowing evaluation, and questionnaires regarding swallowing, diet and physical activity. The total time for each evaluation will be approximately $3 \frac{1}{2} 2$ hours. All evaluations will be conducted in a quiet private room at one of the University of Rhode Island Speech and Hearing Clinic locations (Kingston or Pawtucket).

With your permission, we will request health information from your physician about the following specific items only:

- Date of diagnosis

- Current medications

- Imaging information about where the brain damage is located (if appropriate)

You will sign a separate form to indicate whether you give your permission to release this health information for the study.

\section{Potential risks and discomforts:}

There are minimal foreseeable risks associated with these evaluations. There have been no reported adverse affects from clinical evaluation of speech and swallowing. There may be some unknown or unanticipated risks, but every precaution will be taken to ensure your personal safety. Even though experienced personnel will obtain the blood samples from a finger prick, there is a chance of discomfort and minor bruising from the finger stick. For physical function testing there is a risk of muscle soreness or other muscle injury as well as skeletal injury but we will minimize these risks by using standard safety practices.

\section{Purpose and benefits of the study:}

The purpose of this study is to describe communication, nutrition, and physical activity behaviors over time to see how they change and affect quality of life. The information obtained is important because it will help us to understand how to provide services to meet the needs of people with neurological diagnoses. This is an investigational study and there is no guaranteed benefit to your communication or nutrition or physical function as a result of participation in this research study. You will receive personal health information such as your height and weight, physical function determined by a physical assessment, your blood lipids such as cholesterol and triglycerides. In addition, you will receive information about your thinking skills and language skills and dietary choices.

\section{Drugs, devices or instruments to be used:}


Drugs will not be used in this study. The equipment for the evaluations include: microphone, sound level meter, tongue blade, a digital tuner, tape recorder, and video cameras. All equipment used to collect cognitive-linguistic and physical function data is considered non-invasive. A lancet and capillary tube will be used to obtain the blood sample from a finger prick and the sample will be analyzed on a small portable machine that is on a table.

\section{Cost to participant:}

There is no cost to you for participation in the evaluations. Parking is available for free.

\section{Confidentiality:}

Your part in this study is confidential. Your individual privacy will be maintained in all published and written data resulting from this study. No names of participants will be published or included in written data resulting from this study. Results of this study may be used for purposes of research, educational lectures, and/or professional presentations. When you are entered into the study you will be assigned a code that does not include any identifying information. For example, the first participant will be coded as Long01. The code number will be used on all response forms and in the analysis of the data.

Dr. Mahler and her research team will have sole access to all contact information and evaluation results containing your name. This information will be kept in a locked filing cabinet in a locked office. However, the U.S. Department of Health and Human Services, and the University of Rhode Island Institutional Review Board have the right to inspect all of your records relating to this research for the purpose of verifying data. Because of the need to release information to these parties, absolute confidentiality cannot be guaranteed. Following completion of this project, contact information will be destroyed for those participants who wish, for any reason, not to be contacted in the future. All other information will be archived and kept in a locked filing cabinet with the study results at the University of Rhode Island. All research data will be retained for a minimum of three years following completion of the study and then will be destroyed. Research data will be located in a locked filing cabinet in the principal investigator's locked office.

Cognitive-linguistic evaluations will be audio and video recorded to allow for data analyses. At times these recordings can be useful for teaching students or professionals about the disorders of people with a neurological diagnosis such as yours. Please indicate by signing below whether you give your permission to use your samples for lectures and presentations. Audio and/or videotapes may be used for teaching for up to 3 years after completion of the study. If you agree, you will never be identified by name in the presentations or lectures. Your decision to give permission to use audio and/or video samples in lectures has no impact on your participation in the study. 
Yes, I give permission to use audio samples in lectures and presentations.

Yes, I give permission to use video samples in lectures and presentations.

No, I do not want audio samples used except for research

analysis.

No, I do not want video samples used except for research

analysis.

In case there is any injury to you during the study:

If this study causes you any injury, you should immediately contact Dr. Leslie Mahler at (401) 874-2490 or contact the University of Rhode Island Speech and Hearing Clinic at (401) 874-5969. You may also call the office of the Vice President for Research Integrity, 70 Lower College Road, University of Rhode Island, Kingston, RI at (401) 874-4328. If you are injured during an evaluation or during treatment every effort will be made to get you medical attention but you will be responsible for paying for the medical treatment needed.

\section{Decision to quit at any time:}

The decision to take part in this study is up to you. You do not have to participate. If you decide to take part in the study, you may quit and stop participating in this study at any time. You have the right to refuse to answer any question(s) or participate in any procedure for any reason. Deciding not to participate will have no effect on your potential to receive services from a speech-language pathologist. If you wish to quit, simply inform Leslie Mahler at 874-2490 of your decision. If you wish to pursue an alternative treatment instead of completing the study you will be provided with information on how to obtain those services.

\section{Rights and complaints:}

If you are not satisfied with the way this study is performed, you may discuss your complaints with Dr. Leslie Mahler (lmahler@uri.edu; 401-874-2490), Dr. Ingrid Lofgren (ingridlofgren@uri.edu, 401-874-5706), or Dr. Matthew Delmonico (delmonico@uri.edu; 401-874-5440), or you may contact the office of the Vice President for Research for concerns or any questions about your rights as a research subject at: 70 Lower College Road, University of Rhode Island, Kingston, RI at (401) 874-4328 and speak to them anonymously if you choose. 


\section{Authorization:}

Your authorization means that you have read this paper and know the purpose of the study and the possible risks and benefits. It also means you know that being in this study is voluntary and you choose to be in this study. You can also withdraw at any time. Your questions have been answered. Your signature on this form means that you understand the information and you agree to participate in this study.

Signature of Participant

Participant Typed/printed Name

Date

Signature of Guardian

Guardian Typed/printed Name

Date
Signature of Researcher

$\overline{\text { Researcher Typed/printed name }}$

Date

Signature of Researcher

Researcher Typed/printed name

Date

Please sign both consent forms, keeping one for yourself. 


\section{Appendix D: Assessment Materials \\ INTERVIEW \\ Longitudinal Study of Communication, Nutrition and Physical Activity \\ Leslie Mahler, PhD, CCC-SLP, Principal Investigator \\ Ingrid Lofgren, $\mathrm{PhD}$, co-Investigator \\ Matthew Delmonico, $\mathrm{PhD}$, co-Investigator \\ Version 2: 2-17-14}

Participant Name:

Initials:

ID\#:

Name of Interviewer:

Date:

Emergency contact name and address \& phone:

DIRECTIONS: Read the following questions out loud to each prospective volunteer and record the answers. Any answers that require clarification should be written in the space below the question or on the back of the sheet. Indicate whether any follow-up is necessary or if any referrals are appropriate.

What is your neurological diagnosis?

When were you diagnosed?

What were your symptoms at that time?

What are your symptoms now?

What is your communication like?

What is your diet like?

What is your physical activity like? 
Does your speech sound clear to other people?

If not, how does it sound?

Can you think of the words that you want to say?

If you do have trouble, how often does it happen?

Are you experiencing any symptoms of a swallowing disorder?

If yes, what is the problem with your swallowing?

What would you say is your most significant problem with speech or swallowing today?

Did you experience any changes in your speech or swallowing before your diagnosis?

Does medication affect your speech or voice or swallowing?

If yes, in what way?

\section{Speech}

How many hours of speaking do you do in a day?

What is a typical day of communicating like for you?

Do you pronounce your words clearly?

Do people ask you to repeat yourself?

Do people have a hard time understanding you? 
What do you do when you want to be as easy to understand as possible?

What percent of your speech do you think is understandable?

Has your neurological diagnosis caused you to talk less?

If so, how much less?

Why?

\section{Swallowing}

Do you have any difficulty with swallowing?

Do you cough during mealtimes?

If yes, do you cough more with water or solid food?

Do you have difficulty making the food go down (need to swallow twice)?

Does it take you longer to finish a meal than before your neurological diagnosis?

Have you experienced any unintentional recent weight loss?

Have you ever been diagnosed with pneumonia?

If yes, when?

Have you changed your diet since your neurological

diagnosis?

If yes, what did you modify? 


\section{Musculoskeletal system:}

Has your doctor ever told you that you have: (circle all that apply)

- Osteoarthritis or degenerative arthritis

- Rheumatoid arthritis

- Osteoporosis

- Ankylosing Spondylitis

- Unknown or other type of arthritis

- Any other disease of joint or muscle:

- Comments:

\section{Cardiovascular system:}

- Has any family member had a heart attack prior to the age of 55?

If so, how are they related to you?

- Have you ever had frequent cramping in your legs while resting?

- If yes, is it a current problem?

- Have you ever had pain or cramping in your legs while walking?

○ If yes, is it a current problem?

- If yes, is this pain relieved by rest or by discontinuing walking?

- Have you ever been told that you have high blood pressure

- If yes, what was the date of onset?

-Were you given any medications?

- Did a doctor ever tell you that you had a heart problem?

- If yes: What was the date of onset?

- What did the doctor call it?

$\circ$ Were you given any medications?

- Do you have any history of high cholesterol in your blood as evidenced by a previous blood lipid tests?

Comments: 


\section{Endocrine system:}

Have you ever had any of the following: Thyroid problems, adrenal problems, diabetes mellitus?

- If yes to diabetes, which type? Type 1 or Type 2

Date of onset-

Are/were you on any medication, or is it diet controlled?

\section{Neurological system:}

- Do you have any significant problems with your memory? (circle all that apply)

○ When answering the telephone, do you recall what you were doing before it rang?

○ Can you give the directions to your house/apartment?

○ Can you keep appointments without a reminder?

○ Can you remember what clothes you wore yesterday?

- Any problems with vision other than corrective lens changes?

- If yes, which of the following conditions- Blindness, temporary loss of vision, double vision, glaucoma, cataract, macular degeneration or others.

Do you have and of the following?: (circle all that apply)

- Vertigo (a feeling of spinning, or unsteadiness)

- Seizure or convulsions?

- Migraine or severe headaches?

- Paralysis of arm or leg?

- A head injury with loss of consciousness?

- Pain, numbness or tingling in your limbs?

- Pain in your lower back? 
- Do you have pain in any part of body including headaches while exercising?

- Have you been told that you have a peripheral neuropathy?

- Tremors?

- Problems with walking? If yes,

- Do you fall frequently?

○ Is your walking problem related to pain, weakness or loss of balance?

- Have you ever had an operation on skull or brain?

- Have you ever had meningitis or Brain fever?

Comments:

\section{Previous Treatment}

Have you had previous speech or swallow treatment, occupational therapy or physical therapy?

If yes, please describe (when, what)

Was it beneficial?

If yes, what changes did you notice?

\section{Employment}

Are you employed?

Type of employment 
How much speaking do you do at your job?

\section{Smoking Status}

Do you currently smoke cigarettes?

Do you have a history of smoking cigarettes?

If you have quit smoking cigarettes, how many months/years ago did you quit?

\section{Other}

Have you noticed any difficulty with your memory?

Have you experienced any changes in your mood?

Is it difficult for you to pay attention long enough to finish a task?

Do you have any difficulty reading?

Do you have any difficulty writing?

Do you have any other health problems or conditions that would affect communication, nutrition or physical activity?

Are you Hispanic or Latino?

What race do you identify with? (Check all that apply) I prefer not to provide this information

White/Caucasian African American Asian American

Indian/Alaskan Native Native Hawaiian/Pacific Islander

Other

\section{Dietary Screening Tool}


DIRECTIONS: Please check one response to each question that best describes how you eat.

How often do you usually eat fruit as a snack?

Never

Less than once a week

1 or 2 times a week

3 or more times a week

How often do you usually eat whole grain breads?

Never or less than once a week

_ 1 or 2 times a week

_ 3 or more times a week

How often do you usually eat whole grain cereals?

Never or less than once a week

1 or 2 times a week

3 or more times a week

How often do you usually eat candy or chocolate?

Never

Less than once a week

1 or 2 times a week

3 or more times a week

How often do you eat crackers, pretzels, chips, or popcorn?

Never

Less than once a week

1 or 2 times a week

3 or more times a week

How often do you eat cakes or pies?

Never

Less than once a week

1 or 2 times a week

3 or more times a week

How often do you eat cookies?

Never

Less than once a week 
1 or 2 times a week

3 or more times a week

How often do you eat ice cream?

Never

Less than once a week

1 or 2 times a week

3 or more times a week

How often do you eat cold cuts, hot dogs, lunchmeats or deli meats?

Never or less than once a week

1 or 2 times a week

3 or more times a week

How often do you eat bacon or sausage?

Never or less than once a week

1 or 2 times a week

3 or more times a week

How often do you eat carrots, sweet potatoes, broccoli, or spinach?

Never

Less than once a week

1 or 2 times a week

3 or more times a week

How often do you eat fruit (not including juice)? Please include fresh, canned or frozen fruit.

Never or Less than once a week

1 or 2 times a week

3 to 5 times a week

Every day or almost every day

How often do you eat hot or cold breakfast cereal?

Never

Less than once a week 
1 or 2 times a week

3 to 5 times a week

Every day or almost every day

How often do you drink some kind of juice at breakfast?

Never or Less than once a week

1 or 2 times a week

3 to 5 times a week

Every day or almost every day

How often do you eat chicken or turkey?

Never or less than once a week

1 or 2 times a week

More than 3 times a week

How often do you drink a glass of milk?

Never or Less than once a week

1 or 2 times a week

3 to 5 times a week

Every day or almost every day

More than once every day

Do you usually add butter or margarine to foods like bread, rolls, or biscuits?

Yes

No

Do you usually add fat (butter, margarine or oil) to potatoes and other vegetables?

Yes

No

Do you use gravy (when available) at meals?

Yes

No

Do you usually add sugar or honey to sweeten your coffee or tea?

Yes

No 
Do you usually drink wine, beer or other alcoholic beverages?

Yes

No

How often do you eat fish or seafood that IS NOT fried?

Never

Less than once a week

Once a week

More than once a week

How many servings of milk, cheese, or yogurt do you usually have each DAY?

None

One

Two or more

How many different vegetable servings do you usually have at your main meal of the day?

None

One

Two

Three or more

Which of the following best describes your nutritional supplement use.

I don't use supplements

_ I use supplements other than vitamins and mineral

_ I use a multivitamin/mineral preparation (e.g. Centrum) 


\section{NCPAD Physical Activity and Disability Scale}

\section{DEMOGRAPHICS}

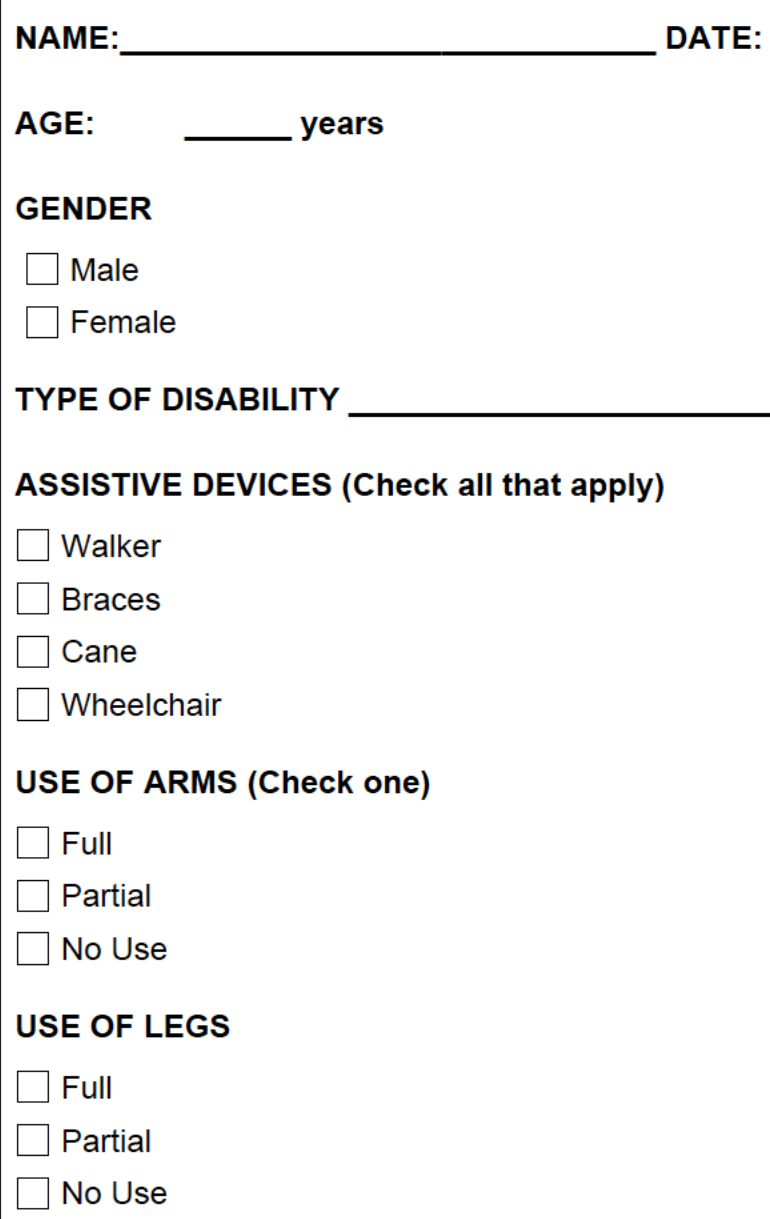

AGE: years

GENDER

Male

Female

TYPE OF DISABILITY

ASSISTIVE DEVICES (Check all that apply)

$\square$ Walker

$\square$ Braces

$\square$ Cane

$\square$ Wheelchair

USE OF ARMS (Check one)

$\square$ Full

$\square$ Partial

$\square$ No Use

USE OF LEGS

$\square$ Full

$\square$ Partial

No Use

Directions: On the following pages are a list of questions related to physical activity and exercise. There are no right or wrong answers and your responses will be kept anonymous. Note that your answers to certain questions in the survey may cause your browser to skip other questions and move to a later item in the survey. Don't worry--this is how the survey was designed in order to save time. Please answer each presented question as accurately and as completely as possible. When you have finished the survey, press the "Submit" button. Your survey responses will be checked and used to create scores reflecting your level of physical activity. A window presenting your scores will then appear.

Page 1 of 8 


\section{NCPAD Physical Activity and Disability Scale}

\section{EXERCISE}

\subsection{Do you currently exercise?}

$\square$ Yes

\section{$\rightarrow$ IF NO, PLEASE GO TO THE LEISURE ACTIVITY SECTION.}

1.01 What kind of exercise do you do?

Directions: List up to four (4) activities below that you do on a regular basis for primary purpose of increasing or maintaining fitness. Aerobics are done for a sustained period of time and result in an increase in your heart rate and breathing rate. Examples include walking, jogging, attending an aerobics class, and bicycling. Strength activities include lifting weights or using elastic bands or weight training machines. Flexibility refers to activities that involve muscle stretching

\section{Activity Type}

\begin{tabular}{ll} 
Code: & Description \\
\hline A: & Aerobic Exercise \\
S: & Strength Exercise \\
F: & Flexibility Exercise
\end{tabular}

Activity Type (check one)

Activity Days/Week Minutes/Day Months/Year

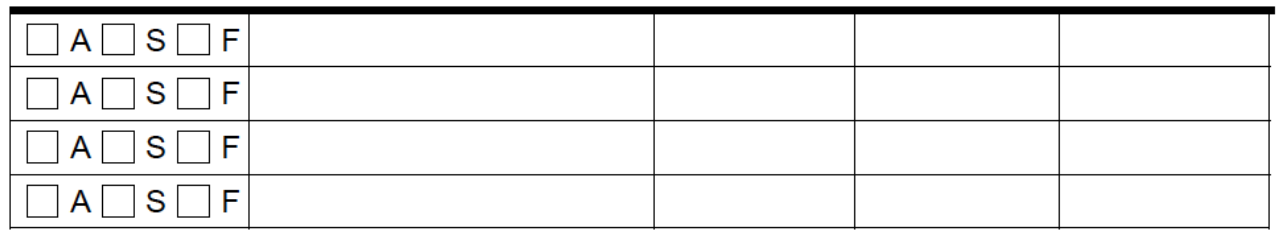

1.02 Have you been exercising for more than one year or less than one year?

$\square$ More than one year

$\square$ Less than one year

1.03 How would you describe the average intensity of your exercise program?

$\square$ Light exercise: Don't sweat or breathe heavily

Moderate exercise: Breathe a little harder and may sweat

Vigorous: Breathe hard and sweat

Page 2 of 8 
NCPAD Physical Activity and Disability Scale

\section{LEISURE ACTIVITY}

2.0 Do you engage in leisure time physical activity?

$\square$ Yes

$\square$ No

IF NO, GO TO THE GENERAL ACTIVITY SECTION ON THE NEXT PAGE.

\subsection{What type of activities do you do?}

Directions: List up to four (4) activities below that you do for leisure or recreation. These activities can be done on a regular or irregular basis and may not necessarily result in sustained increases in heart rate and breathing rate. Examples include hiking, boating, skiing, dancing and sports activities. Please indicate whether the activity is an endurance activity or a Non-Endurance activity. Examples of endurance activities include: hiking, tennis, dancing, skiing. Non-endurance activities include boating, softball and horseback riding. Do not list activities here that you already listed under exercise.

\section{Activity Type}

\begin{tabular}{ll} 
Code & Description \\
\hline $\mathrm{E}$ & Endurance \\
$\mathrm{NE}$ & Non-Endurance
\end{tabular}

Activity Type (check one) Activity Days/Week Minutes/Day Months/Year

\begin{tabular}{|l|l|l|l|l|}
\hline$\square \mathrm{E} \square \mathrm{NE}$ & & & & \\
\hline$\square \mathrm{E} \square \mathrm{NE}$ & & & & \\
\hline$\square \mathrm{E} \square \mathrm{NE}$ & & & & \\
\hline$\square \mathrm{E} \square \mathrm{NE}$ & & & & \\
\hline
\end{tabular}


NCPAD Physical Activity and Disability Scale

\section{GENERAL ACTIVITY}

3.00 From Monday through Friday, how many waking hours a day do you usually spend inside your home?

$\square$ Less than 6 hours a day

6 to 10 hours a day

$\square$ More than 10 hours a day

3.01 On Saturday and Sunday, how many waking hours a day do you usually spend inside your home?

$\square$ Less than 6 hours a day

$\square 6$ to 10 hours a day

$\square$ More than 10 hours a day

3.02 On average, how many hours a day do you sleep including naps?

hours

3.03 On average, how many hours a day are you sitting or lying down, excluding sleeping?

hours

3.04 Are most of your indoor household activities done by you or someone Else?

Done by you

$\square$ Done by someone else

\section{$\rightarrow \quad$ IF DONE BY SOMEONE ELSE, GO TO QUESTION 3.06.}

3.05 Please list up to four (4) indoor household activities you do and the number of minutes a week you spend on each activity.

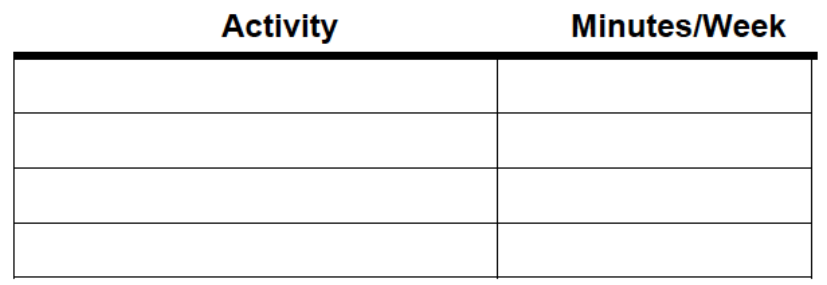

Page 4 of 8 
NCPAD Physical Activity and Disability Scale

3.06 Do you do any outdoor household activities such as gardening?

$\square$ Yes

$\square$ No

IF NO, GO TO QUESTION 3.08.

3.07 Please list up to four (4) outdoor household activities you do and the number of minutes a week you spend on each activity.

\begin{tabular}{|l|l|l|l|}
\hline Activity & Days/Week & Minutes/Day & Months/Year \\
\hline & & & \\
\hline & & & \\
\hline & & & \\
\hline & & & \\
\hline
\end{tabular}

3.08 How much assistance do you need to perform activities of daily living such as dressing and bathing?

No assistance

$\square$ Some assistance

$\square$ Full assistance 
NCPAD Physical Activity and Disability Scale

\section{THERAPY}

4.00 Do you currently receive physical or occupational therapy?

$\square$ Yes

$\square$ No

$\rightarrow$ IF NO, GO TO EMPLOYMENT SECTION ON THE NEXT

PAGE.

4.01 How many days a week do you receive therapy?

Days.

4.02 How long does each therapy session usually last?

Minutes 
NCPAD Physical Activity and Disability Scale

\section{EMPLOYMENT / SCHOOL}

5.00 Are you currently employed / attending school?

$\square$ Employed

Not employed

$\square$ Retired

Attending school

\section{IF UNEMPLOYED OR RETIRED, GO TO WHEELCHAIR} SECTION ON THE NEXT PAGE.

5.01 For most of your work / school day, do you:

$\square$ Move around
$\square$ Stand
$\square$ Sit

5.02 Do you climb any stairs during the work / school day?

$\square$ Yes

$\rightarrow \quad$ IF NO, GO TO OUESTION 5.04 .

5.02a How many flights of stairs do you climb? flights

5.02b How many times a day do you climb the stairs?

5.03 In your transportation to and from work / school, do you get any physical activity?

$\square$ Yes

$\square$ No

$\rightarrow$ IF NO PLEASE GO TO WHEELCHAIR SECTION ON THE NEXT PAGE.

5.04 Please list up to four (4) employment-related physical activities you do and the number of minutes a week you spend on each activity.

\begin{tabular}{|l|l|l|l|}
\hline \multicolumn{1}{c}{ Activity } & Days/Week & Minutes/Day & Months/year \\
\hline & & & \\
\hline & & & \\
\hline & & & \\
\hline & & & \\
\hline
\end{tabular}

Page 7 of 8 
NCPAD Physical Activity and Disability Scale

\section{WHEELCHAIR USERS}

6.00 Do you use a wheelchair?

$\square$ Yes

$\square$ No

$\Rightarrow$

IF NO, STOP HERE.

6.01 How many years have you used a wheelchair? years?

6.02 During the time that you are awake, how much time do you: spend in your wheelchair?

$\square$ All day

$\square$ Most of the day

$\square$ A few hours

6.03 What type of wheelchair do you primarily use?

Manual wheelchair

Powered wheelchair

$\rightarrow$ IF POWERED WHEELCHAIR, STOP HERE.

6.04 Who usually pushes your wheelchair?

$\square$ Myself

$\square$ Someone else

$\rightarrow \quad$ IF SOMEONE ELSE, STOP HERE.

6.05 On average, how many minutes a day do you push yourself in your wheelchair?

$\square$ Less than 60 minutes

$\square$ Sixty minutes or more

Thank you for completing this survey!

Page 8 of 8 
1.

Balance Tests

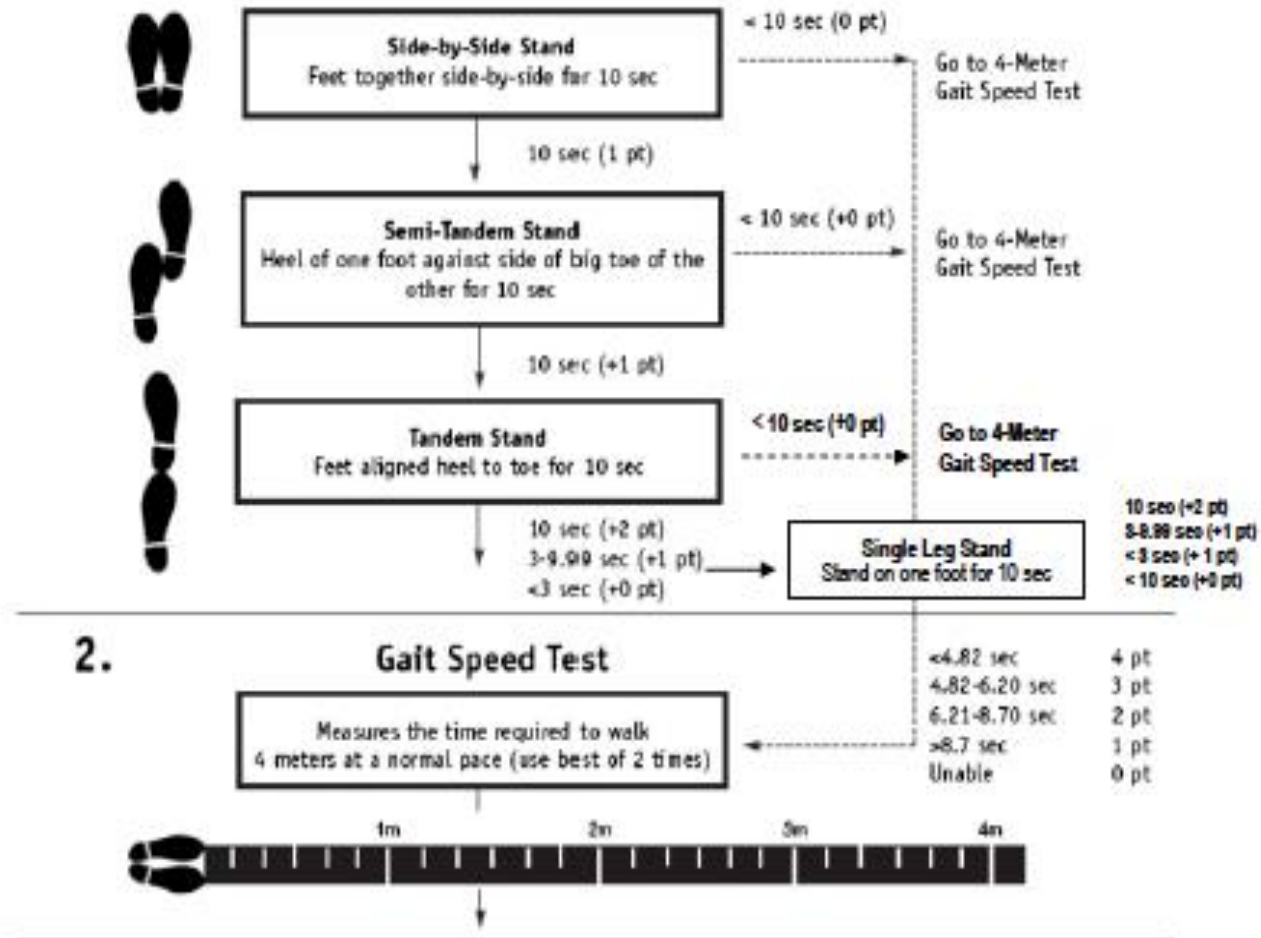

3.

Chair Stand Test

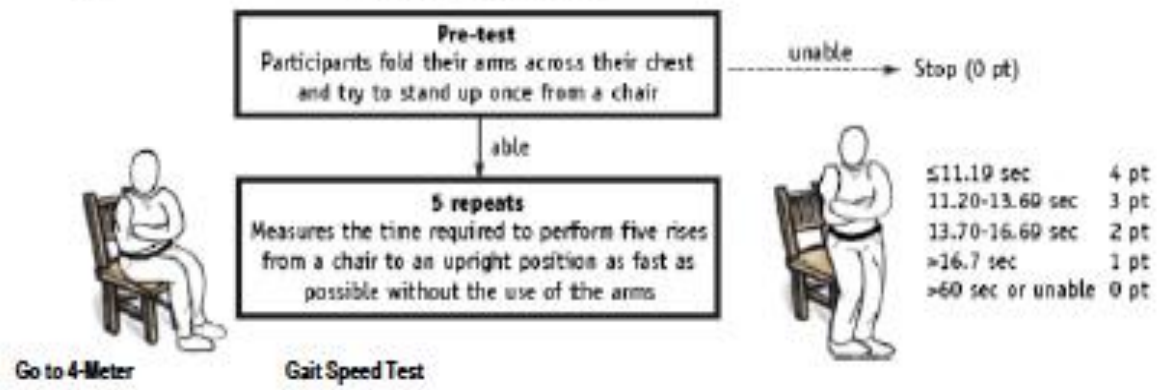

